Construção automática de redes bayesianas para extração de interações proteína-proteína a partir de textos biomédicos

Pedro Nelson Shiguihara Juárez 



\section{Construção automática de redes bayesianas para extração de interações proteína-proteína a partir de textos biomédicos}

\section{Pedro Nelson Shiguihara Juárez}

Orientador: Prof. Dr. Alneu de Andrade Lopes

Dissertação apresentada ao Instituto de Ciências Matemáticas e de Computação - ICMC-USP, como parte dos requisitos para obtenção do título de Mestre em Ciências - Ciências de Computação e Matemática Computacional. VERSÃO REVISADA 
Ficha catalográfica elaborada pela Biblioteca Prof. Achille Bassi e Seção Técnica de Informática, ICMC/USP, com os dados fornecidos pelo(a) autor(a)

Shiguihara Juárez, Pedro Nelson
Construção automática de redes bayesianas para
extração de interações proteína-proteína partir de
textos biomédicos / Pedro Nelson Shiguihara Juárez;
orientador Alneu de Andrade Lopes. -- São Carlos,
2013.
$91 \mathrm{p.}$
Dissertação (Mestrado - Programa de Pós-Graduação en
Ciências de Computação e Matemática Computacional) --
Instituto de Ciências Matemáticas e de Computação,
Universidade de São Paulo, 2013.
1. Aprendizado de máquina. 2. Redes bayesianas.
3. Extração de informação. 4. Extração de relação. 5.
Extração de interaçóes proteína-proteína. I. de Andrade
Lopes, Alneu, orient. II. Título.


Dedicatória $=$

A Deus.

Aos meus pais, Evert e Felícita. $E$ aos meus irmãos, Mónica, Rosario e Antonio. 



\section{Agradecimentos}

a Deus, a minha fortaleza, por Seu amor incondicional em todo tempo e por todas as bênçãos a mim concedidas;

gostaria de agradecer em espanhol à minha família. Mis padres, Evert Shiguihara e Felícita Juárez, por ser los gestores de la persona que soy ahora, lo hayan querido adrede o no. A mis hermanos, Mónica, Rosario y Antonio, por su apoyo desde siempre. Cada uno, a su manera, es responsable de poder estar concluyendo este trabajo. Mi querida familia, llevo conmigo, agradecido, el apoyo incondicional que siempre me han brindado. Los amo;

ao meu orientador, Dr. Alneu de Andrade Lopes, por ter acreditado no meu trabalho e ter me permitido formar parte do ICMC-USP. Sou muito agradecido por sua paciência, apoio e dedicação quando eu precisei;

aos amigos e colegas do LABIC, Newton Spolaôr, Nils Murrugarra, Lilian Berton, Thiago de Paulo, Jorge Valverde, Igor Braga, Rafael Giusti, Rafael Rossi, Ricardo Marcacini, Fabiano Fernandes, Bruno Nogueira, Merley Conrado, Everton Cherman, Celso R. de Souza, Vinícius Souza, Jean Metz, Diego Silva, Nathalie Portugal e Tatiane Nogueira. Também como aos professores, Dra. Solange Rezende, Dra. Carolina Monard e Dr. Gustavo Batista;

aos amigos e colegas que eu conheci em São Carlos. Em especial a, Paola L. Valdivia, Nereida L. Valdivia e Jorge Ramirez, presentes e compreensivos em todo momento. Também como a Laura Florián, Ivar Vargas, Marleny Hilasaca, Jeaneth Machicao, Rosa Encinas, Christian Wong, Roni Apaza, Aurea Soriano, Oscar Cuadros, Fernando Alva e a todos que, direta ou indiretamente, contribuíram neste trabalho;

à Claudia R. Urquiaga, uma mulher especial na minha vida. Sou muito agradecido pela paciência, carinho, apoio, confiança e compreensão durante este tempo. Eu nunca vou esquecer o que você tem feito por mim;

à banca examinadora, que gentilmente aceitou o convite de defesa deste trabalho de mestrado;

e ao Conselho Nacional de Desenvolvimento Científico e Tecnológico - CNPq, pelo apoio financeiro. 

A extração de Interações Proteína-Proteína (IPPs) a partir de texto é um problema relevante na área biomédica e um desafio na área de aprendizado de máquina. $\mathrm{Na}$ área biomédica, as IPPs são fundamentais para compreender o funcionamento dos seres vivos. No entanto, o número de artigos relacionados com IPPs está aumentando rapidamente, sendo impraticável identificá-las e catalogá-las manualmente. Por exemplo, no caso das IPPs humanas apenas $10 \%$ foram catalogadas. Por outro lado, em aprendizado de máquina, métodos baseados em kernels são frequentemente empregados para extrair automáticamente IPPs, atingindo resultados considerados estado da arte. Esses métodos usam informações léxicas, sintáticas ou semânticas como características. Entretanto, os resultados ainda são insuficientes, atingindo uma taxa relativamente baixa, em termos da medida $\mathrm{F}$, devido à complexidade do problema. Apesar dos esforços em produzir kernels, cada vez mais sofisticados, usando árvores sintáticas como árvores constituintes ou de dependência, pouco é conhecido sobre o desempenho de outras abordagens de aprendizado de máquina como, por exemplo, as redes bayesianas. As árvores constituintes são estruturas de grafos que contêm informação importante da gramática subjacente às sentenças de textos contendo IPPs. Por outro lado, a rede bayesiana permite modelar algumas regras da gramática e atribuir para elas uma distribuição de probabilidade de acordo com as sentenças de treinamento. Neste trabalho de mestrado propõe-se um método para construção automática de redes bayesianas a partir de árvores contituintes para extração de IPPs. O método foi testado em cinco corpora padrões da extração de IPPs, atingindo resultados competitivos, em alguns casos melhores, em comparação a métodos do estado da arte.

Palavras-chave: Aprendizado de Máquina. Redes Bayesianas. Extração de Informação. Extração de Relação. Extração de Interações Proteína-Proteína. 

Extracting Protein-Protein Interactions (PPIs) from text is a relevant problem in the biomedical field and a challenge in the area of machine learning. In the biomedical field, the PPIs are fundamental to understand the functioning of living organisms. However, the number of articles related to PPIs is increasing rapidly, hence it is impractical to identify and catalog them manually. For example, in the case of human PPIs only $10 \%$ have been cataloged. On the other hand, machine learning methods based on kernels are often employed to automatically extract PPIs, achieving state of the art results. These methods use lexical, syntactic and semantic information as features. However, the results are still poor, reaching a relatively low rate of F-measure due to the complexity of the problem. Despite efforts to produce sophisticate kernels, using syntactic trees as constituent or dependency trees, little is known about the performance of other Machine Learning approaches, eg, Bayesian networks. Constituent tree structures are graphs which contain important information of the underlying grammar in sentences containing PPIs. On the other hand, the Bayesian network allows modeling some rules of grammar and assign to them a probability distribution according to the training sentences. In this master thesis we propose a method for automatic construction of Bayesian networks from constituent trees for extracting PPIs. The method was tested in five corpora, considered benchmark of extraction of PPI, achieving competitive results, and in some cases better results when compared to state of the art methods.

Keywords: Machine Learning. Bayesian Networks. Information Extraction. Relation Extraction. Protein-Protein Interaction Extraction. 

Lista de Figuras . . . . . . . . . . . . . . . . . . . . . . . iii

Lista de Tabelas . . . . . . . . . . . . . . . . . . . vii

Lista de Algoritmos . . . . . . . . . . . . . . . . . . . ix

Lista de Abreviaturas e Símbolos . . . . . . . . . . . . . . . xi

1 Introdução 1

1.1 Contextualização . . . . . . . . . . . . . . . . . . . . . . 1

1.2 Motivação . . . . . . . . . . . . . . . . . . . . . . . . . . . . . . .

1.3 Hipóteses e Objetivos . . . . . . . . . . . . . . . . . 6

1.4 Contribuições . . . . . . . . . . . . . . . . . . . 7

1.5 Organização . . . . . . . . . . . . . . . . . . 7

2 Técnicas para Extração de IPPs 9

2.1 Considerações Iniciais . . . . . . . . . . . . . . . . . . . . . . . . . . . . . . . . . . . . . . . . .

2.2 Seleção de Características . . . . . . . . . . . . . . . . . . . . . 11

2.2.1 Características baseadas em Palavras . . . . . . . . . . . . . . . 12

2.2.2 Características baseadas em Análise Sintática . . . . . . . . . . . . . 14

2.3 Definição da Tarefa de Extração de IPPs . . . . . . . . . . . . . . . . . . . 15

2.4 Técnicas para a Extração de IPPs . . . . . . . . . . . . . . . . . . . . 17

2.4.1 Técnicas baseadas em Coocorrência e Templates . . . . . . . . . . . 17

2.4.2 Classificadores baseados em SVM . . . . . . . . . . . . . 18

2.4.3 Classificadores baseados em Redes Bayesianas . . . . . . . . . . . 21

2.5 Avaliação das Técnicas . . . . . . . . . . . . . . . . . . . . . 23

2.5.1 Conjuntos de Dados . . . . . . . . . . . . . . . . . . . . 23

2.5.2 Medidas de Avaliação . . . . . . . . . . . . . . . . . . 24

2.6 Considerações Finais . . . . . . . . . . . . . . . . . . . 25

3 Fundamentação de Redes Bayesianas 27

3.1 Considerações Iniciais . . . . . . . . . . . . . . . . . . . . . . . . 27

3.2 Conceitos da Teoria de Probabilidade . . . . . . . . . . . . . . 28

3.2.1 Espaço de Eventos . . . . . . . . . . . . . . . . . . . . . . . . . . . . . . . . . . . . . . . . . . 28

3.2.2 Variável Aleatória . . . . . . . . . . . . . . . . . 28

3.2.3 Probabilidade Conjunta . . . . . . . . . . . . . . . . . 29

3.2.4 Probabilidade Condicional . . . . . . . . . . . . . . . . . . . 29

3.2 .5 Independência e Independência Condicional . . . . . . . . . . . . . 30

3.2.6 Importância das Probabilidades a Priori, a Posteriori e Condicional 30 
3.3 Rede Bayesiana . . . . . . . . . . . . . . . . . . . . . . . . . 31

3.4 Inferência Probabilística . . . . . . . . . . . . . . . . . . . . . 33

3.5 Aprendizado de Rede Bayesiana . . . . . . . . . . . . . . . . . . 35

3.5.1 Aprendizado de Estrutura baseado em Pontuação . . . . . . . . . . 35

3.5.1.1 Medidas de Qualidade . . . . . . . . . . . . 35

3.5.1.2 Busca de Estruturas . . . . . . . . . . . . . . . . 37

3.5.2 Aprendizado de Estrutura baseado em Restrições . . . . . . . . . . . 38

3.5.3 Aprendizado de Parâmetros . . . . . . . . . . . . . . . . . . . 41

3.6 Considerações Finais . . . . . . . . . . . . . . . . . . . . . . . . 42

4 Construção Automática de Redes Bayesianas

baseada em Árvores Constituintes $\quad \mathbf{4 5}$

4.1 Considerações Iniciais . . . . . . . . . . . . . . . . . . . . . . . . . 45

4.2 Criação de um Grafo Dirigido a partir de Árvores Constituintes . . . . . . 46

4.3 Remoção de Ciclos a partir do Grafo Dirigido . . . . . . . . . . . . . . . . 49

4.3.1 Detecção de Arestas Conflitivas . . . . . . . . . . . . . . . . . 50

4.3.2 Remoção de Arestas Conflitivas . . . . . . . . . . . . . . . . . . 51

4.4 Adição do Nó Classe $\mathcal{C}$. . . . . . . . . . . . . . . . . . . . . . . 54

4.5 Restrição do Número de Nós Pais . . . . . . . . . . . . . . . . . . 56

4.6 Classificação de uma IPP . . . . . . . . . . . . . . . . . . . . . . . 57

4.7 Considerações Finais . . . . . . . . . . . . . . . . . . . 58

5 Resultados $\quad 59$

5.1 Considerações Iniciais . . . . . . . . . . . . . . . . . . . . . . . 59

5.2 Pré-processamento de Sentenças . . . . . . . . . . . . . . . . 60

5.3 Configuração dos Experimentos . . . . . . . . . . . . . . . . . . . 60

5.4 Avaliação do Método Proposto . . . . . . . . . . . . . . . . . . 61

5.4.1 Experimentos com as Medidas de Qualidade . . . . . . . . . . . 62

5.4.2 Experimentos com as Estimações de Parâmetros: MLE e Bayes . . 68

5.5 Comparação de Resultados com o Estado da Arte . . . . . . . . . . . . . . 71

6 Conclusões $\quad 73$

6.1 Contribuições . . . . . . . . . . . . . . . . . . . . . 74

6.2 Trabalhos Futuros . . . . . . . . . . . . . . . . . . . 75

$\begin{array}{ll}\text { Referências Bibliográficas } & 77\end{array}$

A Tabelas de crescimento da quantidade de textos biomédicos 85

$\begin{array}{ll}\text { Índice Remissivo } & 89\end{array}$ 
1.1 Quantidades cumulativas de publicações biomédicas entre os anos 1984 a

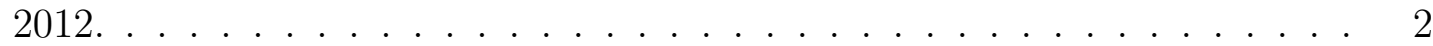

2.1 Uma sentença de texto contendo duas IPPs . . . . . . . . . . . . . 10

2.2 Um conjunto de três sentenças de texto . . . . . . . . . . . . . . . . 13

2.3 Vetores de palavras construídos a partir de sentenças de texto . . . . . . . 13

2.4 POS tags atribuídos às palavras de uma sentença de texto . . . . . . . . . 14

2.5 Árvore constituinte obtida a partir de uma sentença de texto . . . . . . . . 14

2.6 Extrato de uma árvore de dependência obtida a partir de um fragmento de sentença de texto . . . . . . . . . . . . . . . . . 15

2.7 Conjunto de vetores de características com $M$ instâncias . . . . . . . . 16

2.8 Rede bayesiana proposta em Chowdhary et al. (2009) para extração de IPPs 21

2.9 Rede bayesiana dinâmica proposta em Rosario e Hearst (2005) para extração de IPPs . . . . . . . . . . . . . . . . . . . . . . . . . . . 22

2.10 Comparação entre os cinco corpora tipicamente usados na extração de IPPs: AImed, BioInfer, IEPA, HPRD50 e LLL . . . . . . . . . . . . . . . . . . . 24

3.1 Exemplo de um modelo de rede bayesiana $\mathcal{B}_{1}=\left\{\mathcal{G}_{1}, \Theta_{1}\right\} \ldots \ldots$. . . . . 32

3.2 Tipos de raciocínio em redes bayesianas . . . . . . . . . . . . . . . 33

3.3 Operações básicas para gerar novas estruturas de redes bayesianas a partir de uma estrutura inicial . . . . . . . . . . . . . . . . . . . . 39

3.4 Conjunto cobertor de Markov em uma rede bayesiana . . . . . . . . . . . 39

3.5 Estimação do parâmetro $\theta_{i 1}$, onde $\theta_{i 1}=P\left(X_{i}=1\right) \ldots \ldots \ldots . . \ldots . \quad 42$

4.1 Exemplo de três árvores constituintes produzidas a partir de três extratos de sentenças com (a) ID="AIMed.d224.s1951", (b) ID="AIMed.d224.s1954" e (c) ID="AIMed.d224.s1945" respectivamente, pertencentes ao corpus AImed. Os nós de cor cinza são conhecidos como nós terminais, enquanto que o resto de nós são não terminais. . . . . . . . . . . . . . . . . . . . . . . . 4

4.2 Grafo dirigido, gerado a partir das três árvores constituintes ilustradas na Figura 4.1. . . . . . . . . . . . . . . . . . . . . . . . . 49

4.3 Grafo dirigido com dois ciclos detectados, os quais são marcados em linhas pontilhadas. O número em cada nó é a ordem em que esse nó foi visitado ao percorrer o grafo. . . . . . . . . . . . . . . . 53

4.4 Adição do nó chamado de $C L A S S(\mathcal{C})$ no grafo acíclico dirigido, $\mathcal{G}$. . . . . 55 
4.5 Estrutura final de rede bayesiana, contendo POS tags e uma variável CLASS. A variável $C L A S S$ deve ser ligada com os POS tags, usando uma medida de qualidade $Q$ para avaliar tais ligações. . . . . . . . . . . . . . . . 56

4.6 Árvore constituinte que corresponde a uma sentença de teste. . . . . . . . . 57

4.7 Classificação de uma sentença de teste usando a rede bayesiana construída pelo método PT-BN . . . . . . . . . . . . . . . . . 58

5.1 Método de poda aplicado sobre uma árvore constituinte. . . . . . . . . . . 61

5.2 Boxplot do desempenho, em termos de medida $\mathrm{F}$, de todas as configurações com relação a seis medidas de qualidade no corpus BioInfer. . . . . . . . . 63

5.3 Frequência de uso de regras entre POS tags no corpus BioInfer . . . . . . . 63

5.4 Boxplot do desempenho, em termos de medida $\mathrm{F}$, de todas as configurações com relação a seis medidas de qualidade no corpus AImed. . . . . . . . . . 64

5.5 Frequência de uso de regras entre POS tags no corpus AImed . . . . . . . 65

5.6 Boxplot do desempenho, em termos de medida F, de todas as configurações com relação a seis medidas de qualidade no corpus IEPA. . . . . . . . . . . 65

5.7 Frequência de uso de regras entre POS tags no corpus IEPA . . . . . . . . 66

5.8 Boxplot do desempenho, em termos de medida F, de todas as configurações com relação a seis medidas de qualidade no corpus HPRD50. . . . . . . . . 66

5.9 Frequência de uso de regras entre POS tags no corpus HPRD50 . . . . . . 67

5.10 Boxplot do desempenho, em termos de medida $\mathrm{F}$, de todas as configurações com relação a seis medidas de qualidade no corpus LLL. . . . . . . . . . 67

5.11 Frequência de uso de regras entre POS tags no corpus LLL . . . . . . . . . 68

5.12 Comparação, no corpus BioInfer, de três algoritmos de remoção de ciclos: Rem1, Rem2 e Rem3. Os algoritmos foram testados com a medida de pontuação Bayes. O cálculo de parâmetros foi feito usando a estimação de Bayes com hiperparâmetros $\alpha=\{1, \ldots, 50\}$. Em (a) é ilustrado o desempenho dos três algoritmos, usando árvores constituintes de treinamento sem poda. Em contraste, em (b) é mostrado o desempenho com as árvores

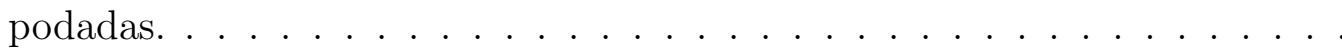

5.13 Comparação, no corpus AImed, de três algoritmos de remoção de ciclos: Rem1, Rem2 e Rem3. Os algoritmos foram testados com a medida de pontuação Bayes. O cálculo de parâmetros foi feito usando a estimação de Bayes com hiperparâmetros $\alpha=\{1, \ldots, 50\}$. Em (a) é ilustrado o desempenho dos três algoritmos, usando árvores constituintes de treinamento sem poda. Em contraste, em (b) é mostrado o desempenho com as árvores podadas. . . . . . . . . . . . . . . . . . .

5.14 Comparação, no corpus IEPA, de três algoritmos de remoção de ciclos: Rem1, Rem2 e Rem3. Os algoritmos foram testados com a medida de pontuação Bayes. O cálculo de parâmetros foi feito usando a estimação de Bayes com hiperparâmetros $\alpha=\{1, \ldots, 50\}$. Em (a) é ilustrado o desempenho dos três algoritmos, usando árvores constituintes de treinamento sem poda. Em contraste, em (b) é mostrado o desempenho com as árvores podadas. . . . . . . . . . . . . . . . . . . 
5.15 Comparação, no corpus HPRD50, de três algoritmos de remoção de ciclos: Rem1, Rem2 e Rem3. Os algoritmos foram testados com a medida de pontuação Bayes. O cálculo de parâmetros foi feito usando a estimação de Bayes com hiperparâmetros $\alpha=\{1, \ldots, 50\}$. Em (a) é ilustrado o desempenho dos três algoritmos, usando árvores constituintes de treinamento sem poda. Em contraste, em (b) é mostrado o desempenho com as árvores podadas. . . . . . . . . . . . . . . . . 70

5.16 Comparação, no corpus LLL, de três algoritmos de remoção de ciclos: Rem1, Rem2 e Rem3. Os algoritmos foram testados com a medida de pontuação Bayes. O cálculo de parâmetros foi feito usando a estimação de Bayes com hiperparâmetros $\alpha=\{1, \ldots, 50\}$. Em (a) é ilustrado o desempenho dos três algoritmos, usando árvores constituintes de treinamento sem poda. Em contraste, em (b) é mostrado o desempenho com as árvores podadas. . . . . . . . . . . . . . . . . . . 


\section{Lista de Tabelas}

2.1 Classes principais de palavras usadas por POS-Taggers . . . . . . . . . . 13

2.2 Comparação de classificadores propostos em trabalhos prévios para extração de IPPs, em termos de precisão, revocação e da medida F, no corpus AImed . . . . . . . . . . . . . . . . . . . . 20

2.3 Informações dos conjuntos de dados: AIMed, BioInfer, HPRD50, IEPA e LLL. . . . . . . . . . . . . . . . . . . . . . . 23

4.1 Configurações do Algoritmo 4.5 para a remoção de ciclos a partir de um grafo dirigido. . . . . . . . . . . . . . . . . . . . 54

5.1 Comparação de métodos do estado da arte, em termos da medida F, usando cinco corpora de IPPs . . . . . . . . . . . . . . . . . . . . . . . 72

5.2 Comparação de métodos do estado da arte, em termos da medida F, usando cross-corpora ........................... 72

A.1 Frequência de artigos publicados no período entre 1984 a 2012 . . . . . . 86

A.2 Distribuição de artigos publicados no período entre 1984 a 2012 . . . . . . 87

A.3 Taxa média em anos para dobrar o número de artigos publicados . . . . . . 87 


\section{Lista de Algoritmos}

3.1 Busca de $\operatorname{Subida~de~} \operatorname{Encosta}\left(Q, \mathrm{w}, \mathcal{O}, \mathcal{B}_{0}\right) \ldots \ldots \ldots \ldots$

4.2 Detecção de $\operatorname{Arestas} \operatorname{Conflitivas}\left(\mathcal{G}^{\circ}, \mathrm{w}, \mathcal{L}, \mathcal{Q}\right) \ldots \ldots \ldots$

4.3 Detecção de Uma Aresta Conflitiva $\left(\mathcal{G}^{\circ}\right) \ldots \ldots \ldots \ldots \ldots$

4.4 Busca em Profundidade $\left(\mathcal{G}^{\circ}, w, S, E, Q\right) \ldots \ldots \ldots \ldots \ldots$

4.5 Remoção de Arestas $\operatorname{Conflitivas}\left(\mathcal{G}^{\circ}\right) \ldots \ldots \ldots \ldots \ldots . \ldots \ldots$

4.6 Adição de Nó $\operatorname{Classe}(\mathcal{G}, \mathcal{C}, Q) \ldots \ldots \ldots \ldots \ldots \ldots$ 
$|Y| \quad$ Cardinalidade do conjunto $Y$

X Variável aleatória

$\operatorname{Val}(X)$ Conjunto de valores mutuamente exclusivos que podem serem atribuídos à variável $X$

$x \quad$ Qualquer valor que pode ser atribuído a $X$, isto é, $x \in \operatorname{Val}(X)$

$x^{k} \quad k$-ésimo valor de $X$, isto é, $x^{k} \in \operatorname{Val}(X)$

X Conjunto de variáveis aleatórias

$\mathcal{X} \quad$ Conjunto de todas as variáveis de um domínio

$X_{i} \quad i$-ésima variável pertencente ao conjunto $\mathcal{X}$

$\xi \quad$ Conjunto de valores que podem serem atribuídos ao conjunto de variáveis $\mathcal{X}$, isto é, $\xi \in \operatorname{Val}(\mathcal{X})$

$\mathcal{D} \quad$ Conjunto de dados

$M \quad$ Número de exemplos no conjunto $\mathcal{D}$

$m \quad m$-ésimo exemplo, tal que, $1 \leq m \leq M$

$x[m]$ Valor atribuído à variável $X$ no $m$-ésimo exemplo

$\xi[m] \quad$ Valores atribuídos às variáveis em $\mathcal{X}$ no $m$-ésimo exemplo

$M[x]$ Função que calcula o número de exemplos contendo o valor $x$ para a variável $X$

$P \quad$ Distribuição de probabilidade

$P^{*} \quad$ Verdadeira distribuição subjacente ao conjunto $\mathcal{D}$

IPP Interação proteína-proteína

SVM Support Vector Machines - Máquinas de vetores de suporte 


\subsection{Contextualização}

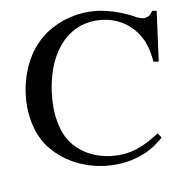

om o progresso da área biomédica principalmente na compreensão e nos mecanismos de prevenção de doenças, uma crescente quantidade de textos (artigos) científicos é publicada em jornais de biomedicina. Vale ressaltar que, em geral, artigos científicos são escritos em inglês, a língua franca das ciências (Tardy, 2004). A Figura 1.1 ilustra o crescimento da quantidade de artigos em inglês entre os anos 1984 e 2012 de cinco tópicos biomédicos: proteômica, genômica, microarranjos, bioinformática e filogenética (ver Apêndice A para maior informação). Nesse conjunto de artigos biomédicos existem relações de interesse que precisam ser extraídas para posteriormente serem armazenadas e consultadas, utilizando, por exemplo, um banco de dados. Um exemplo concreto disso é a extração de relações de interações proteína-proteína (IPPs). As IPPs são relações que ajudam na compreensão do funcionamento de entes biológicos como vírus ou células cancerosas (Cannataro et al., 2010). De uma maneira geral, tais relações são parte do estudo do tópico biomédico chamado de proteômica. Assim, informações de relações de IPPs contribuem nos avanços da proteômica.

Como parte desse esforço, especialistas da área biomédica têm sido contratados por organizações que gerenciam bancos de IPPs a fim de realizarem processos manuais de extração a partir de artigos (Hakenberg et al., 2010). Alguns bancos conhecidos são $M u$ nich Database of Interacting Proteins (MIPS) e Database of Interacting Proteins (DIP). Embora esses esforços têm permitido um relativo crescimento do número de IPPs catalogadas, a quantidade de artigos da proteômica teve um crescimento ainda maior, tendo sido 


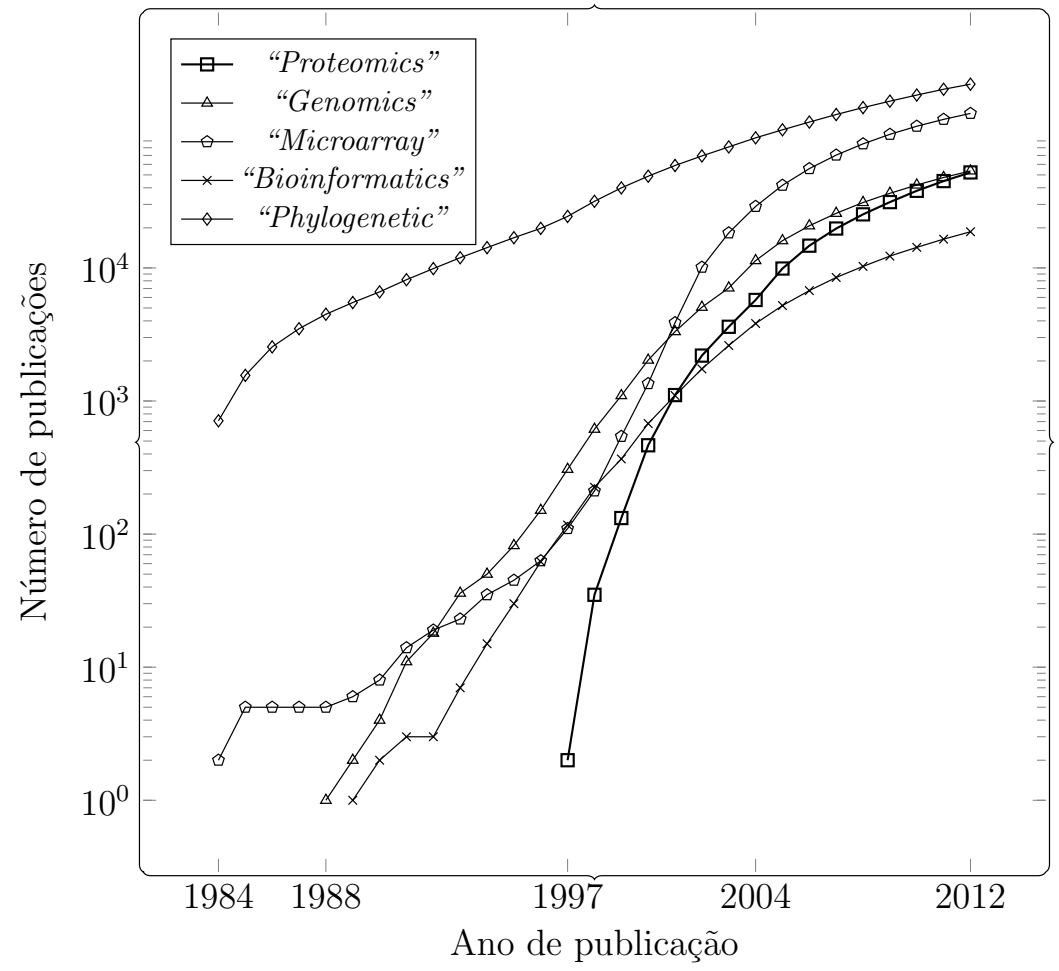

Figura 1.1: Quantidades cumulativas de publicações entre os anos 1984 a 2012 e organizadas pelos tópicos de pesquisa: "proteomics", "genomics", "microarray", "bioinformatics" e "phylogenetic". Dados extraídos usando o buscador ISI Science Citation Index, disponível em http://apps.webofknowledge.com/.

duplicada a cada 1,18 anos (ver Apêndice A). Essa é a taxa de crescimento mais rápida em comparação com as taxas de outros tópicos biomédicos como genômica, microarranjos, bioinformática e filogenética. Dessa forma, extrações manuais são impraticáveis na extração de IPPs (Chowdhary et al., 2009), sendo que muitas dessas relações se encontram apenas em artigos digitais (Rosario e Hearst, 2005). Por exemplo, no caso humano, apenas 10\% das IPPs foram catalogadas em bancos de dados (Browne et al., 2010). Assim, a tarefa de extração de IPPs torna-se crítica, sendo necessário o emprego de métodos computacionais para automatizá-la.

A área que estuda métodos computacionais para extrair IPPs a partir de artigos é chamada a Extração de Informação (Simpson e Demner-Fushman, 2012). Em geral, a extração de informação estuda o processo de tornar a informação não estruturada, no texto, em informação estruturada (Jurafsky e Martin, 2008). Cabe ressaltar, que embora na literatura um texto tipicamente é considerado como informação não estruturada, o termo fracamente estruturado ajusta-se melhor como afirmado em Feldman e Sanger (2006). Isso porque de alguma maneira o texto está sujeito a uma estruturação que, mesmo sendo fraca, é refletida, por exemplo, pela ordem das palavras estabelecidas no texto. Assim, um artigo científico é considerado como informação fracamente estruturada (Feldman e Sanger, 2006). A partir dessas considerações, a extração de uma IPP pode ser considerada 
como a identificação de uma informação estruturada, tal como interage $\operatorname{Com}(A, B)$, a partir de informação fracamente estruturada tal como, "...a interação entre duas proteínas $A$ e $B \ldots$... Nesse caso, " $A$ " e " $B$ " são duas proteínas (entidades) que têm uma relação de interação de acordo com a descrição dada na sentença. A ideia por trás da relação, interageCom(A, $B)$, é detectar se duas proteínas estão interagindo, independentemente do tipo de interação envolvida. Embora esse processo de identificação de IPP insira-se na extração de informação, esse processo envolve duas subtarefas mais específicas: (1) reconhecimento de entidades mencionadas (Named Entity Recognition - NER), e (2) extração de relação. Ambas as subtarefas pertencem à área de extração de informação. No contexto de extração de IPPs, a primeira subtarefa consiste na detecção de nomes das proteínas; lidando com sinônimos, acrônimos e abreviaturas entre outros inconvenientes. Entretanto, a segunda consiste na detecção de relação entre duas proteínas, sendo essa mais complicada do que o reconhecimento de entidades mencionadas (Simpson e DemnerFushman, 2012). Uma das razões é que a relação entre entidades pode ser descrita de múltiplas maneiras. Por exemplo, a relação anterior, interageCom $(A, B)$, pode também ser extraída a partir da sentença, “...A é ativada por B...”. Este trabalho de mestrado aborda diretamente a segunda subtarefa.

Dentre os vários métodos de extração de relação que têm abordado a extração de IPPs estão os baseados em coocorrência, templates e classificação. Um método baseado em coocorrência tipicamente calcula a frequência de dois nomes de proteínas ocorrer conjuntamente nos textos e determina se essa frequência é estatisticamente significante. A suposição é que ambas as proteínas estão envolvidas em uma função biológica quando a frequência de coocorrência é estatisticamente significante (Stapley e Benoit, 2000). Uma característica de tais métodos é sua relativa simplicidade (Daraselia et al., 2004). Porém, o principal problema de tais métodos reside no fato de obterem uma baixa taxa de precisão, isto é, a detecção de um alto número de falsos IPPs. Isso porque, em um contexto real, duas proteínas coocorrentes não determinam necessariamente uma relação de interação (Bernardi et al., 2002). Diferentemente desses métodos, os métodos baseados em templates melhoram a taxa de precisão. Esses métodos, também conhecidos como regras (ou padrões) linguísticas, empregam templates, tal como "< proteína $>\ldots<$ verbo $>\ldots<$ proteína $>$ ", a fim de descobrir as sentenças que se ajustam a esses padrões. Tais sentenças são assumidas ter grandes possibilidades de conter uma IPP (Blaschke et al., 2001; Wong, 2001). Apesar de lidar com a detecção de falsos IPPs, os métodos baseados em templates produzem uma baixa taxa de revocação, isto é, não detectam todas as ocorrências de IPPs. Isso porque é necessário o uso de um grande conjunto de templates para cobrir todas as possíveis maneiras em que IPPs podem ser descritas em sentenças de texto, resultando em um processo custoso. Por fim, os métodos baseados em classificação têm atingido melhores resultados em termos de precisão e 
revocação em comparação com os métodos anteriormente mencionados, despertando um maior interesse para tratar a extração de IPPs (Simpson e Demner-Fushman, 2012).

Técnicas de classificação formam parte da área de aprendizado de máquina, especificamente de aprendizado de máquina supervisionado. O aprendizado supervisionado tem como objetivo que uma "máquina" ou "sistema" possa aprender um modelo ou hipótese que generaliza a relação existente entre um par de entrada-saída, $\left(\mathcal{Z}_{i}, \mathcal{C}_{i}\right)$, a partir de um conjunto de dados $\mathcal{D}=\left\{\left(\mathcal{Z}_{\mathrm{i}}, \mathcal{C}_{\mathrm{i}}\right)\right\}_{\mathrm{i}=1}^{\mathrm{M}}$, onde $M$ é o número de pares (Barber, 2012). Em particular, a classificação restringe a saída $\mathcal{C}_{i}$ com valores nominais. Caso essa saída contenha apenas dois valores possíveis, a classificação é considerada binária (Murphy, 2012). Assim, em classificação, o modelo induzido a partir de $\mathcal{D}$ é chamado de classificador. Para classificar, como entrada é necessário um conjunto de atributos, $\mathcal{Z}_{i}$. O classificador deve encontrar uma relação entre tais atributos com a saída esperada, a qual é um valor da variável classe, $\mathcal{C}_{i}$. No contexto de extração de IPPs, os termos classificação e extração podem ser considerados como equivalentes. Para tratar a extração, a maioria de métodos executa uma classificação binária, $\mathcal{C}_{i} \in\{0,1\}$ (Qian e Zhou, 2012; Bui e Sloot, 2011; Choi e Myaeng, 2010; Miwa et al., 2009b; Airola et al., 2008), onde o valor '0' indica "não existe interação", enquanto que o valor " 1 ' indica "existe interação". Embora essa delimitação reduza a complexidade do problema de extração, o problema ainda continua sendo não trivial. De fato, em um estudo comparativo em Pyysalo et al. (2008a) é reportado que métodos do estado da arte, testados sobre cinco conjuntos de dados de IPPs, atingiram uma taxa média da medida $\mathrm{F}$ entre $19 \%$ e 30\%, sendo a medida $\mathrm{F}$ a média harmônica entre as taxas de precisão e revocação.

De forma a lidar com esse baixo desempenho, a pesquisa de novos métodos tem sido focada principalmente em dois aspectos. O primeiro aspecto está relacionado com o objeto $\mathcal{Z}_{i}$. Embora, na literatura, a saída $\mathcal{C}_{i}$ seja tipicamente definida como $\mathcal{C}_{i}=\{0,1\}$, a definição de $\mathcal{Z}_{i}$ varia amplamente. $\mathcal{Z}_{i}$ pode ser considerado como um objeto que contém informação relevante a partir de uma sentença $\mathcal{S}_{i}$ analisada. Esse objeto pode ser um vetor n-dimensional, uma árvore sintática, uma árvore de dependência, um grafo ou algum outro tipo de objeto contendo informação relevante para a extração. As definições de todos esses tipos de objetos são descritos no capítulo a seguir. A importância de $\mathcal{Z}_{i}$ é que deve permitir a um classificador relacionar um par de proteínas (A,B), em $\mathcal{S}_{i}$, com o valor $\hat{c}_{i} \in \mathcal{C}_{i}$, onde $\hat{c}_{i}$ é o valor correto atribuído para esse caso. O segundo aspecto consiste em procurar novos tipos de classificadores a fim de melhorar os resultados na extração de IPPs. Dentre alguns classificadores que foram propostos anteriormente estão os kernels de grafos (Airola et al., 2008), as redes bayesianas (Chowdhary et al., 2009), os kernels de árvores constituintes (Choi e Myaeng, 2010), entre outros. Em geral, os classificadores baseados em kernels têm obtido os melhores resultados na extração de IPPs, daí esses serem os mais empregados para tal fim (Erkan, 2007; Airola et al., 2008; Miwa et al., 2009b; Liu et al., 2010; Choi e Myaeng, 2010; Saetre et al., 2010; Chowdhury et al., 2011; 
Bui et al., 2011). Kernels são funções matemáticas que permitem discriminar sentenças por meio da análise de suas descrições $\mathcal{Z}$. Isto é, os kernels quantificam tipicamente a similaridade entre duas sentenças, $S_{i}$ e $S_{j}$, por meio das representações $\mathcal{Z}_{i}$ e $\mathcal{Z}_{j}$. Isso demonstra a flexibilidade dos kernels em se adaptar a qualquer tipo de entrada. Esses são tipicamente empregados em Máquinas de Vetores de Suporte (SVM). Dessa maneira, tanto a descrição $\mathcal{Z}$ quanto o tipo de classificador contribuem no desempenho de classificadores na extração de IPPs.

\subsection{Motivação}

As redes bayesianas(RBs) são classificadores aplicados em diversos domínios, no entanto, essas têm sido pouco usadas na extração de IPPs, apesar de serem capazes de representar conhecimento do domínio do problema de maneira explícita, eficiente e com uma base estatística robusta (Koller e Friedman, 2009). Russell e Norvig (2010) afirmam que a vantagem das redes bayesianas é a capacidade de tratar três características importantes de um problema: (1) a dificuldade ou impraticabilidade de se representar o conhecimento via regras, (2) a ignorância teórica, quando não existe uma teoria completa para o domínio do problema como no caso das interação proteína-proteína, e (3) a ignorância prática, dado que mesmo tendo todas as regras lógicas, eventualmente não é possível saber quais regras devem ser aplicadas.

Na revisão bibliográfica deste trabalho de mestrado, foram encontradas redes naive Bayes empregadas para comparação com outros tipos de classificadores no contexto da extração de IPPs (Donaldson et al., 2003; Kolchinsky et al., 2010; Schneider et al., 2011). Uma rede naive Bayes assume que os atributos, $\mathcal{Z}=\left\{\mathcal{Z}_{1}, \ldots, \mathcal{Z}_{n}\right\}$ são condicionalmente independentes entre si, dada a variável classe $\mathcal{C}$. Esse tipo de rede é a mais simples dentro das redes bayesianas, mesmo assim, em alguns casos o seu desempenho pode ser razoável (Koller e Friedman, 2009).

Outros dois classificadores alternativos, baseados em redes bayesianas (RBs), foram encontrados na literatura de extração de IPPs. O primeiro foi proposto em Rosario e Hearst (2005). Nesse caso, foi empregada uma RB para extrair IPPs em um contexto de classificação multiclasse. Assim, o objetivo foi detectar se um par de proteínas tinha um tipo de interação dentre dez possíveis interações. A RB definida consiste em uma estrutura tipo árvore, onde o nó raiz é a variável classe $\mathcal{C}$. No segundo nível da árvore, os nós filhos de $\mathcal{C}$, são as variáveis representando nomes de proteínas. Por fim, no terceiro nível, é usada bag-of-words (BOW). Dessa forma, a RB foi construída manualmente, onde os nós do segundo nível são considerados como variáveis ocultas ${ }^{1}$ e os nós do terceiro nível são as palavras da BOW. Uma bag-of-words tipicamente caracteriza a sentença $S_{i}$ como

\footnotetext{
${ }^{1}$ Segundo (Koller e Friedman, 2009), uma variável oculta é uma variável cujo valor não pode ser observado diretamente a partir de $\mathcal{D}$, no entanto, é possível saber da sua existência.
} 
um vetor $\mathcal{Z}_{i} n$-dimensional, onde $n$ representa o número de termos considerados. Para cada sentença $S_{i}$, é armazenada a informação quando a $j$-ésima palavra aparece $\left(\mathcal{Z}_{i}^{j}=1\right)$ ou quando não $\left(\mathcal{Z}_{i}^{j}=0\right)$. Esses atributos em $\mathcal{Z}_{i}$ são condicionalmente independentes entre si, dadas as variáveis ocultas. Assim também, essas variáveis ocultas são condicionalmente independentes entre si, dada a variável classe $\mathcal{C}$.

Embora esse trabalho seja interessante, já que trata um nível de complexidade maior (problema multiclasse) na extração de IPPs, os resultados da RB proposta não foram melhores do que os resultados da naive Bayes, a qual foi usada como classificador de comparação. Na segunda proposta, em Chowdhary et al. (2009), foi empregada uma RB usando como atributos um pequeno conjunto de sete palavras definidas pelo autor. A RB final foi aprendida usando o algoritmo busca de subida de encosta, usando uma função de pontuação Bayesiana. Diferente do naive Bayes, o uso dessa RB permite encontrar novas independências condicionais. Com isso é possível ajustar o grau de incerteza das variáveis em $\mathcal{Z}$ e $\mathcal{C}$ produzindo um modelo que mais se ajusta com a realidade. Apesar dessa contribuição, essa rede usa apenas um conjunto de sete variáveis $\mathcal{Z}=\left\{\mathcal{Z}^{j}\right\}_{j=1}^{7}$, extraídas a partir da informação lexical das sentenças contidas em $\mathcal{D}$. O problema disso é que o número de variáveis é consideravelmente pequeno para conseguir extrair uma grande quantidade de IPPs, as quais são descritas de diferentes formas nas sentenças de texto. Fayruzov e colegas (Fayruzov et al., 2009) mostraram que o uso de informações lexicais não são tão relevantes na extração de IPPs em comparação com o uso de informações sintáticas. Nesta revisão bibliográfica não foi encontrado outro tipo de classificador baseado em RBs.

De fato, essas duas RBs usadas para a extração de IPPs têm utilizado apenas informações lexicais. Assim também, em ambas as propostas foram usados conjuntos de textos (corpus) que não são referentes na extração de IPPs, sendo difícil a comparação com os métodos do estado da arte. Em contraste, os kernels, que têm atingido um alto desempenho, usam informações sintáticas tais como árvores sintáticas, árvores de dependências ou diversos tipos de grafos derivados daquelas árvores. Isto é, objetos $\mathcal{Z}$ mais sofisticados que fornecem maior informação das sentenças (Miwa et al., 2009b). Assim, um compromisso entre a modelagem de RBs com informações do domínio do problema pode levar a um alto desempenho na extração de IPPs. Isso deve envolver a geração de novos algoritmos que permitam processar tais objetos sofisticados, que não podem ser processados diretamente por uma RB como no caso dos kernels.

\subsection{Hipóteses e Objetivos}

Na investigação de solução para os problemas citados anteriormente, esse trabalho de mestrado parte da seguinte hipótese: 
É possível modelar a construção de redes bayesianas a partir de informações de atributos linguísticos, tais como as fornecidas pelas árvores constituintes para a extração de relações a partir de textos.

As relações anteriormente mencionadas são as IPPs. Dada essa hipótese, o objetivo é identificar cini empregar as relações sintáticas, providas pelas árvores constituintes, para construir RBs de forma a obter resultados confiáveis na extração de IPPs. Assim, devese considerar que um resultado é mais confiável quando a medida F obtida é superior aos outros métodos de extração de IPPs. Tais fatores podem estar relacionados com as informações que fornecem atributos, o número de atributos e as relações entre eles, bem como, com os tipos de algoritmos utilizados para construir a rede. Portanto, uma vez que os fatores são identificados, é possível fazer uso das redes bayesianas mais representativas no domínio de extração de IPPs e compará-las com técnicas do estado da arte.

\subsection{Contribuições}

A fim de atingir os objetivos descritos nesta dissertação, como primeiro passo foi realizado um estudo dos métodos do estado da arte na extração de IPPs, assim como, um estudo das técnicas para aprendizado automático de RBs. Com isso, foi possível estabelecer o marco teórico que envolve a contribuição deste trabalho de mestrado.

Assim, duas técnicas de aprendizado de RBs foram criadas para a extração de IPPs. A primeira técnica (PT-BN) baseia-se na construção automática das RBs diretamente a partir de árvores constituintes (parse trees). As relações sintáticas das árvores são empregadas como dependências entre os atributos. A segunda técnica é uma combinação do uso de árvores de análise sintática com o critério de seleção de nós pais de uma RB, empregado pelo algoritmo K2 (Cooper e Herskovits, 1992). Além dessas técnicas, foram encontrados alguns fatores que permitem orientar as técnicas para obter um melhor desempenho das RBs.

Como resultado direto deste trabalho de mestrado, foi publicado um artigo no congresso internacional Conference on Intelligent Text Processing and Computational Linguistics (CICLing 2013), com H-index 29.

\subsection{Organização}

Os próximos capítulos desta dissertação estão organizados da seguinte forma:

- No Capítulo 2 é detalhada uma revisão bibliográfica sobre as técnicas de extração de IPPs, ressaltando as suas principais vantagens e limitações. Em particular, devido 
ao fato que técnicas baseadas em Aprendizado de Máquina têm atingido os melhores resultados nesta tarefa, elas são apresentadas com maior detalhe.

- No Capítulo 3 é descrita a fundamentação das técnicas de redes bayesianas. Isto envolve a sua representação, aprendizado e inferência. Dado que o principal objetivo desta dissertação é o aprendizado automático de redes bayesianas, as principais técnicas de aprendizado são apresentadas.

Estes dois primeiros Capítulos representam a base teórica sobre a qual as técnicas descritas nesta dissertação são detalhadas.

- No Capítulo 4 é descrita a técnica de construção de redes bayesianas usando árvores constituintes para extrair IPPs.

- No Capítulo 5 são apresentados os resultados de aplicar a técnica proposta em cinco conjuntos de dados comumente usados por outras técnicas na extração de IPPs.

- No Capítulo 6 são apresentadas as conclusões deste trabalho de mestrado.

- No Apêndice A são apresentados os resultados de um estudo de taxas de crescimento de textos biomédicos, servindo como informação complementária para a justificação de abordar o problema de IPP. 


\section{Técnicas para Extração de IPPs}

\subsection{Considerações Iniciais}

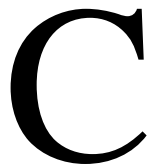

omo foi mencionado no capítulo anterior, investigação sobre automatização de extração de IPPs a partir de textos é importante tanto para a área da computação quanto para a área biomédica. Na primeira, a extração de IPPs representa um problema real que permite estudar novas técnicas de extração de relação, em particular, as que são baseadas em aprendizado de máquina. Na segunda área, a automatização da extração de IPPs é um processo que contribui nos avanços da pesquisa biomédica.

Alguns aspectos ligados com a complexidade da extração de IPPs são: (1) número de proteínas interagindo, (2) número de tipos de interação, (3) direcionamento da interação e (4) ocultamento de nomes de proteínas. Esses quatro aspectos são descritos a seguir. Primeiro, para um número $m$ de proteínas interagindo é assumido que existem $\left(\begin{array}{l}n \\ m\end{array}\right)$ possíveis conjuntos de proteínas candidatas a interagir em uma sentença com $n$ proteínas. Segundo, para um número $k$ de tipos de interação, é assumido que um conjunto candidato de proteínas deve ser classificado com um tipo de interação dentre $k$ tipos possíveis. Terceiro, para o direcionamento da interação é assumido que se um conjunto candidato de proteínas $\left(\right.$ prot $_{1}, \ldots$, prot $\left._{m}\right)$ tem uma interação, não implica que o conjunto candidato $\left(\right.$ prot $_{m}, \ldots$, prot $\left._{1}\right)$ tenha essa mesma interação. Finalmente, com o ocultamento de nomes de proteínas é assumido que, em um conjunto de proteínas candidatas, os nomes de proteínas candidatas devem ser substituídos por tokens como PROT1, PROT2, ..., PROTM, enquanto os nomes das proteínas restantes devem ser substituídos por PROT. Cabe ressaltar que prot $_{i}$ refere-se a um nome de proteína e não a um token. Assim, com 
apenas esses quatro critérios, a tarefa de extração de IPPs pode apresentar maior ou menor complexidade. Maior informação e detalhes desses critérios são descritos em Pyysalo et al. (2008a,b).

ADP-ribosylation of actin at Arg 177 by Clostridium perfringens iota toxin increased the nucleotide dissociation rate from $2.2 \times$ $10(-3)$ s- 1 to $4.5 \times 10(-3)$ s- 1 without affecting the profilin-induced stimulation of nucleotide exchange.

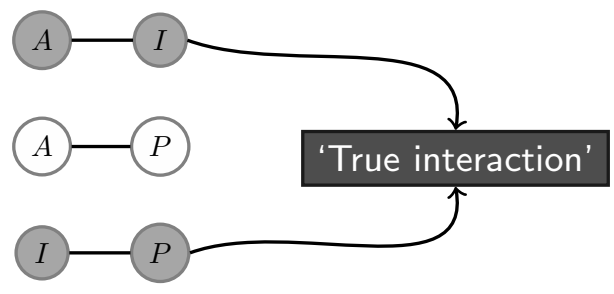

(a)

ADP-ribosylation of PROT1 at Arg 177 by Clostridium perfringens PROT2 increased the nucleotide dissociation rate from $2.2 \times 10(-3)$ s-1 to $4.5 \times 10(-3)$ s-1 without affecting the PROT-induced stimulation of nucleotide exchange.

(b)

ADP-ribosylation of PROT1 at Arg 177 by Clostridium perfringens PROT increased the nucleotide dissociation rate from $2.2 \times 10(-3)$ s- 1 to 4.5 x $10(-3)$ s- 1 without affecting the PROT2-induced stimulation of nucleotide exchange.

(c)

ADP-ribosylation of PROT at Arg 177 by Clostridium perfringens PROT1 increased the nucleotide dissociation rate from $2.2 \times 10(-3)$ s- 1 to 4.5 x 10(-3) s- 1 without affecting the PROT2-induced stimulation of nucleotide exchange.

(d)

Figura 2.1: Uma sentença de texto contendo duas IPPs. (a) A sentença, do conjunto de dados BioInfer com ID = "BioInfer.d27.s0", contém três nomes de proteínas: actin (A), iota toxin (I) e profilin (P). Portanto, três instâncias são produzidas a partir da sentença, das quais duas são classificadas como "existe interação" ("True interaction"). (b) Instância $(A, I)$. (c) Instância $(A, P)$. (d) Instância $(I, P)$.

Para simplificar a tarefa de extração de IPPs, os critérios tipicamente usados são: $m=2, k=2$, o uso de interações não direcionadas e o uso de ocultamento de nomes de proteínas (Airola et al., 2008; Miwa et al., 2009a; Choi e Myaeng, 2010). Com $m=$ 2, assume-se que a interação acontece apenas entre um par de proteínas (PP), sendo denominada essa relação de interesse como IPP. Com $k=2$, no contexto de aprendizado de máquina, assume-se que a tarefa pode ser vista como um problema de classificação binário: "existe interação" ou "não existe interação". Com o uso de interações não direcionadas é assumido que os PPs candidatos ( prot $_{1}$, prot $\left._{2}\right)$ e $\left(\right.$ prot $_{2}$, prot $\left._{1}\right)$ são iguais, sendo necessário analisar apenas um desses PPs. Por fim, com o ocultamento de nomes de proteínas é assumido que os nomes em um PP candidato, em uma sentença, devem ser substituídos por PROT1 e PROT2, enquanto que os nomes restantes de proteínas devem ser substituídos 
por PROT. Nesse contexto, a Figura 2.1(a) ilustra um exemplo de uma sentença com $m=3$ nomes de proteínas, a partir da qual são obtidas $\left(\begin{array}{l}3 \\ 2\end{array}\right)=3$ PPs candidatas ou instâncias. Essas instâncias são ilustradas nas Figuras 2.1(b), 2.1(c) e 2.1(d), nas quais os nomes de cada PP candidato são substituídos pelos tokens PROT1 e PROT2 e o resto de nomes são substituídos por PROT. Apesar da simplificação da tarefa, novas técnicas de extração de IPPs são propostas (Qian et al., 2013; Qian e Zhou, 2012; Li et al., 2011a), mostrando que o problema de extração de IPPs ainda precisa de melhores resultados.

Dentre as várias técnicas que tratam a tarefa de extração de IPPs, as baseadas em classificação têm atingido melhores resultados, porém o problema ainda não foi resolvido. Como foi mencionado na Seção 1, dois aspectos são estudados na procura de melhores desempenhos na extração de IPPs: (1) o estudo de diferentes tipos de objetos, $\mathcal{Z}_{i}$, para representar uma sentença $S_{i}$, e (2) o estudo de novas técnicas de classificação. Tais aspectos são os temas de discussão nesta seção.

Na Seção 2.2 são descritos alguns dos tipos de atributos $\mathcal{Z}_{i}$ mais representativos que são usados por métodos de classificação. Na Seção 2.3 é descrita uma definição formal da extração de IPPs considerando os critérios de simplificação mencionados anteriormente. Assim, assume-se que a tarefa é vista como um problema de aprendizado de máquina, em especial, como um problema de classificação. Na Seção 2.4 são mencionadas as técnicas para a extração de IPPs, dando especial ênfase nos métodos de classificação. Na Seção 2.5 é apresentada a forma de avaliação das técnicas. Finalmente, na Seção 2.6 são apresentadas as considerações finais deste capítulo.

\subsection{Seleção de Características}

Um problema ligado com a extração correta de IPPs é a seleção de características. Neste capítulo, é denotado como $\mathcal{Z}_{i}$ o objeto contendo as características da sentença $\mathcal{S}_{i}$. Dados os critérios de simplificação descritos na Seção 2.1, uma sentença $\mathcal{S}_{i}$ contém apenas um PP. Esse PP é o alvo do classificador e a informação restante na sentença $\mathcal{S}_{i}$ é usada para conseguir detectar se realmente existe uma IPP. As figuras 2.1(b), 2.1(c) e 2.1(d) ilustram três sentenças, $\mathcal{S}_{1}, \mathcal{S}_{2}$ e $\mathcal{S}_{3}$, cujas informações serão empregadas para detectar os PPs (PROT1 e PROT2) correspondentes. Apesar dessas três sentenças serem parecidas, os objetos $\mathcal{Z}_{1}, \mathcal{Z}_{2}$ e $\mathcal{Z}_{3}$ correspondentes podem variar substancialmente entre si, dependendo do método de seleção e do tipo de características utilizados.

De forma geral, existem três tipos de características usadas na extração de IPPs: (1) as baseadas em palavras ou termos, (2) as baseadas em análise sintática, e (3) as baseadas em templates. As características baseadas em palavras, geralmente utilizadas, são: a representação bag-of-words (BOW) e as classes de palavras conhecidas como Part-Of-Speech (POS), detalhadas na próxima seção. Em ambos os casos, existem diversas maneiras de 
usá-las segundo os critérios de cada autor. No caso das características baseadas em análise sintática, a diversidade é maior. Isso porque existem várias representações de sentenças como estruturas sintáticas. Assim, a partir dessas estruturas é comum construir outras que forneçam informações adicionais. Essas tipicamente são construídas de uma maneira ad-hoc e têm permitido melhorar os desempenhos dos classificadores. Por fim, os templates permitem usar certos padrões do tipo "<proteína $1>\ldots<$ verbo $>\ldots<$ proteína2 $>$ ". Esses, geralmente são usados conjuntamente com as características baseadas em palavras e em análise sintática.

Vários estudos foram realizados buscando avaliar as características baseadas em palavras e em análise sintática. Assim, em Miyao et al. (2009) foi encontrado que as características baseadas em análise sintática melhoram o desempenho dos classificadores substancialmente em comparação às características baseadas em palavras. De forma similar, em Fayruzov et al. (2009), foi encontrado que as características baseadas em análise sintática permitem altos desempenhos e o uso delas, junto com as baseadas em palavras, melhoram o desempenho de maneira pouco significativa.

\subsubsection{Características baseadas em Palavras}

As representações BOW e POS tags têm sido usadas isolada ou conjuntamente em diferentes trabalhos de extração de IPPs (Chowdhary et al., 2009; Bunescu e Mooney, 2005; Rosario e Hearst, 2005).

A BOW é um vetor de palavras $n$-dimensional, onde $n$ é o número de termos diferentes a partir de um conjunto de instâncias $\mathcal{D}$, o qual é chamado de conjunto de treinamento. Essa é uma das representações mais simples para sentenças de texto e é considerada um tipo de característica padrão na extração de IPPs (Miyao et al., 2009). Embora, a BOW tenha sido usado tradicionalmente para classificar documentos, essa tem sido usada na extração de IPPs (Rosario e Hearst, 2005; Culotta e Sorensen, 2004). A idéia é representar a i-ésima instância de texto como um vetor $n$-dimensional, $\mathcal{Z}_{\mathrm{i}}$. Assim, quando uma palavra $j$, tal que $j \in[1, n]$, está presente na i-ésima instância, o valor ' 1 ' é atribuído à j-ésima posição do vetor $\mathcal{Z}_{\mathrm{i}}: \mathcal{Z}_{i j}=1$. Caso contrário, o valor '0' é atribuído: $\mathcal{Z}_{i j}=0$. A Figura 2.2 ilustra um conjunto de três instâncias. A partir dessas são gerados três vetores $\mathcal{Z}_{1}$, $\mathcal{Z}_{2}$ e $\mathcal{Z}_{3}$ com dimensão $n=10$. A Figura 2.3 ilustra esse caso, onde cada posição $j$ do i-ésimo vetor $\mathcal{Z}_{i}$ armazena um valor binário. Esse valor binário indica se existe ('1') ou não existe ('0') a $j$-ésima palavra na instância $\mathcal{Z}_{i}$.

Apesar da BOW ser uma técnica fácil de implementar, ela pode levar a uma alta dimensionalidade. Isso acontece principalmente quando o conjunto $\mathcal{D}$ tem muitas instâncias. Assim, o número de palavras encontradas no corpus é alto, levando a uma perda de eficiência das técnicas para extração de IPPs. Adicionalmente, a BOW não permite manter a ordem das palavras, o qual é indicado como um aspecto importante na extração 


\begin{tabular}{|l|l|}
\hline $\mathcal{S}_{1}$ & $P R O T 1_{0}$ is $_{6}$ mediated $_{3}$ by $_{8} P R O T 2_{1}$ \\
$\mathcal{S}_{2}$ & $P R O T 2_{1}$ and $_{9} P R O T 2_{1}$ related $_{4}$ pathways $_{5}$ \\
$\mathcal{S}_{3}$ & PROT $_{0} /$ PROT $_{2}$ pathways $_{5}$ are $_{7}$ mediated $_{3}$ by $_{8} P R O T 2_{1}$ \\
\hline
\end{tabular}

Figura 2.2: Um conjunto de três sentenças de texto: $\mathcal{S}_{1}, \mathcal{S}_{2}$ e $\mathcal{S}_{3}$. Nas sentenças, cada palavra tem um número identificador como índice.

\begin{tabular}{|c|c|c|c|c|c|c|c|c|c|c|}
\hline & PROT1 & PROT2 & PROT & mediated & related & pathways & is & are & by & and \\
& 0 & 1 & 2 & 3 & 4 & 5 & 6 & 7 & 8 & 9 \\
\hline $\mathcal{Z}_{1}$ & 1 & 1 & 0 & 1 & 0 & 0 & 1 & 0 & 1 & 0 \\
\hline $\mathcal{Z}_{2}$ & 1 & 1 & 0 & 0 & 1 & 1 & 0 & 0 & 0 & 1 \\
\hline $\mathcal{Z}_{3}$ & 1 & 1 & 1 & 1 & 0 & 1 & 0 & 1 & 1 & 0 \\
\hline
\end{tabular}

Figura 2.3: Vetores de palavras $\mathcal{Z}_{1}, \mathcal{Z}_{2}$ e $\mathcal{Z}_{3}$ construídos a partir das sentenças de texto $\mathcal{S}_{1}, \mathcal{S}_{2}$ e $\mathcal{S}_{3}$, as quais foram ilustradas na Figura 2.2. Em cada posição $\left(\mathcal{Z}_{i}\right.$, palavra $\left._{j}\right)$, é atribuído o valor "1" quando palavra ${ }_{j}$ está presente na sentença $\mathcal{S}_{i}$; caso contrário, é atribuído o valor "0".

de IPPs (Bunescu e Mooney, 2005). Assim, outras alternativas têm sido propostas para reduzir o número de palavras e considerar sua ordem. Uma proposta é o uso de "palavras vizinhas" tanto de PROT1 quanto de PROT2 (Bunescu et al., 2005). As "palavras vizinhas" são divididas em três grupos: (1) as palavras antes de PROT1 e as palavras entre PROT1 e PROT2; (2) as palavras entre PROT1 e PROT2; por fim, (3) as palavras entre PROT1 e PROT2 e aquelas localizadas após PROT2. Em cada grupo, o número máximo de "palavras vizinhas" é 4 .

Por outro lado, POS tags são considerados classes de palavras (Jurafsky e Martin, 2008). Essas classes podem ser, por exemplo, verbos, pronomes ou preposições. Existem oito classes de palavras principais em POS-tagging: verbos-VB, substantivos-NN, adjetivos-JJ, advérbios-RB, preposições-IN, conjunções-CC, pronomes-PR e determinantesPDT. Porém, existem outras classes como, interjeições e sinais de pontuação, as quais não são consideradas principais (Konchady, 2006).

Tabela 2.1: Classes principais de palavras usadas por POS-Taggers

\begin{tabular}{cccc}
\hline Classe principal & Símbolo & Classe principal & Símbolo \\
\hline Verbo & VB & Preposição & IN \\
Substantivos & NN & Conjunção & CC \\
Adjetivo & JJ & Pronome & PR \\
Advérbio & RB & Determinante & PDT \\
\hline
\end{tabular}

Um exemplo concreto de POS tags, a partir de uma sentença, é ilustrado na Figura 2.4. Nessa figura, a sentença do PP (RelA, AGB939) foi processada por um POS tagger, dessa forma, os tags para cada palavras foram obtidos. Para os POS tags serem usados em um objeto $\mathcal{Z}_{i}$, tipicamente é usada uma abordagem parecida com a BOW, só que em vez de usar palavras são usadas as classes de palavras (Zhang et al., 2011). 
RelA interacts with AB28 to disassemble the AGB939 filaments

\begin{tabular}{|c|c|c|c|c|c|c|c|}
\hline PROT1 & interacts & with & PROT & to & disassemble & PROT2 & filaments \\
\hline NN & VB & IN & NN & TO & VB & NN & NN
\end{tabular}

Figura 2.4: POS tags atribuídos às palavras de uma sentença de texto. Baseado em um exemplo descrito em Airola et al. (2008).

Além de POS tags e BOW, outros termos têm sido usados na extração de IPPs. Por exemplo, o uso de palavras-chave tais como verbos importantes de interações: "bind", "inhibit" e "activate" tem demonstrado sua utilidade para a discriminação de sentenças, em favor da deteç̧ão de IPPs (Huang et al., 2004). Palavras tais como "not" e "but" também têm sido empregadas visando lidar com sentenças negativas (Zhang et al., 2011; Chowdhary et al., 2009).

\subsubsection{Características baseadas em Análise Sintática}

Para extrair características baseadas em análise sintática é necessário o uso de um parser. Um parser é uma técnica de processamento de língua natural que permite representar uma sentença de texto como uma estrutura sintática (Bui et al., 2011). Existem diferentes tipos de estruturas dependendo do tipo de parser usado. Na extração de IPPs, três tipos de parsers são comumente usados (Miyao et al., 2009). Esses parsers são para estruturas constituintes, de dependências e profundas.

No caso de estruturas constituintes, essas são árvores contendo as palavras de uma sentença nas folhas (ou nós terminais) e as classes de palavras como nós internos (ou nós não terminais). A Figura 2.5 ilustra um exemplo de árvore constituinte a partir da sentença, "In summary, FGFR3 signaling pathway utilizes two GRB2-containing complexes; Shc.". Para esse caso, o PP é (GRB2, Shc).

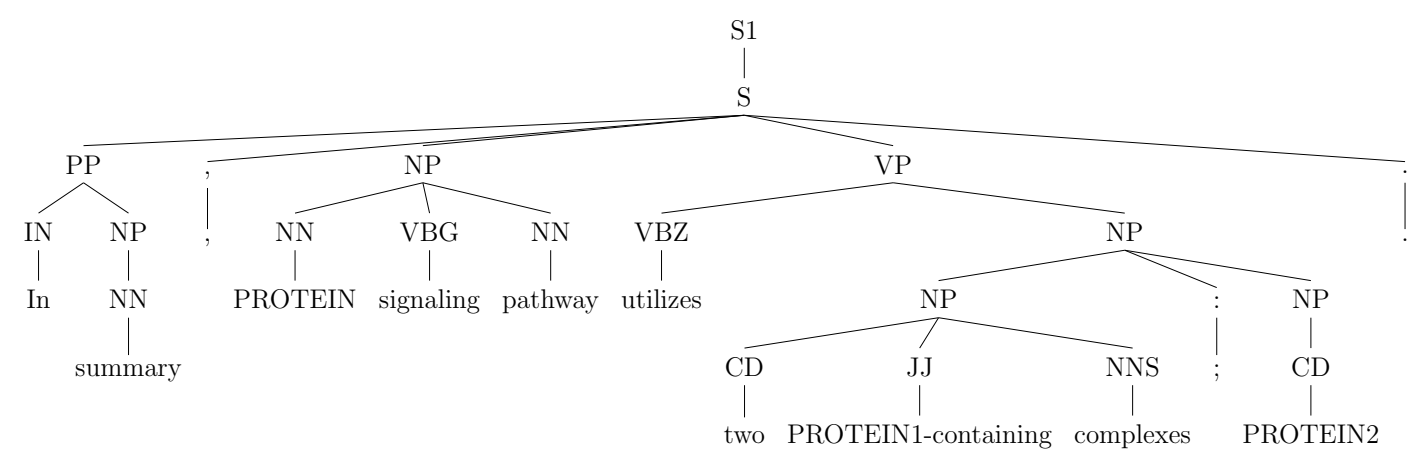

Figura 2.5: Árvore constituinte obtida a partir de uma sentença de texto. Essa sentença forma parte do corpus AImed com ID="AIMed.d199.s1710". 
As árvores de dependência são estruturalmente mais simples em comparação às árvores constituintes. Assim, essas têm uma menor quantidade de arestas e nós. Porém, diferentemente de árvores constituintes, as árvores de dependência podem armazenar palavras de uma sentença tanto em nós terminais quanto em nós não terminais. A Figura 2.6 ilustra uma árvore de dependência a partir da sentença do exemplo anterior. Segundo Miyao et al. (2009), as árvores de dependência aproximam melhor a semântica das sentenças.

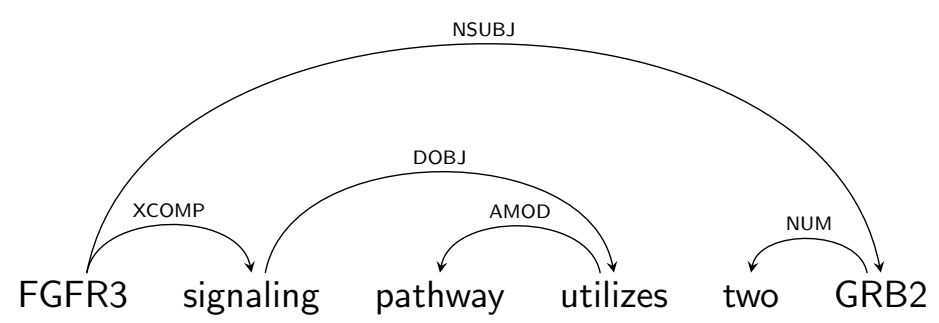

Figura 2.6: Extrato de uma árvore de dependência obtida a partir de um fragmento de sentença de texto. A sentença forma parte do corpus AImed com ID="AIMed.d199.s1710".

Por fim, no caso das estruturas profundas, essas são construídas a partir de teorias sintáticas (Miyao et al., 2009). Essas tipicamente são grafos, nos quais as arestas representam relações entre palavras. De maneira geral, as estruturas profundas representam conhecimento sintático e semântico das sentenças e levam maior tempo de processamento em comparação às outras estruturas.

A partir desses tipos de estruturas, diversas características têm sido extraídas. Por exemplo, caminhos sintáticos foram extraídos por meio dessas estruturas em (Sætre et al., 2007). A exploração de um caminho de dependência mais curto entre PROT1 e PROT2 foi proposta em Kim et al. (2010). O uso de vários caminhos na estrutura de dependência foi proposto em (Airola et al., 2008). Além dessas propostas, outras utilizaram a combinação das estruturas sintáticas com as características baseadas em palavras (Miwa et al., 2009a,b). Porém, foi demonstrado que a sobreposição desses tipos de características não oferece melhores resultados, mas produz um aumento na complexidade da técnica de extração de IPPs de forma desnecessária (Fayruzov et al., 2009). Assim, ainda é necessário pesquisar outros tipos de características capazes de oferecer altos desempenhos de forma contundente (Bui et al., 2011).

Na seguinte seção são apresentadas as técnicas de extração de IPPs, das quais, as técnicas de classificação são as principais.

\subsection{Definição da Tarefa de Extração de IPPs}

Considerando os critérios que simplificam a tarefa de extração de IPPs, já mencionados na seção anterior, essa tarefa é definida como um problema de classificação nesta seção. A 
classificação apresenta duas etapas: construção e teste do classificador. Para construir um classificador é necessário o uso de um conjunto de treinamento. O conjunto de treinamento permite ao classificador generalizar ou 'aprender' uma função (hipótese) a fim de usá-la para classificar novas instâncias. Por outro lado, para testar esse classificador é necessário de um conjunto novo, chamado de conjunto de teste. O conjunto de teste contém novas instâncias com as quais é avaliada a capacidade de generalização do classificador.

Para a avaliação, as instâncias devem ter sido classificadas de modo manual antes de formar parte dos conjuntos ou de treinamento ou de teste. Por exemplo, a sentença ilustrada na Figura 2.1 contém 3 instâncias classificadas manualmente como: interactsWith $(A, I)=1$, interactsWith $(A, P)=0$ e interactsWith $(I, P)=1$, onde interactsWith pode ser considerada uma função que atribui uma classe para uma IPP candidata: "existe interação" ('1') ou não "não existe interação" ('0'). Tais conjuntos de instâncias são chamados de corpora, existindo vários corpora que permitem o aprendizado e a avaliação de classificadores na extração de IPPs (Pyysalo et al., 2008a).

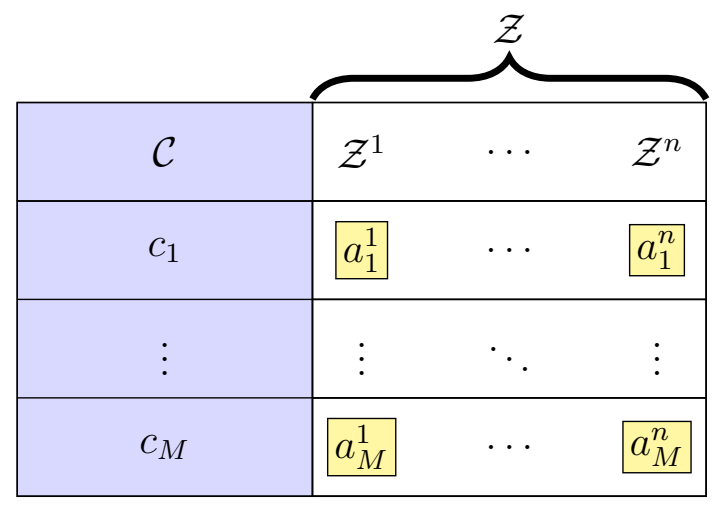

Figura 2.7: Conjunto de vetores de características com $M$ instâncias. Cada vetor contém $n$ atributos e uma classe. $\mathcal{Z}$ é o conjunto de atributos e $\mathcal{C}$ é a variável classe

As instâncias classificadas são representadas por um objeto $\mathcal{Z}$ e uma variável classe $\mathcal{C}$. O objeto pode ser um vetor $n$-dimensional, uma árvore, um grafo, entre outros tipos de representação. Por outro lado, a classe contém valores nominais (Murphy, 2012). No caso de classificação binária, a classe contém dois valores $(\mathcal{C}=\{0,1\})$. A Figura 2.7 ilustra um conjunto de $M$ instâncias com $n$ atributos, onde cada instância é representada pelo par $\{\mathcal{Z}, \mathcal{C}\}$, isto é, um vetor de atributos $\mathcal{Z}$ e uma variável classe $\mathcal{C}$. Nesse caso, um classificador deve ser treinado a partir do conjunto $\mathcal{D}=\left\{\mathcal{Z}_{\mathrm{i}}, \mathcal{C}_{\mathrm{i}}\right\}_{\mathrm{i}=1}^{M}$. Essa classificação é definida pela máxima probabilidade a posteriori (Murphy, 2012), conforme Equação (2.1).

$$
\hat{y}=\arg _{\mathcal{C}} \max \{P(\mathcal{C}=0 \mid \mathcal{M}, \mathcal{D}, x), P(\mathcal{C}=1 \mid \mathcal{M}, \mathcal{D}, x)\} .
$$

onde $\mathcal{M}$ é um classificador; $\mathcal{D}$ é um conjunto de instâncias de treinamento; $x$ é uma instância de teste; $P(\mathcal{C}=0)$ e $P(\mathcal{C}=1)$ são as probabilidades de classificar $x$ com as classes $\mathcal{C}=0$ e $\mathcal{C}=1$, respectivamente, dado o classificador $\mathcal{M}$ e o conjunto de dados $\mathcal{D}$. 
Formalmente, a instância de teste $x$ é definida como $x=\left\{\mathcal{Z}_{\mathrm{x}}, \mathcal{C}_{\mathrm{x}}\right\}$, mas, de maneira intuitiva, ela faz referência a um PP avaliado em uma sentença. Por exemplo, a instância $(A, P)$ intuitivamente indica que esse $\mathrm{PP}$ está sendo analisado na sentença como ilustrado na Figura 2.1(b). Porém, quando a instância $(A, P)$ é referida no contexto de classificação, ela está sendo considerada da forma $x=\left\{\mathcal{Z}_{\mathrm{x}}, \mathcal{C}_{\mathrm{x}}\right\}$, onde $x$ seria a representação formal de $(A, P)$. Como parte disso, a proteína $A$ e $P$ podem ser mapeadas a partir de $x$ usando a função $\operatorname{prot} 1(x)$ e $\operatorname{prot} 2(x)$ respectivamente. Dessa forma, os conceitos de classificação e extração de relação, de alguma maneira, são unificados no contexto deste trabalho de mestrado.

As instâncias de teste, tal como $x$, permitem avaliar um classificador $\mathcal{M}$. $\mathcal{M}$ classificará $x$ como $\hat{y}$, sendo $\hat{y}$ o valor da variável $\mathcal{C}$ com maior probabilidade de ser atribuído para tal instância. Assim, a tarefa de extração de IPPs é definida pela equação (2.2):

$$
\operatorname{extractRelation}(\hat{y}, x)= \begin{cases}\hat{y}=1 & \text { interactsWith }(\operatorname{prot} 1(x), \operatorname{prot} 2(x)) \\ \hat{y}=0 & \emptyset\end{cases}
$$

onde interactsWith $(\operatorname{prot} 1(x), \operatorname{prot} 2(x))$ é a informação estruturada extraída, a qual indica a existência de uma relação de IPP entre as proteínas $\operatorname{prot} 1(x)$ e $\operatorname{prot} 2(x)$. Como é mostrado nessa equação, a IPP, interactsWith $(\operatorname{prot} 1(x), \operatorname{prot} 2(x))$, é extraída quando o classificador $\mathcal{M}$ obtém $P(\mathcal{C}=1)$ como máxima probabilidade a posteriori. Caso contrário, $P(\mathcal{C}=0)$, nenhuma informação $(\emptyset)$ é extraída.

\subsection{Técnicas para a Extração de IPPs}

Nesta seção são descritos alguns dos métodos mais importantes na extração de IPPs. Primeiro, são descritos os métodos baseados em coocorrência e templates na Seção 2.4.1. A seguir, são apresentados os métodos baseados em classificação. Em particular, na Seção 2.4.2 são descritos os classificadores baseados em kernels, os quais têm atingido melhores desempenhos em comparação a outros classificadores. Finalmente, na Seção 2.4.3 são detalhados trabalhos da literatura relacionados com redes bayesianas para classificação de IPPs.

\subsubsection{Técnicas baseadas em Coocorrência e Templates}

Métodos baseados em coocorrência já foram utilizadas na detecção de pares de genes que contribuem conjuntamente em uma função biológica (Stapley e Benoit, 2000). A deteção baseia-se na idéia que uma alta coocorrência entre um par de genes aumenta a probabilidade de tal par contribuir em uma função biológica. Essa é uma técnica simples 
em comparação com outras técnicas de extração de IPPs (Daraselia et al., 2004). Ela consiste em assumir uma interação entre um par de proteínas (PP) quando esse PP aparece frequentemente nas sentenças de texto. Como resultado, as técnicas de coocorrência produzem uma alta revocação (Bui et al., 2011). Apesar disso, apresentam uma baixa precisão, causada pela detecção de falsos positivos (Chowdhary et al., 2009). Por isso, sua aplicação na extração de IPPs tem recebido pouco interesse nos últimos anos.

Por outro lado, os métodos baseados em templates utilizam padrões para encontrar interações (Blaschke et al., 2001; Wong, 2001; Ng e Wong, 1999). Por exemplo, $<A>\ldots<f n>\ldots<B>$ pode ser um padrão, no qual, a primeira proteína $A$ segue a relação (interação) $f n$ e finalmente a proteína $B$. Dessa maneira, estruturas semelhantes podem ser encontradas nas sentenças de texto analisadas. Embora alguns trabalhos sejam interessantes (Ng e Wong, 1999; Park et al., 2001), tipicamente apresentam uma baixa taxa de revocação. O problema principal desse método é que não é possível cobrir a todas as formas em que uma sentença pode ser escrita, pois os diferentes tipos de escrita produzem uma vasta diversidade estrutural. De maneira geral, o funcionamento de templates pode ser descrito em duas fases. Na primeira fase, os templates são definidos de modo a identificar estruturas gramaticais que representem informações relevantes. Tais templates podem indicar, por exemplo, a ordem de aparição do verbo, sujeito e adjetivo (Park et al., 2001; Ng e Wong, 1999). Posteriormente, na segunda fase, é procurada a existência de estruturas que coincidem com esses templates na sentença (Moens, 2006). No entanto, isso exige uma grande quantidade de templates para cobrir todas as possíveis estruturas que pode apresentar uma sentença, sendo custoso. Em Bui et al. (2011) são utilizados templates junto com características baseadas em análise sintática.

\subsubsection{Classificadores baseados em SVM}

Como foi mencionado anteriormente, os métodos baseados em classificação com melhor desempenho têm sido os de SVM. Além disso, muitos desses métodos têm sido testados com conjuntos padrões para extração de IPPs, o que também tem permitido uma comparação mais justa entre esses métodos. De fato, existem cinco conjuntos de dados que são amplamente utilizados para comparar técnicas baseadas em classificação: AImed, BioInfer, IEPA, HPRD50 e LLL. Os detalhes desses conjuntos são descritos na Seção 2.5.1. Em geral, um conjunto de textos é chamado de corpus. Além disso, os cincos conjuntos mencionados são conhecidos como os PPI corpora ou Five PPI corpora. Na Tabela 2.2 são mostrados os melhores resultados de alguns métodos mencionados nesta subseção usando um desses corpora, o corpus AImed. Embora com o uso desse corpus seja possível saber quais técnicas (e características) são mais apropriadas para extração de IPPs, o pré-processamento de texto e a configuração dos parâmetros dos classificadores usados podem ser diferentes. Porém, os resultados descritos nessa tabela são uma estimativa 
aceitável. Os resultados são avaliados em termos da medida F (ver Subseção 2.5.2 para maior informação).

Em Bunescu et al. (2005) é proposto o uso do corpus AImed e a aplicação de características baseadas em palavras para classificadores KNN e SVM, sendo que o classificador SVM teve um melhor desempenho. Em Erkan (2007), é proposta uma técnica transdutiva baseada em SVM usando árvores de dependência. A partir dessas árvores são extraídos os caminhos mais curtos entre PROT1 e PROT2. Depois, um par de caminhos é comparado usando um kernel baseado em similaridade por cosseno. Em Zhang et al. (2011) é utilizado um conjunto de características baseadas em palavras e em análise sintática. De fato, esse trabalho emprega essas características de maneira conjunta em uma representação de vetores como $\mathcal{Z}_{i}$ n-dimensional a partir de uma sentença $\mathcal{S}_{\rangle}$. Esses vetores são usados por classificadores de SVM com kernels lineares. Nesse trabalho é demonstrado que as características baseadas em análise sintática e POS tags têm grande importância na extração de IPPs, sendo que quando essas são removidas, o desempenho decresce em aproximadamente $12 \%$. Por outro lado, quando as características baseadas em palavras-chave são removidas, o resultado decresce aproximadamente em 6\%. De uma maneira sistemática, em Miyao et al. (2009) foi analisado o impacto de usar diferentes parsers para a classificação de IPPs usando SVM com kernel linear. Assim, são empregados oito parsers dos três tipos diferentes de análise sintática: de dependência, constituinte e profunda. Além disso, é usado uma representação BOW. De maneira similar às anteriores, a contribuição da BOW é pouco significativa. Em Miwa et al. (2008) são combinados múltiplos kernels. Cada kernel processa um tipo diferente de objeto $\mathcal{Z}_{i}$. Esses são, BOW kernel, Subset tree kernel e Graph kernel. O Subset tree kernel calcula a similaridade entre duas sentenças $\mathcal{S}_{i}$ e $\mathcal{S}_{j}$, levando uma contagem das subárvores iguais encontradas nelas. O Graph kernel calcula a similaridade entre as sentenças $\mathcal{S}_{i}$ e $\mathcal{S}_{j}$ ao comparar as relações de acordo com as arestas em comum entre elas. De forma similar, em Yang et al. (2012) foram usados múltiplos kernels, onde a cada kernel é atribuído um peso. Esses foram: BOW kernel, Subset tree kernel e Graph kernel. No caso de BOW kernel, são usadas "palavras vizinhas" das proteínas e também palavras-chave. Embora a união de vários kernels tenham permitido melhorar os resultados na extração de IPPs, o processamento é custoso. Em Yakushiji et al. (2006) são usadas estruturas profundas junto com templates. O objetivo é detectar tais templates a partir de uma árvore de uma sentença. Apesar disso, em termos da taxa de revocação, o resultado é baixo.

Em Airola et al. (2008) são utilizados grafos de dependência. Esses são usados com Regular Least Squares (RLS) que é semelhante ao classificador SVM. No grafo, cada nó representa uma palavra da sentença e cada aresta uma relação de dependência entre nós. Além disso, é usado um peso que representa a distância entre duas proteínas e permite determinar se elas são vizinhas ou não. A atribuição dos pesos é realizada de maneira manual. Em Choi e Myaeng (2010) é usado um Subtree kernel. Nesse trabalho, um aspecto 
característico é o uso de poda nas árvores constituintes, tal que os ramos colocados à esquerda do nó contendo a primeira proteína (PROT1) são removidos. Os ramos à direita da segunda proteína também são removidos, tornando a árvore menor. Segundo Choi e Myaeng (2010), com isso é possível utilizar apenas a informação relevante contida na árvore. Em Bui et al. (2011) é proposta uma técnica baseada em SVM com a utilização de regras semânticas. Nesse trabalho também são utilizadas árvores de dependência, obtendo melhores acurácias do que as outras técnicas de kernels. Em Li et al. (2011a) é usada uma técnica de geração semisupervisionada de características. O objetivo dessa é ajustar o espaço de características a fim de melhorar o desempenho de um classificador. O classificador empregado é uma SVM com kernel RBF. Porém, não foram observadas melhoras na extração em comparação às outras técnicas prospostas.

Dentre algumas técnicas não baseadas em SVM, existe uma técnica semisupervisionada baseada em KNN (Qian et al., 2013). Essa utiliza POS tags e templates como característcas, atingindo resultados competitivos em comparação a outras técnicas. No entanto, não foi especificada a forma em que foi feita a divisão de sentenças para treinamento e teste. Uma divisão simples, isto é, uma divisão sem considerar as sentenças de um mesmo documento em apenas um conjunto (seja ou de treinamento ou teste), pode levar o classificador "observar" informação do conjunto de teste e limitando a capacidade de generalização desse (Pyysalo et al., 2008a).

Tabela 2.2: Comparação de classificadores propostos em trabalhos prévios para extração de IPPs em termos de precisão, revocação e da medida $\mathrm{F}$ no corpus AImed. $\mathrm{C}=$ características, $\mathrm{C}(\mathrm{I})=$ características baseadas em palavras, $\mathrm{C}(\mathrm{II})=$ características baseadas em análise sintática, $\mathrm{C}(\mathrm{III})=$ características baseadas em templates, $\mathrm{P}=$ precisão, $\mathrm{R}=$ revocação, $\mathrm{F}=$ medida $\mathrm{F}$.

\begin{tabular}{llcccc}
\hline Trabalho prévio & Classificador & C & P & R & F \\
\hline Choi e Myaeng (2010) & SVM-kernels múltiplos & II & 0.73 & 0.62 & $\mathbf{0 . 6 7}$ \\
Li et al. (2011b) & SVM-kernel RBF & I, III & - & - & 0.65 \\
Miwa et al. (2008) & SVM-kernels múltiplos & I, II & 0.60 & 0.69 & 0.64 \\
Yang et al. (2012) & SVM-kernels múltiplos & I, II & 0.57 & 0.71 & 0.64 \\
Qian et al. (2013) & KNN & I, III & 0.65 & 0.61 & 0.63 \\
Erkan (2007) & TSVM-cos & II & 0.58 & 0.61 & 0.6 \\
Miyao et al. (2009) (2 parsers $)$ & SVM-kernel linear & I, II & - & - & 0.6 \\
Zhang et al. (2011) & SVM-kernel linear & I, II & 0.61 & 0.57 & 0.59 \\
Miyao et al. (2009) (1 parser $)$ & SVM-kernel linear & I, II & 0.58 & 0.6 & 0.58 \\
Yakushiji et al. (2006) & SVM-kernel RBF & II, III & 0.72 & 0.49 & 0.57 \\
Airola et al. (2008) & RLS & I, II & 0.53 & 0.62 & 0.56 \\
Bunescu et al. (2005) & SVM & I & 0.70 & 0.45 & 0.54 \\
\hline
\end{tabular}




\subsubsection{Classificadores baseados em Redes Bayesianas}

Redes bayesianas também têm sido usadas para extração de IPPs. Em Chowdhary et al. (2009) é proposta uma rede bayesiana que utiliza características baseadas em palavras e classes de palavras como atributos. A rede é construída a partir de uma grande quantidade de sentenças de treinamento. O modelo de rede empregada é ilustrado na Figura 2.8. Tal modelo emprega 12 atributos (ou nós): numberOfInteractors, breaker, D2, comma, but, which, not, D1, order, interactor, prep e conditional. Para ligar esses nós, é usado o algoritmo de busca de subida de encosta. Assim, considera-se um espaço de busca onde operadores para adicionar, remover e inverter arestas são empregados, a fim de encontrar uma rede que se ajuste melhor aos dados. Esses atributos descrevem palavras e classes de palavras que podem ser encontradas em uma mésima sentença de texto, $S_{\mathrm{m}}$. Por outro lado, uma variável chamada de class é adicionada ao modelo a fim da rede poder classificar e extrair IPPs. Para cada variável do conjunto $\mathcal{Z}[m]$, com os valores dos atributos observados em $S_{\mathrm{m}}$, é atribuído um valor: $\mathcal{Z}[m]=\left\{\mathcal{Z}[m]^{1}, \ldots, \mathcal{Z}[m]^{12}\right\}$. Entretanto, a variável class tem um valor não observado, $\mathcal{C}[m]$. Para estimar o valor da class, é usado o cálculo da probabilidade máxima a posteriori: $\arg _{\mathcal{C}[\mathrm{m}]} \max \{P(\mathcal{C}[m]=0 \mid \mathcal{Z}[m], \mathcal{D}), P(\mathcal{C}[m]=1 \mid \mathcal{Z}[m], \mathcal{D})\}$.

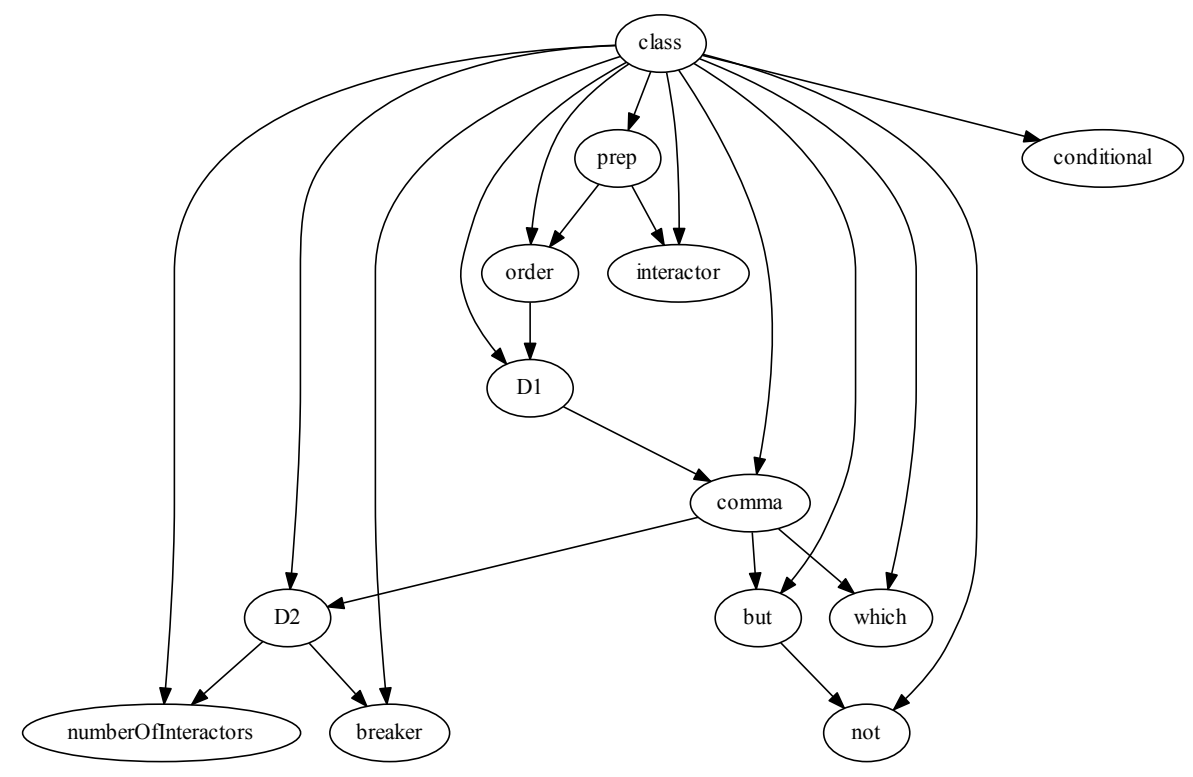

Figura 2.8: Rede bayesiana proposta em Chowdhary et al. (2009) para extração de IPPs. Tal rede usa uma variável oculta chamada de class. As outras 12 variáveis são observadas na sentença de teste.

Embora a construção automática dessa rede permita encontrar modelos com bom desempenho, a mesma utiliza apenas características baseadas em palavras. Isso pode levar 
a rede bayesiana não conseguir resultados competitivos com o estado da arte. De fato, o uso de características baseadas em análise sintática foi demonstrado ser mais relevante, segundo Fayruzov et al. (2009). Na Tabela 2.2 pode ser observado que os trabalhos com altos desempenhos na extração de IPPs, utilizam características baseadas em análise sintática. Além disso, em Chowdhary et al. (2009) é afirmado que o desempenho da rede foi semelhante aos do estado da arte. No entanto, essa rede bayesiana foi testada com um conjunto de dados não padrão, dificultando a realização de uma comparação.

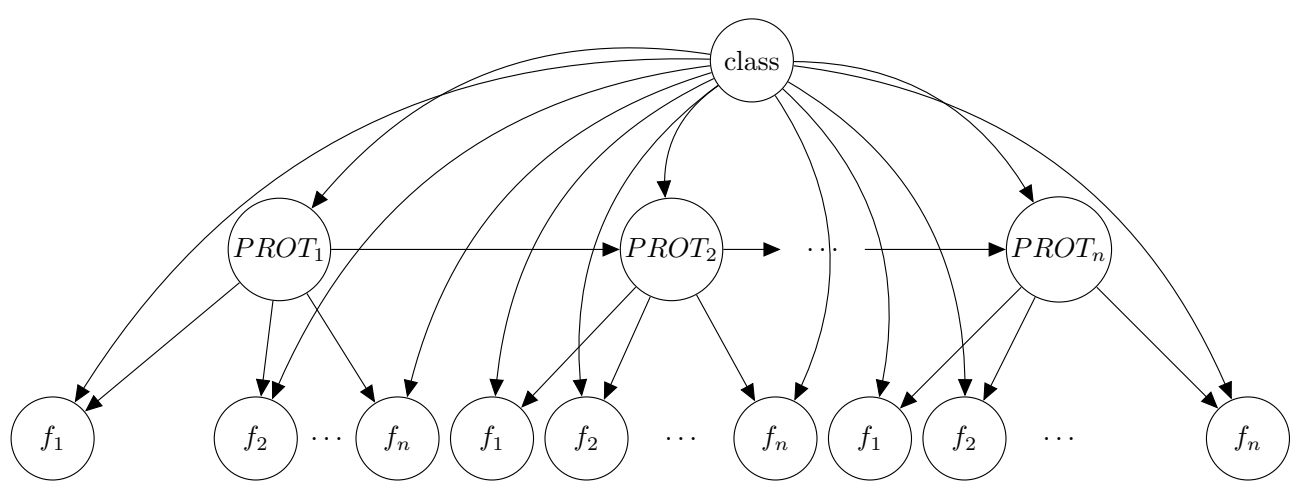

Figura 2.9: Rede bayesiana dinâmica proposta em Rosario e Hearst (2005) para extração de IPPs. O nó class é a variável classe, enquanto cada nó $P R O T_{i}$ é uma variável oculta. Finalmente, cada nó $f_{i}$ é uma palavra observada no conjunto de dados, $\mathcal{D}$. O nó class está ligada com o resto de nós da rede bayesiana.

Em Rosario e Hearst (2005) foram utilizadas redes bayesianas dinâmicas (RBD) na extração de IPPs. Uma RBD pode reutilizar a distribuição de probabilidades de um conjunto de nós. Por exemplo, a Figura 2.9 ilustra um conjunto de nós $f_{1}, \ldots, f_{n}$ que repetidamente aparecem como nós filhos de uma variável $P R O T_{i}$. Assim, dado que existe uma estrutura padrão nessa rede, é possível reutilizar uma distribuição da forma $P\left(f_{j} \mid\right.$ $\left.P R O T_{i}\right)$. Além disso, os nós $P R O T_{i}$ são variáveis ocultas dentro da rede, enquanto os nós $f_{i}$ são as variáveis observáveis no conjunto de dados $\mathcal{D}$. Em particular, essa RBD busca estabelecer uma dependência entre uma palavra sucessora com a precedente, de forma que, a detecção de uma proteína condiciona a aparição da proteína seguinte. Cabe ressaltar que essa rede foi usada no contexto de classificação multiclasse, abordando o problema de detectar qual o tipo de interação existente em uma sentença de texto. Para testar a RBD, foram propostos dois corpora que formam parte do conjunto de dados chamado de BioText. Os resultados da RBD foram semelhantes com os da naive Bayes e de uma rede neural padrão. Nesta revisão bibliográfica, não foram encontradas outras propostas baseadas em redes bayesianas. 


\subsection{Avaliação das Técnicas}

Nesta seção, são apresentados vários conjuntos de dados relacionados com o problema de extração de IPPs. Também, são apresentadas as medidas de avaliação tipicamente usadas para calcular o desempenho dos métodos propostos para extração de IPPs.

\subsubsection{Conjuntos de Dados}

Com o objetivo de avaliar as técnicas de extração de IPPs, são apresentados cinco conjuntos de dados padrões: BioInfer (Pyysalo et al., 2007), AIMed (Bunescu et al., 2005), IEPA (Ding et al., 2002), HPRD50 (Fundel et al., 2007) e LLL (Nédellec, 2005). Em cada um desses conjuntos, existem sentenças de texto anotadas por especialistas. Desse modo, com cada sentença de texto, existe informação sobre a posição das proteínas e os rótulos para cada par de nomes de proteínas $(P P)$ na sentença. Assim, a partir de uma sentença de texto, é possível obter várias instâncias de classificação de IPPs, onde uma instância está associada com um PP. O rótulo para cada instância pode ser "1" ("existe interação") ou "0" ("não existe interação"). Quando uma instância é rotulada como "1", essa é conhecida como instância positiva; caso contrário, é uma instância negativa.

As informações dos 5 conjuntos de dados são mostradas na Tabela 2.3. Observa-se que os maiores conjuntos são AIMed e BioInfer, os quais contêm 5834 e 9666 instâncias respectivamente. Esses são considerados os principais conjuntos na extração de IPPs. Já os conjuntos HPRD50, IEPA e LLL são menores, contendo cada um 433, 817 e 330 instâncias, respectivamente. Note-se que cada conjunto de dados tem sentenças de diversos documentos. Isso é considerado importante e levado em conta na avaliação dos métodos quando é aplicada a validação cruzada com 10-fold. Com a validação cruzada, o conjunto é dividido em dois subconjuntos: um de treinamento e outro de teste. Segundo Pyysalo et al. (2007), é necessário adicionar sentenças dos mesmos documentos só em um desses subconjuntos. Dessa maneira, é possível reduzir o overfitting dos métodos.

Tabela 2.3: Informações dos conjuntos de dados: AIMed, BioInfer, HPRD50, IEPA e LLL.

\begin{tabular}{lrrrrr}
\hline & AIMed & BioInfer & HPRD50 & IEPA & LLL \\
\hline \# documentos & 225 & 836 & 43 & 200 & 45 \\
\# sentenças & 1955 & 1100 & 145 & 486 & 77 \\
\# instâncias & 5834 & 9666 & 433 & 817 & 330 \\
\# inst. positivas & 1000 & 2534 & 163 & 335 & 164 \\
\# inst. negativas & 4834 & 7132 & 270 & 482 & 166 \\
\hline
\end{tabular}

Outro aspecto importante desses conjuntos é a taxa de instâncias positivas com relação ao total de instâncias. Segundo Pyysalo et al. (2008b), se o número de instâncias 
positivas for pequeno em comparação ao total, a probabilidade de classificar as instâncias corretamente é menor. Isso é um problema adicional da extração de IPPs. A Figura 2.10 ilustra a relação de instâncias positivas e negativas para os 5 conjuntos de dados. Assim, os conjuntos AIMed e BioInfer apresentam um número de instâncias negativas maior do que as positivas. Por outro lado, os conjuntos HPRD50, IEPA e LLL apresentam um número equilibrado de instâncias positivas e negativas.

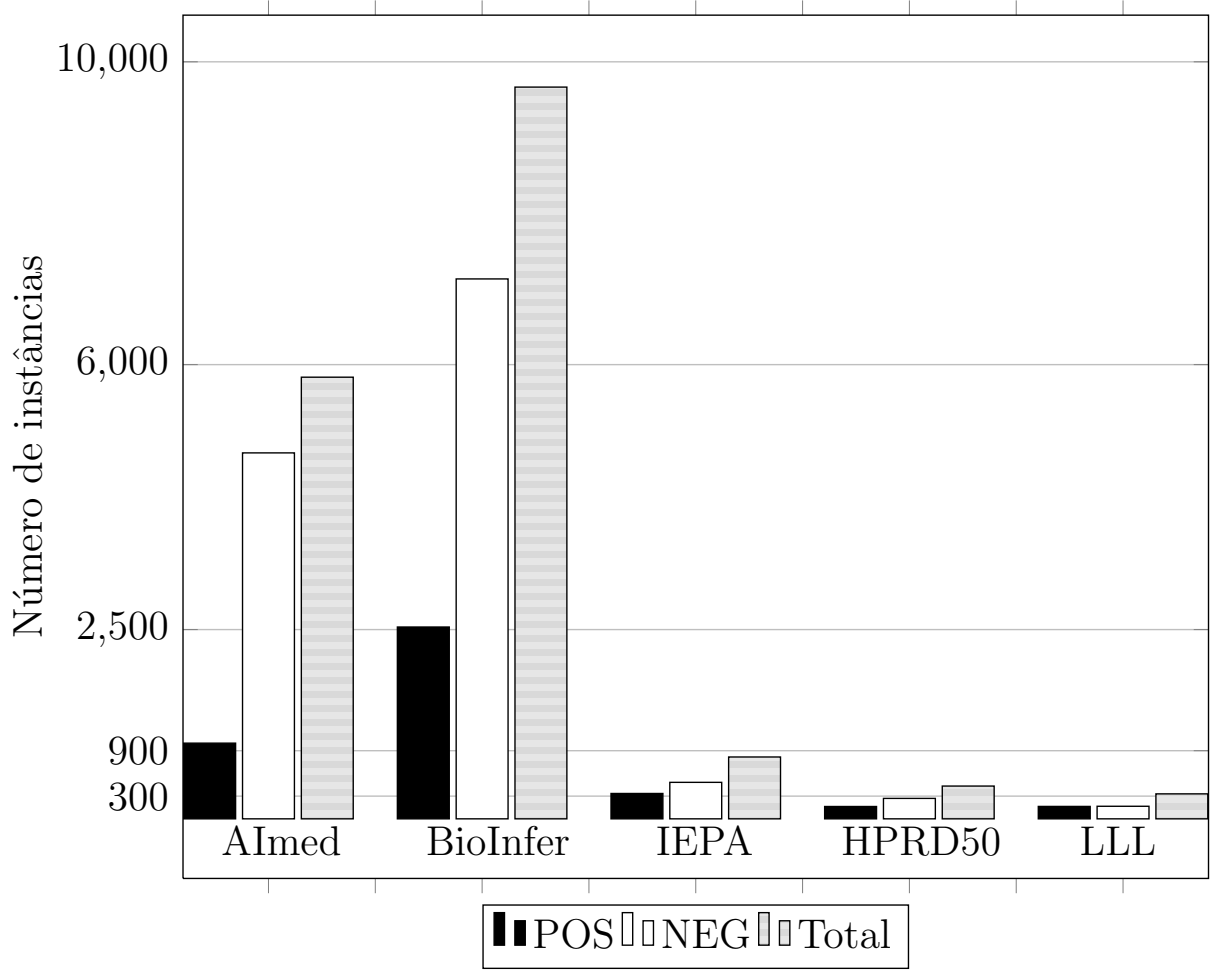

Figura 2.10: Comparação entre os cinco corpora tipicamente usados na extração de IPPs: AImed, BioInfer, IEPA, HPRD50 e LLL pelo número de instâncias positivas (POS), negativas (NEG) e o número total de instâncias.

Dado que cada conjunto de dados tem um formato particular para acessar às sentenças anotadas, uma padronização foi proposta em Pyysalo et al. (2008a). As anotações padronizadas estão em formato XML ${ }^{1}$, tendo sido utilizados por vários trabalhos prévios de extração de IPPs (Zhang et al., 2012; Bui et al., 2011; Choi e Myaeng, 2010; Saetre et al., 2010; Miwa et al., 2010; Liu et al., 2010; Miwa et al., 2009a,b; Airola et al., 2008).

\subsubsection{Medidas de Avaliação}

Os métodos são avaliados com as medidas de precisão, revocação e medida $\mathrm{F}$ (F-measure), das quais são definidas a seguir.

Precisão (P): mede as extrações corretas $(\mathrm{C})$ pelo número total de IPPs extraídas (E).

$$
P=\frac{|C|}{|E|}
$$

\footnotetext{
${ }^{1}$ http://bionlp.utu.fi/ppicorpora.html
} 
Revocação (R): mede as extrações corretas (C) de IPPs pelo número total (T) de IPPs que existem no conjunto de dados. $R=\frac{|C|}{|T|}$

Medida F: é a média harmônica das medidas precisão e revocação (Manning e Schuetze, 1999): $F=\frac{2 P R}{R+P}$

Para cada uma dessas medidas de avaliação, são reportados os valores em probabilidades. Cabe ressaltar que, em um estudo comparativo realizado por Pyysalo et al. (2008a), é mostrado que os métodos do estado da arte apresentam baixas taxas de desempenho na extração de IPPs. Esses métodos foram testados com os 5 conjuntos de dados. As taxas reportadas, em termos da medida $\mathrm{F}$, atingiram valores entre 0.19 e 0.30 .

\subsection{Considerações Finais}

O uso das características tipicamente usadas para extração de IPPs são: as baseadas em palavras e as baseadas em árvores sintáticas. No caso das características baseadas em árvores sintáticas, o desempenho dos classificadores geralmente é melhor em comparação com as baseadas palavras. Por outro lado, os métodos comumente utilizados para tratar o problema de extração de IPPs: Coocorrência, Regras Gramaticais e Aprendizado de Máquina. Nesse contexto, foi dado ênfase ao terceiro método devido sua importância na extração de IPPs e para esta investigação. A maioria dos métodos baseiam-se em classificadores. Um classificador usa como entrada um conjunto de características ou atributos e retorna um rótulo ou classe. Esse rótulo indica se existe interação ("1") ou não ("0") em uma sentença de texto.

Embora as novas propostas sejam mais direcionadas a melhorar as funções de avaliação, como na abordagem de kernels, não é garantido obter um bom desempenho em termos da medida F. Desse modo, nem a utilização de um modelo mais sofisticado do que os modelos padrões, pode garantir uma melhora na acurácia, como no caso de RBD e naive Bayes. Assim, é necessário um melhor compromisso entre o classificador proposto e o tipo de característica usado, sendo esse um dos objetivos deste trabalho de mestrado. 


\section{Fundamentação de Redes Bayesianas}

\subsection{Considerações Iniciais}

$\mathrm{N}$

o capítulo anterior foram mencionadas várias propostas de trabalhos relacionados com extração de IPPs a partir de textos. Esses trabalhos apontam que as propostas baseadas em classificação conseguem melhores resultados do que as técnicas baseadas em coocorrência e templates.

Entretanto, o estudo das redes bayesianas para tratar a tarefa de extração de IPPs ainda tem sido pouco explorado, sendo a maioria das técnicas prospotas baseadas em kernels. Uma diferença importante entre kernels e redes bayesianas é a forma de analisar as instâncias (PPs) a serem classificadas. Considere que $\mathbf{Z}$ é um conjunto de atributos e $\mathcal{Z} \in \mathbf{Z}$ é um atributo. Os kernels tipicamente calculam a similaridade entre duas instâncias $m$ e $w$ por meio de seus atributos. Isto é, o cálculo de similaridade entre $\mathbf{Z}[m]$ e $\mathbf{Z}[w]$. Nesse abordagem, existe um risco de overfitting quando o espaço de atributos analisado é muito grande (Culotta e Sorensen, 2004). Por outro lado, diferentemente dos kernels, as redes bayesianas não calculam similaridade entre instâncias. Em vez disso, procuram estimar as distribuições de probabilidade de cada atributo $\mathcal{Z} \in \mathbf{Z}$, as quais são denotadas por $\theta_{\mathcal{Z}} \in \Theta$. Cada atributo $\mathcal{Z}$ é chamado de variável aleatória e pode ter vários valores $\mathcal{Z}=\left\{z^{1}, \ldots, z^{k}\right\}$, onde $k$ é o número de valores. Desse modo, é possível analisar "internamente" cada um dos atributos que compôem $\mathbf{Z}$.

Com o objetivo de estudar o impacto de construir redes bayesianas para extração de IPPs, neste capítulo é apresentado a fundamentação de redes bayesianas, necessária para o desenvolvimento deste trabalho de mestrado. 


\subsection{Conceitos da Teoria de Probabilidade}

A teoria de probabilidade permite atribuir um grau de crença a um evento do mundo real. No contexto de extração de interações de IPPs, é possível assumir que um evento de interação pode ser detectado de acordo com informações de outros eventos. Esses eventos poderiam ser, por exemplo, a existência do advérbio "not" e de qualquer verbo ser encontrados entre dois nomes de proteínas em uma sentença de texto. Na prática, os eventos a serem considerados para a extração de IPPs são mais sofisticados.

\subsubsection{Espaço de Eventos}

O conjunto de eventos mensuráveis, em um espaço de todos os resultados possíveis, é denotado por $\mathcal{R}$. O espaço de resultados possíveis é definido como $\Omega$. Cada evento $\alpha \in \mathcal{R}$ é um subconjunto de $\Omega$ (Koller e Friedman, 2009).

O grau de crença é atribuído a cada evento por meio do uso de uma distribuição de probabilidade, a qual é definida por $P$. Essa distribuição deve satisfazer os seguintes axiomas:

- $P(\alpha) \geq 0, \forall \alpha \in \mathcal{R}$.

- $P(\Omega)=1$.

- Se $\alpha, \beta \in \mathcal{R}$ e $\alpha \cap \beta=\emptyset$, então $P(\alpha \cup \beta)=P(\alpha)+P(\beta)$.

De acordo com tais axiomas, a probabilidade de um evento é sempre um valor positivo. Também, a probabilidade máxima, considerando todos os possíveis resultados dos eventos em $\Omega$, é 1 . A probabilidade de dois eventos mutuamente exclusivos é a soma das probabilidades de cada evento.

\subsubsection{Variável Aleatória}

Para atribuir uma probabilidade a um evento, usa-se o conceito de variável aleatória. Aqui, letras maiúsculas referem-se a variáveis aleatórias, tais como: $A, B, C, \ldots, Z$. A variável aleatória é uma função que associa um evento em $\Omega$ com um valor. Por exemplo, uma variável aleatória $V P$, relacionada com o evento verbo, pode mapear a presença de um verbo entre duas proteínas, isto é, a indicação de presença de um verbo com valores: 1 ("existe verbo") ou 0 ("não existe verbo"). Então, o evento $V P=1$ indica a presença de um verbo, enquanto que $V P=0$ indica a ausença de um verbo entre duas proteínas.

Uma variável aleatória pode ser discreta, considerando um conjunto finito de valores. Caso contrário, ela pode ser contínua, podendo ter valores reais. Nesta dissertação, é 
de interesse o uso de variáveis discretas. Assim, define-se o conjunto finito de valores de uma variável aleatória $A$ como $\operatorname{Val}(A)$ e, os valores dessa variável em letras minúsculas: $a \in \operatorname{Val}(A)$. Em suma, usa-se $a^{i}$ para indicar o i-ésimo valor de $A$. Assim, $\operatorname{Val}(A)=$ $\left\{a^{1}, \ldots, a^{k}\right\}$ e $k=|\operatorname{Val}(A)|$. Quando $k>2$, a distribuição da variável $A$ é denominada multinomial. Por outro lado, no caso $k=2$, isto é, uma variável binária, a distribuição é chamada de Bernoulli. Assim, na variável $V P$, a distribuição é de Bernoulli. Na distribuição de uma variável aleatória $A$, cumpre-se que:

$$
\sum_{i=1}^{k} P\left(A=a^{i}\right)=1 .
$$

Por simplicidade, daqui em diante, são usadas notações mais curtas para esses conceitos: $P(A=a)$ como $P(a)$ e, $\sum_{i=1}^{k} P\left(A=a^{i}\right)$ como $\sum_{a} P(a)$, e $P((A=a) \cap(B=b))$ como equivalente a $P(a, b)$.

\subsubsection{Probabilidade Conjunta}

Com $n$ variáveis aleatórias, tal que $X_{j}$ é a j-ésima variável aleatória, o conjunto dessas variáveis é denotado por $\mathcal{X}=\left\{X_{1}, \ldots, X_{n}\right\}$. A distribuição conjunta envolve a todas as variáveis aleatórias:

$$
P\left(X_{1}, X_{2}, X_{3}, \ldots, X_{n}\right),
$$

e atribui probabilidades aos eventos relacionados com tais variáveis. Para indicar a atribuição de valores para as variáveis em $\mathcal{X}$, é usado $\xi \in \operatorname{Val}(\mathcal{X})$. A notação $\xi$ refere-se à atribuição de um valor para cada variável em $\mathcal{X}$.

A probabilidade conjunta é importante para responder consultas sobre eventos relacionados com as variáveis aleatórias, sendo possível detectar um evento de interação. O emprego da probabilidade conjunta para responder consultas é descrito na Seção 3.4.

\subsubsection{Probabilidade Condicional}

A probabilidade condicional é representada por $P(X \mid Y)$, onde a probabilidade de $X$ está condicionada por $Y$. Quando é conhecido que $X$ está condicionada por $Y$, é possível reescrever a probabilidade conjunta $P(X, Y)$ como $P(Y) P(X \mid Y)$.

A probabilidade condicional pode ser calculada pelo Teorema de Bayes, conforme a Equação 3.2.

$$
P(X \mid Y)=\frac{P(X \mid Y) P(Y)}{P(X)}
$$

Como uma rede probabilística baseia seus cálculos no teorema de Bayes, ela é chamada comumente de rede bayesiana. 
A distribuição de probabilidade condicional é uma distribuição mais informada sobre a relação entre variáveis, como no caso de $X$ e $Y$. Isso permite redefinir o cálculo da probabilidade conjunta, na maiorira dos casos, em termos mais curtos. Por outro lado, se essa distribuição implica um conhecimento de relação entre variáveis, também existem casos onde é conhecida a ausência de relação entre variáveis. Isso é detalhado a seguir.

\subsubsection{Independência e Independência Condicional}

Em alguns casos, a probabilidade condicional entre um par de variáveis, $X$ e $Y$, indica a ausência de relação entre ambas as variáveis. Nesse caso, ambos os eventos são chamados de independentes entre si. Assim, $X$ é independente de $Y$, se $P(X \mid Y)=P(X)$ ou se $P(Y)=0$. Isso é denotado por $P \vDash(X \perp Y)$, onde $\vDash$ indica "satisfaz" e, $\perp$ denota independência.

Em outro caso, $X$ e $Y$ são independentes dada uma terceira variável $Z$. Este caso particular é chamado de independência condicional e é denotado por: $P \vDash(X \perp Y \mid Z)$, se $P(X \mid Y \cap Z)=P(X \mid Y)$ ou se $P(Y \cap Z)=0$. Assim, o uso desses conceitos é importante no cálculo da probabilidade conjunta, a fim de estimar o grau de crença de um evento. Nesse contexto, na próxima seção é descrita a importância das probabilidades a priori, a posteriori e condicional.

\subsubsection{Importância das Probabilidades a Priori, a Posteriori e Condi- cional}

No estudo das técnicas de aprendizado de redes bayesianas, as probabilidades a priori, a posteriori e condicional são conceitos essenciais. No caso da probabilidade a priori (ou incondicional), ela é utilizada na inicialização de uma rede bayesiana, sendo calculada para cada variável dessa rede. Já quando a probabilidade de alguma variável é atualizada, esse acontecimento é denominado evento e aquela é chamada variável evento $(E)$. Dessa forma, se na rede bayesiana existir um evento, então um algoritmo de inferência probabilística deve ser utilizado a fim de atualizar também as probabilidades das variáveis relacionadas à variável evento. Assim, essas novas probabilidades são chamadas de probabilidades $a$ posteriori.

Além disso, essas relações entre variáveis são quantificadas pela distribuição de probabilidade condicional, que é especificada para cada variável. A probabilidade condicional quantifica a relação entre uma variável conhecida como evento $E$ e uma variável conhecida como hipótese $H$. Assim, $P(H \mid E)$ é interpretada como: a probabilidade da hipótese $H$, quando observado E (Russell e Norvig, 2010). Por exemplo, na planta Arabidopsis thaliana, a proteína $L H Y$ está associada à "regulação" de outras proteínas (Cristianini e Hahn, 
2007). Se a proteína $L H Y$ é mencionada em uma sentença de texto, essa condiciona a existência da interação "regulação", isto é, $P($ Interacao $=$ regulacao $\mid L H Y)$.

Com os conceitos de probabilidades condicionais e incondicionais apresentados, uma definição formal de redes bayesianas é descrita a seguir.

\subsection{Rede Bayesiana}

Um modelo de rede bayesiana (Pearl, 1988), descrito como modelo gráfico, tem uma estrutura de grafo $\mathcal{G}$ e um conjunto $\Theta$ de distribuições de probabilidade condicional local que está associado aos nós da rede (Cooper e Herskovits, 1992; Pernkopf e Bilmes, 2010). Cabe ressaltar que os termos: parâmetros e conjunto de distribuições de probabilidade condicional local, são utilizados para referenciar ao conjunto $\Theta$. Assim, considerando aquela definição de modelo, a estrutura da rede é um grafo acíclico dirigido $\mathcal{G}=\{\mathcal{X}, \mathcal{E}\}$, com um conjunto de variáveis aleatórias $\mathcal{X}$ que envolve aos nós da rede e a um conjunto de arestas $\xi$, o qual especifica as dependências entre nós.

Assim, uma rede bayesiana é composta de um conjunto de variáveis aleatórias denotadas por $\mathcal{X}=\{\mathbf{Z}, \mathcal{C}\}$, onde $\mathbf{Z}=\left\{\mathcal{Z}_{1}, \ldots, \mathcal{Z}_{n}\right\}$ é um conjunto de $n$ características de uma instância (por exemplo, os nós de uma árvore constituinte) e $\mathcal{C}$ é a variável classe. A fim de considerar qualquer variável em $\mathcal{X}$, usamos a notação $X_{i}$ para indicar alguma variável desse conjunto. $\mathrm{O}$ conjunto de valores atribuídos para $\mathcal{X}$ é denotado por $\xi \in \operatorname{Val}(\mathcal{X})$. Assim, o conjunto de treinamento pode ser definido como $\mathcal{D}=\{\xi[1], \ldots, \xi[\mathrm{m}]\}$, onde $m=|\mathcal{D}|$ é o número de instâncias. O objetivo de uma rede bayesiana é representar a probabilidade conjunta $P\left(\mathcal{Z}_{1}, \ldots, \mathcal{Z}_{n}, \mathcal{C}\right)$ das variáveis em $\mathcal{X}$. Para isso, dois aspectos são levados em conta: (1) a geração de um grafo $\mathcal{G}=\{\mathcal{X}, \mathcal{E}\}$, onde $\mathcal{X}$ é um conjunto de nós e $\mathcal{E}$ é um conjunto de arestas dirigidas tal que $X_{i} \rightarrow X_{j} \in \mathcal{E}$; e (2) o cálculo de parâmetros $\theta_{\mathcal{Z}_{i}} \in \Theta$ para cada variável $X_{i} \in \mathcal{X}$. Vale ressaltar que, de aqui em diante, a notação $\theta_{i}$ é usada para se referir a $\theta_{\mathcal{Z}_{i}}$. Uma vez construída a rede bayesiana $\mathcal{B}=\{\mathcal{G}, \Theta\}$, essa pode ser utilizada para classificar PPs.

Com o uso de uma rede bayesiana, assume-se que os dados foram gerados a partir de um processo que não é completamente conhecido. Desse modo, o processo é modelado como se fosse estocástico (Alpaydin, 2004). Nesse processo, o grau de crença de um evento é calculado fazendo uso da probabilidade conjunta de variáveis aleatórias.

Se em um processo estocástico, sem usar redes bayesianas, considerarmos um conjunto de $n$ variáveis aleatórias binárias, a complexidade de espaço para armazenar as distribuições de probabilidades de tais variáveis seria de $O\left(2^{n}\right)$. Essa complexidade seria inviável quando o número de variáveis $n$ for alto. Em contraste, o uso de redes bayesianas viabiliza o cálculo de tais distribuições de probabilidades, já que sua estrutura de grafo semânticamente fatoriza tal distribuição, reduzindo a complexidade de espaço. Essa redução está 
relacionada com as dependências condicionais e com o conceito de independência condicional entre variáveis (Koller e Friedman, 2009). Nesse caso, a complexidade de espaço depende da configuração do grafo da rede bayesiana, isto é, das ligações entre variáveis aleatórias (nós).

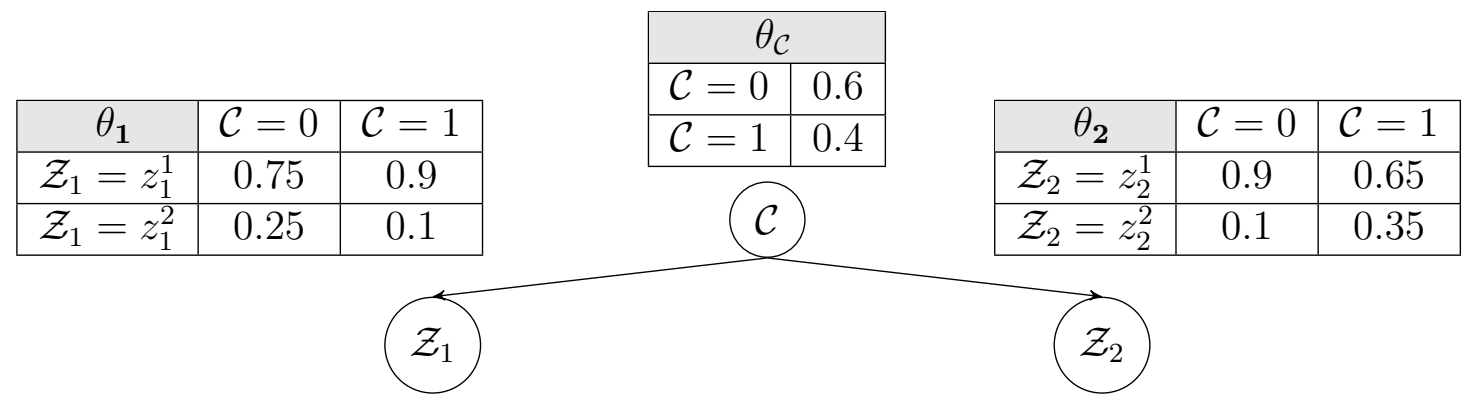

Figura 3.1: Exemplo de um modelo de rede bayesiana $\mathcal{B}_{1}=\left\{\mathcal{G}_{1}, \Theta_{1}\right\}$. $\mathcal{G}_{1}$ é definido como um grafo acíclico dirigido $\mathcal{G}_{1}=\{\mathcal{X}, \mathcal{E}\}$, onde $\mathcal{X}=\left\{\mathcal{Z}_{1}, \mathcal{Z}_{2}, \mathcal{C}\right\}$ é o conjunto de variáveis aleatórias (ou nós) e $\mathcal{E}=\left\{\left(\mathcal{C}, \mathcal{Z}_{1}\right),\left(\mathcal{C}, \mathcal{Z}_{2}\right)\right\}$ é o conjunto de arestas. $\Theta_{1}$ é o conjunto de parâmetros: $\theta_{\mathcal{C}}, \theta_{1}, \theta_{2} \in \Theta_{1}$.

A Figura 3.1 ilustra um modelo de rede bayesiana $\mathcal{B}_{1}=\left\{\mathcal{G}_{1}, \Theta_{1}\right\}$ de três variáveis aleatórias binárias, cujos valores podem ser: $\mathcal{C}=\{0,1\}, \mathcal{Z}_{1}=\left\{z_{1}^{1}, z_{1}^{2}\right\}$ e $\mathcal{Z}_{2}=\left\{z_{2}^{1}, z_{2}^{2}\right\}$, onde os valores representados por $z_{1}$ e $z_{2}$ são discretas. Dessas variáveis, $\mathcal{C}$ é a variável classe e $\mathbf{Z}=\left\{\mathcal{Z}_{1}, \mathcal{Z}_{2}\right\}$ é o conjunto de atributos desse modelo.

Cada variável, $\mathcal{C}, \mathcal{Z}_{1}$ e $\mathcal{Z}_{2}$, contém um conjunto de probabilidades condicionais locais representado por $\theta_{\mathcal{C}}, \theta_{1}$ e $\theta_{2}$ respectivamente. Um parâmetro codifica a probabilidade condicional pertencente a um desses conjuntos. Por exemplo, o parâmetro do conjunto de pontuação $\theta_{1}$ que descreve o evento $\mathcal{Z}_{1}=1$ dado o evento de seu nó pai $\mathcal{C}=1$, pode ser descrito como $P\left(\mathcal{Z}_{1}=z_{1}^{1} \mid \mathcal{C}=1\right)=0.9$. Essa probabilidade condicional é representa por uma aresta, $\mathcal{C} \rightarrow \mathcal{Z}_{1}$, no grafo $\mathcal{G}$. O conjunto de nós pais de $Z_{1}$ é $\pi_{1}=\{\mathcal{C}\}$.

Dado que a variável $\mathcal{C}$ não tem nós pais $\pi_{\mathcal{C}}$, então o parâmetro $\theta_{\mathcal{C}}$ é equivalente a sua probabilidade a priori, já que não ela não é dependente de outro nó.

A partir do grafo da Figura 3.1, é possível deduzir que $\mathcal{Z}_{1} \perp \mathcal{Z}_{2} \mid \mathcal{C}$. Assim, existem cinco parâmetros independentes nessa rede. Esses são: $P\left(\mathcal{Z}_{1}=z_{1}^{1} \mid \mathcal{C}=0\right)$, $P\left(\mathcal{Z}_{1}=z_{1}^{1} \mid \mathcal{C}=1\right), P\left(\mathcal{Z}_{2}=z_{2}^{1} \mid \mathcal{C}=0\right), P\left(\mathcal{Z}_{2}=z_{2}^{1} \mid \mathcal{C}=1\right)$ e $P(\mathcal{C}=0)$. As outras probabilidades condicionais são consideradas como complementos. Tal complemento é definido por $(1-P)$, sendo elas: $P\left(Z_{1}=x_{12} \mid \mathcal{C}=x_{c 1}\right), P\left(Z_{1}=x_{12} \mid \mathcal{C}=x_{c 2}\right), P\left(Z_{2}=x_{22} \mid \mathcal{C}=x_{c 1}\right)$, $P\left(Z_{2}=x_{22} \mid \mathcal{C}=x_{c 2}\right)$ e $P\left(\mathcal{C}=x_{\mathcal{C} 2}\right)$ respectivamente.

Como esses conceitos, são tratados a inferência probabilística e as técnicas de aprendizado de redes bayesianas descritas a seguir. 


\subsection{Inferência Probabilística}

Existem vários algoritmos que permitem executar uma inferência sobre a rede bayesiana, isto é, calcular a probabilidade de distribuição conjunta e lidar com diferentes tipos de raciocínio existentes. Tipicamente, existem quatro tipos de raciocínio, os quais são ilustrados na Figura 3.2 (Korb e Nicholson, 2003). O raciocínio de diagnóstico (Figura 3.2(a)) está dirigido em sentido oposto das arestas da rede, implicando: se existe um efeito, a causa pode ser estimada. O raciocínio preditivo (Figura 3.2(b)) calcula efeitos futuros segundo as causas apresentadas. A direção desse raciocínio coincide com a direção das arestas. O raciocínio intercausal (Figura 3.2(c)) relaciona as causas correspondentes a um efeito comum. Finalmente, o raciocínio combinado (Figura 3.2(d)) é o mais complexo, implicando o uso dos raciocínios de diagnóstico e preditivo. Assim, algoritmos de inferência sofisticados tratam os diferentes tipos de raciocínio principalmente nos casos quando apenas um subconjunto das variáveis são observadas.

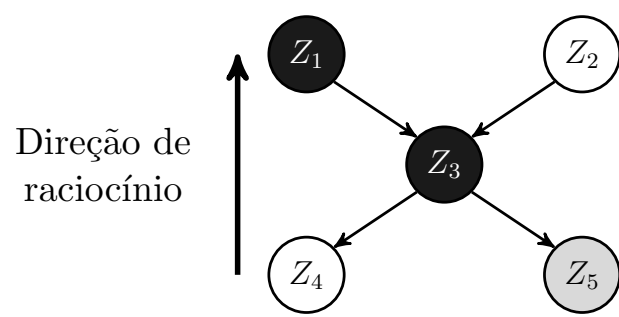

(a) Diagnóstico

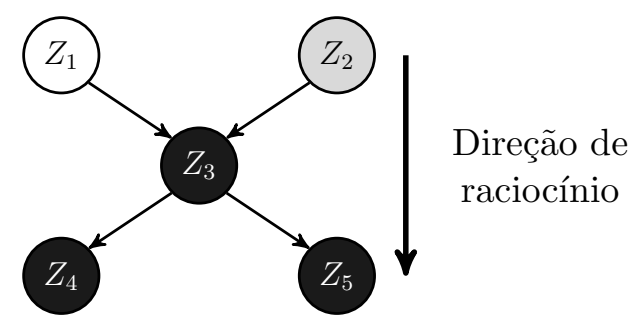

(b) Predição

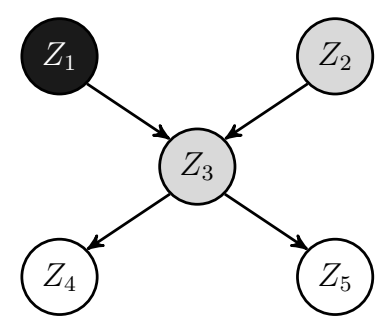

(c) Intercausal

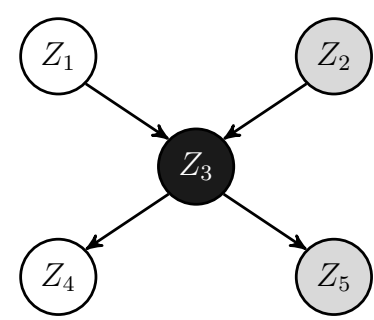

(d) Combinado

Figura 3.2: Tipos de raciocínio em redes bayesianas. Os nós de cor cinza são as variáveis evento, os nós de cor preto são os nós hipóteses. Um nó hipótese é atualizado devido ao nó evento e, portanto, é necessário consultar a sua nova probabilidade. Traduzido e modificado de Korb e Nicholson (2003)

Embora tais algoritmos sejam úteis para tratar informação não observada, este trabalho de mestrado assume que, no caso da extração de IPPs, os valores de todas as variáveis em $\mathbf{Z}$ são visíveis, sendo necessário inferir apenas o valor de $\mathcal{C}$. De fato, isso também é assumido pela maioria das técnicas de classificação de IPPs.

Dado que uma rede bayesiana codifica a probabilidade conjunta das variáveis em $\mathcal{X}$, é estimado o valor de $\mathcal{C}$ com base nos valores das variáveis em $\mathbf{Z}$. Isso é possível na extração de IPPs se é considerado que as características ou atributos $\mathbf{Z}$ (baseadas em informação 
léxica ou sintática), descritas para cada PP, são visíveis. Nesse caso, os valores $\xi$ das variáveis em $\mathcal{X}$, estão completos. Assim, com a informação das variáveis em $\mathbf{Z}$ é estimado o valor de $\mathcal{C}$ da forma:

$$
\mathcal{C}= \begin{cases}1, & \text { se } P(\mathcal{C}=1 \mid \mathbf{Z})>\alpha \\ 0, & \text { caso contrário }\end{cases}
$$

Na Equação (3.3) é descrita a obtenção do valor de $\mathcal{C}$, onde $\alpha$ é um limiar. Esse limiar é tipicamente $P(\mathcal{C}=0 \mid \mathbf{Z})$. Dessa forma, a inferência de $P(\mathcal{C}=0 \mid \mathbf{Z})$ e $P(\mathcal{C}=1 \mid \mathbf{Z})$ nessa equação estão relacionadas com a máxima probabilidade a posteriori descrita na Equação (2.1). Isso implica uma tarefa de classificação. Assim, a Equação (2.1) pode ser redefinida como:

$$
\hat{y}=\arg _{\mathcal{C}} \max \{P(\mathcal{C}=0 \mid \mathbf{Z}), P(\mathcal{C}=1 \mid \mathbf{Z})\}
$$

onde $\hat{y}$ é o valor mais provável para $\mathcal{C}$. A Equação (3.4) envolve os cálculos tanto de $P(\mathcal{C}=0 \mid \mathbf{Z})$ quanto de $P(\mathcal{C}=1 \mid \mathbf{Z})$. Dado que conhecemos os valores das variáveis em $\mathbf{Z}$ e é necessário calcular essas probabilidades condicionais, é possível fazer um cálculo simples para inferir as probabilidades dos valores $\mathcal{C}=0$ e $\mathcal{C}=1$. Isto é, o cálculo das probabilidades conjuntas quando $\mathcal{C}=0$ e $\mathcal{C}=1: P(\mathcal{C}=0, \mathbf{Z})$ e $P(\mathcal{C}=1, \mathbf{Z})$ respectivamente. Pela regra da cadeia, da teoria de probabilidade, a probabilidade conjunta é expressa pela Equação 3.5:

$$
P\left(X_{1}=x_{1}, X_{2}=x_{2}, \ldots, X_{n}=x_{n}\right)=\prod_{i} P\left(x_{i} \mid x_{1}, \ldots, x_{i-1}\right),
$$

onde $X_{i} \in \mathcal{X}$ e $\mathcal{X}=\{\mathcal{C}, \mathbf{Z}\}$. Além disso, dado que a rede bayesiana tem relações de nós pais com filhos, a equação anterior pode ser reduzida e redefinida pela Equação 3.5 da seguinte forma:

$$
P\left(X_{1}=x_{1}, X_{2}=x_{2}, \ldots, X_{n}=x_{n}\right)=\prod_{i} P\left(x_{i} \mid \operatorname{Pais}\left(X_{i}\right)\right)
$$

onde Pais $\left(X_{i}\right)$ é o conjunto de nós pais do nó $X_{i}$. A variável $X_{i}$ é a hipótese que pode mudar a sua probabilidade a posteriori se valores específicos das variáveis pais Pais $\left(X_{i}\right)$ estão presentes. Assim, considerando as probabilidades conjuntas quando $\mathcal{C}=0$ e $\mathcal{C}=1$, é possível estimar o valor $\hat{y}$ que maximiza a probabilidade conjunta dado $\mathbf{Z}$.

Na próxima seção são apresentadas as técnicas de aprendizado de rede bayesiana, que é o foco deste trabalho de mestrado. 


\subsection{Aprendizado de Rede Bayesiana}

O aprendizado de redes bayesianas envolve tipicamente duas tarefas: (1) o aprendizado de estrutura da rede $\mathcal{G}$ e (2) o cálculo dos parâmetros da rede, representados por $\Theta$. Em geral, ambas as tarefas fazem uso de um conjunto de dados de treinamento $\mathcal{D}$. Tal conjunto constitui a base de alimentação do aprendizado para construir um modelo de rede bayesiana e calcular seus parâmetros. Um parâmetro é a probabilidade $P(X=x)$ de um evento, $X=x$, acontecer. Quando a variável estiver condicionada por um conjunto de variáveis, $\mathbf{Y}$, o parâmetro é $P(X=x \mid \mathbf{Y}=\mathbf{y})$.

Existem dois principais métodos para aprender uma estrutura de rede: (1) os baseados em pontuação e (2) os baseados em restrições (Margaritis et al., 2003). A seguir são apresentadas ambas as técnicas.

\subsubsection{Aprendizado de Estrutura baseado em Pontuação}

No aprendizado de estrutura baseado em pontuação, o objetivo é atribuir uma pontuação a cada uma das estruturas candidatas. A pontuação é dada por uma medida de qualidade, a qual permite avaliar a estrutura candidata $\mathcal{G}$ que melhor ajusta-se com o conjunto de dados de treinamento $\mathcal{D}$.

Por outro lado, o conjunto de estruturas candidatas é obtida por meio de um algoritmo de busca de estruturas. Assim, tenta-se buscar uma estrutura de rede com a mais alta pontuação no espaço de possíveis estruturas. A seguir são descritos a medida de qualidade e o processo de busca de estruturas de redes bayesianas.

\subsubsection{Medidas de Qualidade}

Em geral, a pontuação ou medida de qualidade $Q$ (Bouckaert, 1995) é definida como:

$$
Q(\mathcal{G}, \mathcal{D})=P(\mathcal{G} \mid \mathcal{D})
$$

A Equação 3.7 envolve o cálculo de probabilidade de toda a estrutura da rede $\mathcal{G}=$ $\{\mathcal{Z}, \mathbf{E}\}$, dado o conjunto de treinamento $\mathcal{D}$. De fato, $P\{\mathcal{G} \mid \mathcal{D}\}$ pode ser redefinida pelo teorema de Bayes (Russell e Norvig, 2010) da seguinte forma:

$$
Q(\mathcal{G}, \mathcal{D})=\frac{P(\mathcal{D} \mid \mathcal{G}) P(\mathcal{G})}{P(\mathcal{D})}
$$

Antes de descrever as medidas, definem-se algumas notações importantes. Primeiro, é descrito o cálculo de eventos a partir do conjunto $\mathcal{D}$. Depois, é mostrado o cálculo de probabilidade da forma $P\left(X_{i}=x_{i k} \mid \pi_{i}=x_{\pi_{i} j}\right)$ a partir de $\mathcal{D}$. Após isso, é explicada a 
medida de informação chamada de entropia. Por fim, é descrito o cálculo do número de parâmetros de uma rede bayesiana.

Contagem de Eventos M: A contagem de um evento $X_{i}=x_{i}$ é:

$$
M_{\mathbf{i}}=\sum_{m} \mathbb{1}\left\{X_{i}[m]=x_{i}\right\}
$$

onde $\mathbb{1}$ é uma função indicador e $m$ é a m-ésima instância do conjunto de treinamento $\mathcal{D}$.

Cálculo de Probabilidade: com a forma $P\left(X_{i}=x_{i k} \mid \pi_{i}=x_{\pi_{i} j}\right)$ é:

$$
P\left(X_{i}=x_{i k} \mid \pi_{i}=x_{\pi_{i j}}\right)=\frac{M_{i j k}}{M_{i j}}
$$

Cálculo do Número $K$ de Parâmetros: Se considerarmos $n$ como o número de nós de uma rede bayesiana, o valor de $K$ dessa rede é calculada por:

$$
\mathrm{K}=\sum_{i=1}^{n}\left(r_{i}-1\right) \cdot q_{i}
$$

onde $r_{i}=\left|\operatorname{Val}\left(X_{i}\right)\right|, q_{i}=\left|\operatorname{Val}\left(\pi_{i}\right)\right|$ e, $\pi_{i}$ é o conjunto de nós pais do nó $X_{i}$.

No exemplo da Figura 3.1, a quantidade de parâmetros é calculada por: $K_{1}=\left(r_{\mathcal{C}}-1\right)$. $1+\left(r_{Z_{1}}-1\right) \cdot 2+\left(r_{Z_{2}}-1\right) \cdot 2$. Dado que os nós dessa rede são variáveis binárias $\left(r_{\mathcal{C}}=r_{Z_{1}}=\right.$ $r_{Z_{2}}=2$ ), o resultado final é $K=5$. Por tanto, unicamente 5 parâmetros, de um total de 10, precisam ser calculados a fim de gerar o conjunto de probabilidades condicionais em $\Theta_{1}$. Por sua vez, é possível notar que o nó $\mathcal{C}_{1}$ não tem nós pais e por tanto calcula-se apenas um parâmetro: $q_{\mathcal{C}}=1$, que é sua probabilidade a priori.

As medidas de qualidade podem ser divididas em dois tipos: as baseadas na teoria de informação e as baseadas na abordagem Bayesiana. No primeiro tipo, $Q_{\text {informao }}$, as medidas de qualidade usam a entropia, $H$, para calcular a pontuação de uma rede bayesiana. Desse modo, calcula o número de bits necessários para descrever os dados, com base na distribuição da rede bayesiana. Esse tipo de medidas preferem estruturas de redes mais simples ao invés das complexas (com maior número de parâmetros). Algumas medidas baseadas em informação são: Log-Likelihood, AIC e MDL.

No segundo tipo, $Q_{b a y e s}$, as medidas de qualidade maximizam a probabilidade a posteriori da rede bayesiana com base nos dados em $\mathcal{D}$. Algumas medidas baseadas na abordagem de Bayes são: K2, BDe e Bayes. Assim, as medidas de qualidade de ambos tipos são descritas a seguir: 
Medida Entropia: A medida é definida por:

$$
H(\mathcal{D} \mid \mathcal{G})=\prod_{i=1}^{n} \prod_{j=1}^{q_{i}} \prod_{k=1}^{r_{i}} P\left(X_{i}=x_{i k} \mid \pi_{i}=x_{\pi_{i} j}\right)^{M_{i j k}}
$$

Medida AIC: A medida Akaike (Akaike, 1974) é uma das primeiras medidas propostas. A medida é definida por:

$$
Q_{A I C}(\mathcal{G}, \mathcal{D})=H(\mathcal{G}, \mathcal{D})+K
$$

Medida MDL: em Lam e Bacchus (1994) foi utilizado o Minimum Description Length, que é equivalente à medida Bayes Information Criterion (BIC) proposto em Schwarz (1978). A medida é definida por:

$$
Q_{M D L}(\mathcal{G}, \mathcal{D})=H(\mathcal{G}, \mathcal{D})+\frac{K}{2} \log M
$$

Medida K2: em Cooper e Herskovits (1992) foi apresentado o algoritmo de busca K2 e uma função de pontuação do mesmo nome, definida como:

$$
Q_{K 2}(\mathcal{G}, \mathcal{D})=P(\mathcal{G}) \prod_{i=0}^{|\mathcal{Z}|} \prod_{j=1}^{q_{i}} \frac{\left(r_{i}-1\right) !}{\left(r_{i}-1+M_{i j}\right) !} \prod_{k=1}^{r_{i}} M_{i j k} !
$$

Medida BDe: Conhecida também como medida Bayesian Dirichlet equivalent, foi proposta por Buntine (1991):

$$
Q_{B D e}(\mathcal{G}, \mathcal{D})=P(\mathcal{G}) \prod_{i=0}^{|\mathcal{Z}|} \prod_{j=1}^{q_{i}} \frac{\Gamma\left(\frac{1}{q_{i}}\right)}{\Gamma\left(\frac{1}{q_{i}}+M_{i j}\right)} \prod_{k=1}^{r_{i}} \frac{\Gamma\left(\frac{1}{r_{i} \cdot q_{i}}+M_{i j k}\right)}{\Gamma\left(\frac{1}{r_{i} \cdot q_{i}}\right)}
$$

A função $\Gamma$ é uma função fatorial. A definição de tal função, para números inteiros, é: $\Gamma(x)=(x-1)$ !.

Medida Bayes: Essa medida, segundo Heckerman e Chickering (1995), generaliza as medidas $K 2$ e $B D e$. A medida é definida por:

$$
Q_{\text {Bayes }}(\mathcal{G}, \mathcal{D})=P(\mathcal{G}) \prod_{i=0}^{|\mathcal{Z}|} \prod_{j=1}^{q_{i}} \frac{\Gamma\left(M_{i j}^{\prime}\right)}{\Gamma\left(M_{i j}^{\prime}+M_{i j}\right)} \prod_{k=1}^{r_{i}} \frac{\Gamma\left(M_{i j k}^{\prime}+M_{i j k}\right)}{\Gamma\left(M_{i j k}^{\prime}\right)}
$$

\subsubsection{Busca de Estruturas}

Cada uma das medidas de qualidade, descritas anteriormente, são utilizadas para analisar um conjunto de estruturas de redes bayesianas dentro de um espaço de diferentes possíveis 
estruturas. O tempo que consume analisar todas as possíveis estruturas é impraticável (Cooper e Herskovits, 1992). O algoritmo de busca de Subida de Encosta (Algoritmo 3.1) é tipicamente usado para reduzir o tempo de busca de estruturass.

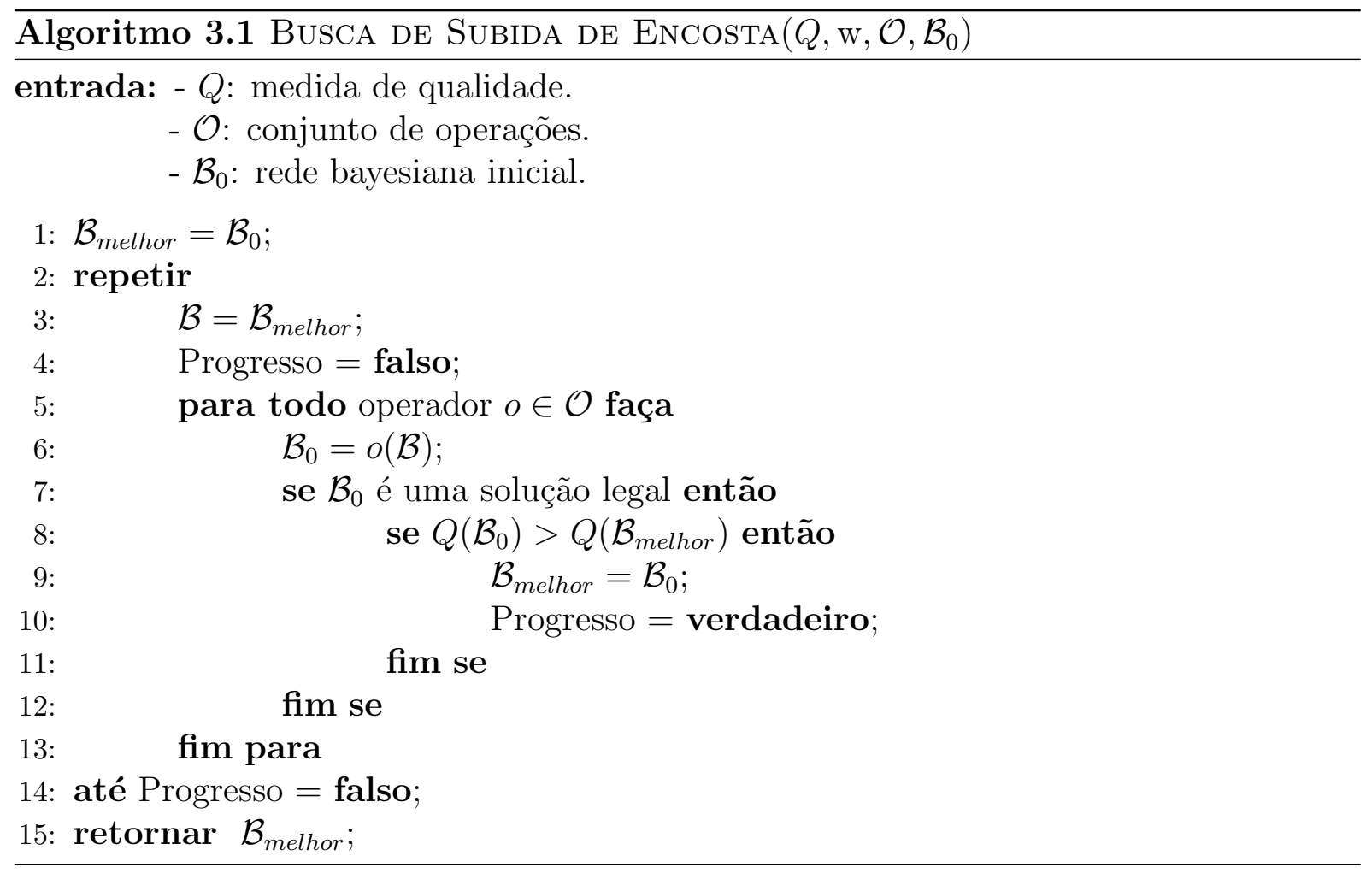

Esse algoritmo tipicamente considera três tipos de operações possíveis dentro do espaço de busca: (1) adição de arestas, (2) mudança de direção de arestas e (3) remoção de arestas. O conjunto que contém essas operações é denotado por $\mathcal{O}$. B é uma rede bayesiana inicial, a partir da qual derivam-se outras redes que serão avaliadas com a medida de qualidade Q. Na Figura 3.3 é possível observar que dado um grafo, três possíveis operações podem ser realizadas sobre qualquer nó dele. Isso, para procurar uma estrutura de grafo melhor do que a original.

\subsubsection{Aprendizado de Estrutura baseado em Restrições}

O uso de restrições ajuda compreender como interagem as variáveis na rede bayesiana. Para isso é necessário conhecer as independências existentes entre as variáveis da rede. Uma das maneiras para conhecer essas independências é com o uso do cobertor de Markov. O cobertor de Markov, correspondente a uma variável de interesse $T$, ou $M B(T)$, é o conjunto mínimo de variáveis condicionadas no qual, as outras variáveis da rede são probabilisticamente independentes de $T$ (Tsamardinos et al., 2003).

Formalmente, o cobertor de Markov pode ser definido como qualquer conjunto $M B(T) \subseteq$ $\mathcal{Z}$ tal que $X \in \mathcal{Z}-M B(T)-\{T\}, T \perp X \mid M B(T)$. Assim, diversas formas de obter o $M B$ foram propostas. Margaritis et al. (2003) propõe o algoritmo Grow-Shrink (GS). Esse 


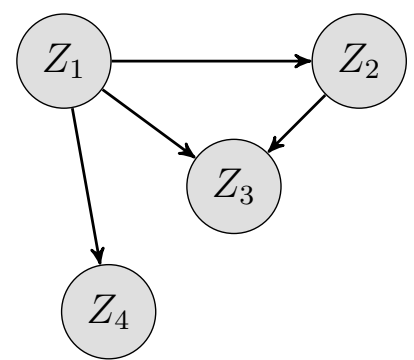

(a) Estrutura inicial

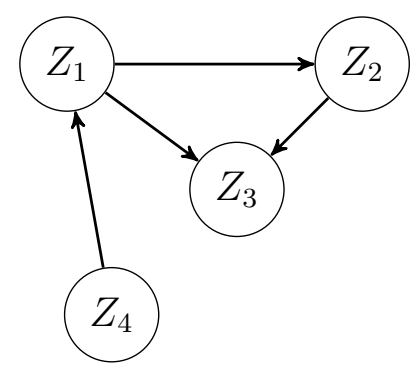

(c) Mudança de direção de aresta

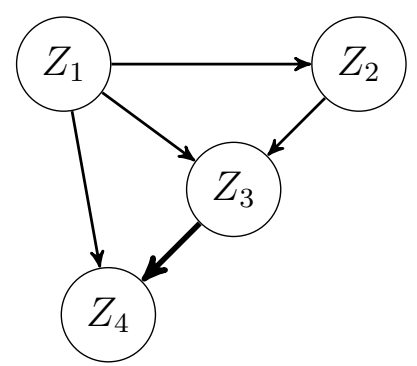

(b) Adição

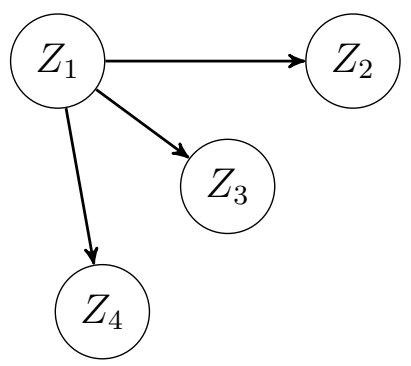

(d) Remoção

Figura 3.3: As três operações básicas para gerar novas estruturas de redes bayesianas a partir de uma estrutura inicial. (a) Estrutura de rede bayesiana inicial, (b) Operação de Adição, criando uma aresta dirigida $Z_{3} \rightarrow Z_{4}$. (c) Operação de Mudança de direção da aresta, invertendo a aresta $Z_{1} \rightarrow Z_{4}$. (d) Operação de Remoção, eliminando a aresta $Z_{2} \rightarrow Z_{3}$.

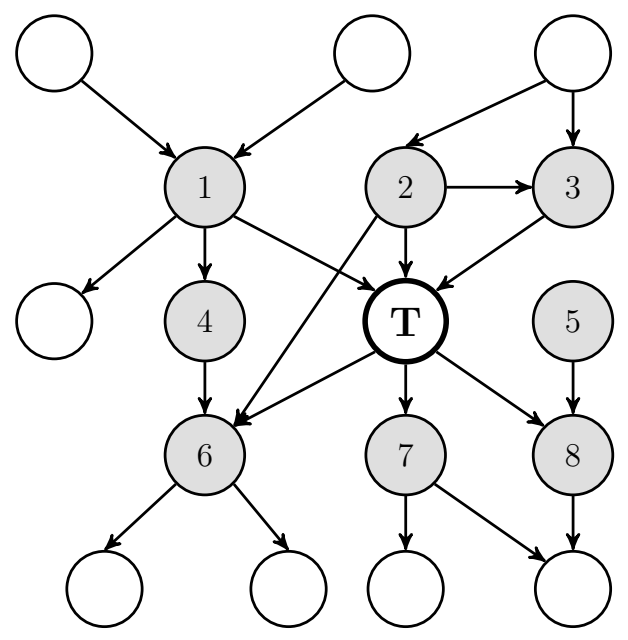

Figura 3.4: Conjunto cobertor de Markov (MB) em uma rede bayesiana. Os nós de cor cinza formam parte do conjunto MB para o nó $T$. Traduzido e modificado de Margaritis et al. (2003).

algoritmo identifica inicialmente a vizinhança local para cada variável da rede. Depois, um conjunto de variáveis candidatas $S$ é formado de acordo a uma ordem específica. Esse conjunto apresenta todas as possíveis variáveis que potencialmente pertencem ao conjunto 
$M B(T)$. Assim, para ser candidata, uma variável não deve ser independente com respeito a $T$ dado o conjunto $S$, enquanto $S$ vai considerando novas variáveis candidatas gradualmente. Uma vez que esse conjunto de candidatos é formado, a fase Shrinking é efetuada. Essa fase começa a eliminar as variáveis candidatas em $S$ que não são verdadeiramente independentes a $T$ dado o conjunto $S$. Finalizada essa fase, é possível afirmar que $S=M B(T)$. Um algoritmo similar foi proposto por Tsamardinos et al. (2003), o algoritmo Incremental Association Markov Blanket (IAMB). Esse algoritmo apresenta as mesmas fases do que o GS, no entanto, utiliza uma heurística distinta para considerar os nós candidatos. Assim, IAMB não utiliza a ordenação de variáveis que é aplicado por GS. Em contraste, esse algoritmo utiliza uma heurística baseada em Minimum Description Length. Na Figura 3.4 é ilustrado o cobertor de Markov (MB) de uma variável T:

- pais de $T:\{1,2,3\}$,

- filhos de $T:\{6,7,8\}$,

- outros pais dos filhos de $T:\{4,5\}$.

Assim, o aprendizado da estrutura pode ser realizado utilizando métricas de pontuação ou restrições de independência condicional a fim de obter uma boa estrutura de rede que visando obter altas acurácias no domínio do problema.

Por outro lado, uma forma de selecionar arestas usando restrições é usando métricas de desvio a partir da hipótese nula (Koller e Friedman, 2009). A hipótese nula assume que as variáveis em um domínio são independentes entre si: $P^{*}(X, Y)=P^{*}(X) P^{*}(Y)$. Para testar se a hipótese nula é efetivamente representativa dos dados em $\mathcal{D}$, métricas de desvio $d(\mathcal{D})$ a partir dessa hipótese foram propostas. Se $d(\mathcal{D})$ tem um valor alto, implica que os dados em $\mathcal{D}$ estão longe de formar parte da hipótese nula. Existem duas métricas comumente usadas para esses fins: (1) qui-quadrado (ver Equação 3.18) e (2) informação mutua () (ver Equação 3.19).

$$
d(\mathcal{D})=\sum_{x, y} \frac{(M[x, y]-M \cdot P(x) \cdot P(y))^{2}}{M \cdot P(x) \cdot P(y)} .
$$

onde $M[x]$ é a contagem do evento $X=x$ acontecer e $P$ é uma distribuição aproximada com a verdadeira.

De maneira similar, a informação mutua é descrita na Equação 3.19:

$$
d_{\mathbf{I}}(\mathcal{D})=\frac{1}{M} \sum_{x, y} M[x, y] \log \frac{M[x, y]}{M[x] M[y]}
$$

Diferentemente do qui-quadrado, a informação mutua não precisa de estimar uma distribuição $P$ para calcular o nível de dependência entre as variáveis $X$ e $Y$. 


\subsubsection{Aprendizado de Parâmetros}

Para calcular o melhor parâmetro $\theta_{i}$ de uma variável $X_{i}$ é utilizada uma função objetivo que tenta maximizar tal parâmetro. A maneira comumente usada para estimar $\theta_{i}$ é a partir dos dados $\mathcal{D}=\{\xi[1], \ldots, \xi[M]\}$, onde $M$ é o número de instâncias.

Para calcular os parâmetros é possível usar duas abordagens: a estimação máxima de verossimilhança (MLE) ou a estimação Bayes.

Na MLE, a função que estima o parâmetro $\theta$ é definida na Equação (3.20):

$$
L(\hat{\theta}: \mathcal{D})=\arg _{\theta \in \Theta} \max L(\theta: \mathcal{D})
$$

onde $L(\theta: \mathcal{D})$ é definida pela Equação (3.21):

$$
L(\theta: \mathcal{D})=\prod_{m} P(\xi[m]: \theta)
$$

A Figura 3.5(a) ilustra um exemplo de estimação de parâmetros $\theta_{i}$ e o cálculo dessas, descrita na Equação (3.21). Isso a partir de uma variável binária $X_{i}$, tal que $\operatorname{Val}\left(X_{i}\right)=$ $\{0,1\}$ e um conjunto $\mathcal{D}=\{0,1,1,0,0\}$. Nesse caso, o objetivo é saber qual é o melhor parâmetro para $P\left(X_{i}=1\right)$ (portanto, $P\left(X_{i}=0\right)=1-P\left(X_{i}=1\right)$ ). Em geral, a MLE assume que a melhor estimativa $\hat{\theta}_{i k}$ para um evento $X_{i}=k$ é a partir da frequência desse evento em $\mathcal{D}$ :

$$
\hat{\theta}_{i k}=\frac{M[k]}{M}
$$

onde $M[k]$ é definido como o número de instâncias em $\mathcal{D}$ que tem $X_{i}[m]=k$.

Por outro lado, a estimação Bayes está baseada na distribuição de dirichlet, sendo usados valores chamados de hiperparâmetros ou pseudo-contas. Em comparação à equação anterior, neste caso, as pseudo-contas são adicionadas:

$$
\hat{\theta}_{i k}=\frac{M[k]+\alpha_{k}}{M+\alpha}
$$

Esses hiperparâmetros são gerados por uma distribuição de dirichlet, $\alpha=\left\{\alpha_{1}, \ldots, \alpha_{k}\right\}$.

No caso particular de uma variável binária, é usada a distribuição beta dirichlet. Por exemplo, na Figura 3.5(b), são selecionados manualmente os hiperparâmetros $\left(\alpha_{0}, \alpha_{1}\right)=$ $\{3,2\}$, onde $\alpha=\alpha_{0}+\alpha_{1}$.

Em geral, um problema da MLE é que, quando os conjuntos de dados $\mathcal{D}$ são pequenos, o cálculo de parâmetros é pouco significativo. Para lidar com isso, a estimação baseada em uma distribuição dirichlet é mais adequada. Neste trabalho de mestrado, ambos os cálculos de parâmetros foram usados. 


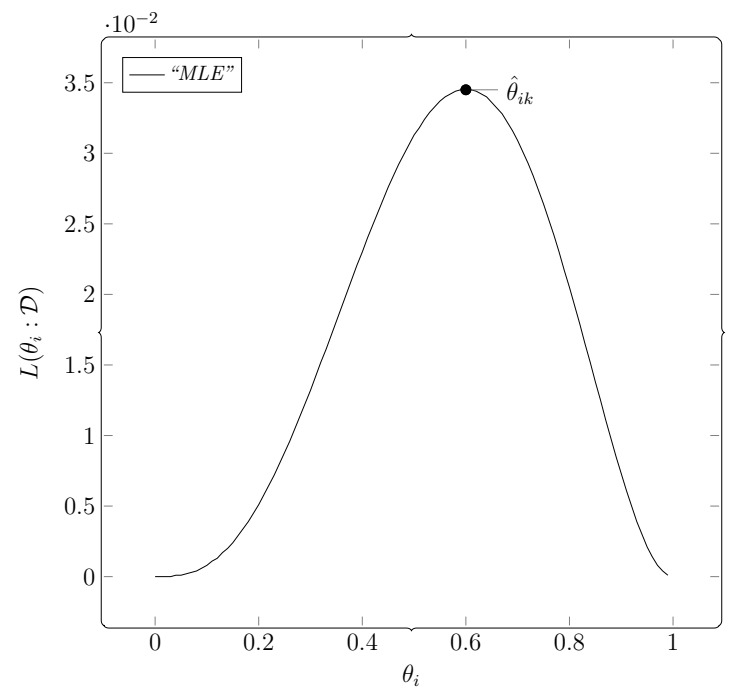

(a)

Figura 3.5: Estimação do parâmetro $\theta_{i 1}$, onde $\theta_{i 1}=P\left(X_{i}=1\right)$. $X_{i}$ é uma variável binária. Diferentes $\theta_{i 1}$ são testados usando a função $L\left(\theta_{i 1}: \mathcal{D}\right)$ a partir de um conjunto $\mathcal{D}=\{X[0], X[1], X[2], X[3], X[4]\}$, onde $X[i]$ é a i-ésima observação. Assim, considerando o conjunto $\mathcal{D}=\{0,1,1,0,0\}$, são ilustradas as estimações MLE e Bayes: (a) o valor MLE é o ponto mais alto da distribuição. (b) o valor de Bayes é $\hat{\theta}_{i 1}$, usando hiperparâmetros $(3,2)$. Exemplo descrito em Koller e Friedman (2009).

\subsection{Considerações Finais}

Neste capítulo foram vistos os conceitos básicos de redes bayesianas tais como a probabilidade a priori, a probabilidade a posteriori, a probabilidade condicional, o teorema de Bayes, a definição de rede bayesiana e a propagação de crença por meio da inferência bayesiana. Após isso, foram descritas as técnicas padrões para construir modelos de redes bayesianas.

Para construir um modelo, é necessário construir uma estrutura e, depois, calcular os parâmetros de uma rede bayesiana. As técnicas de construção de estrutura de rede bayesiana usam uma medida de qualidade para avaliar as estruturas candidatas. Também, essas empregan um algoritmo de busca de estruturas candidatas usando tipicamente algoritmos como busca de subida de encosta. As medidas de qualidade estão baseadas em pontuação e restrições. No caso de uma técnica baseada em pontuação, ela emprega um algoritmo de busca de estruturas para conseguir ter um conjunto de estruturas candidatas da rede. Define-se uma estrutura inicial de rede bayesiana e, posteriormente várias estruturas de rede são derivadas, usando operadores de: adição, mudança de direção e remoção de arestas. Cada uma dessas redes é avaliada com uma medida de qualidade, selecionando a estrutura que maximiza a pontuação das estruturas candidatas.

O cálculo de parâmetros de uma rede bayesiasna pode ser feito usando a estimação máxima de verossimilhança ou empregando hiperparâmetros a partir de uma distribuição 
dirichlet. Esta última estimação é mais robusta quando o número de instâncias de um conjunto de dados, $\mathcal{D}$, é pequeno.

Considerando esses conceitos para a construção de redes bayesiana, no próximo capítulo é detalhada a construção de modelos de redes bayesianas baseadas em árvores constituintes para extração de IPPs a partir de textos biomédicos. 


\section{Construção Automática de Redes Bayesianas baseada em Árvores Constituintes}

\subsection{Considerações Iniciais}

$\mathrm{U}$ m kernel essencialmente calcula as similaridades entre pares de instâncias, e tais cálculos podem ser usados no treinamento de um classificador como SVM. Com essa abordagem, instâncias de árvores constituintes atingiram bons resultados na extração de IPPs (Choi e Myaeng, 2010). Duas árvores constituintes são mais similares quanto maior o número de subestruturas em comum. Para computar isso, as árvores são percorridas à procura de subestruturas comuns, sem "olhar" as regras gramaticais que as compõem. Embora essa estratégia seja competitiva, o uso explícito de regras gramaticais possívelmente melhoraria os resultados da extração de IPPs. Com isso, seria possível detectar o impacto de algumas regras no processo de extração. Isso já foi tratado anteriormente de modo implícito com o emprego de remoção de regras. Em Choi e Myaeng (2010), a poda dessas árvores melhoraram o desempenho dos kernels. Nesse contexto, as redes bayesianas podem ser usadas para modelar regras relevantes do ponto de vista de uma abordagem estatística.

De fato, um modelo de rede bayesiana é transparente ao usuário, já que apresenta uma estrutura definida como grafo acíclico dirigido. Essa estrutura pode representar um conjunto de regras gramaticais. Isto é, a gramática subjacente de um corpus de treinamento. Outro conjunto de regras são desconsiderados obrigatoriamente se a estrutura da rede apresentar ciclos. 
A construção automática da rede permite observar padrões induzidos nas regras. Isso pode levar a uma maior compreensão do problema de extração de IPPs. Com isso, um modelo explícito é uma das diferenças com os kernels. Outra diferença é que as redes bayesianas calculam as probabilidades condicionais das características (nós), ao invés da similaridade entre pares de instâncias (Murphy, 2012). Assim, neste capítulo é apresentado um método de construção automática (aprendizado) de modelos de redes bayesianas baseado em árvores constituintes.

O método visita e analisa cada regra de uma árvore constituinte no conjunto de treinamento. Nessa árvore, uma aresta ligando um nó pai com um nó filho indica uma regra de produção. O método proposto considera uma interpretação adicional para essas ligações. A aresta é vista como uma relação de dependência entre os nós pai e filho e, a ausência dessa aresta é interpretada como uma relação de independência condicional entre o nó filho e seus ancestrais através do nó pai. Isto é, o método não só modela os nós das árvores constituintes como variáveis aleatórias na rede bayesiana, mas usa as arestas das árvores como relações a serem levadas em conta na construção da rede. Porém, muitas dessas relações são desconsideradas para manter a estrutura da rede sem ciclos.

O método desenvolvido é chamado Parse Trees for Bayesian Networks (PT-BN) e consta de cinco etapas: (1) construção de um grafo dirigido a partir de árvores constituintes; (2) remoção de ciclos a partir do grafo dirigido; (3) restrição do número máximo de nós pais; (4) adição e ligação da variável classe no grafo, usando um algoritmo de aprendizado de rede bayesiana baseado em pontuação; e, por fim, (5) cálculo de parâmetros da rede bayesiana a partir das relações de dependência condicional codificadas pelo grafo gerado no passo anterior e o conjunto de treinamento.

\subsection{Criação de um Grafo Dirigido a partir de Árvores Constituintes}

A partir das sentenças de um conjunto de treinamento (corpus), é possível usar um parser a fim de produzir árvores constituintes para cada sentença. Uma vez feito isso, é possível construir um grafo dirigido a partir de tais árvores. Esse grafo permite representar a informação gramatical contida nas árvores, sendo o primeiro passo para construir a estrutura da rede bayesiana.

O grafo dirigido é denotado por $\mathcal{G}^{\circ}=\left(V_{\mathcal{G}^{\circ}}, E_{\mathcal{G}^{\circ}}\right)$, onde $V_{\mathcal{G}^{\circ}}$ é o conjunto de vértices e $E_{\mathcal{G}} \circ$ é o conjunto de arestas. Em suma, cada árvore é denotada por $\mathcal{T}=\left(V_{\mathcal{T}}, E_{\mathcal{T}}\right)$, onde $V_{\mathcal{T}}$ é o conjunto de nós e $E_{\mathcal{T}}$ é o conjunto de arestas dirigidas. Considerando isso, o grafo, $\mathcal{G}^{\circ}$, é gerado a partir de um conjunto de árvores $\mathcal{D}=\{\mathcal{T}[1], \ldots, \mathcal{T}[m]\}$. Sendo $\mathcal{T}[m]$, a m-ésima árvore constituinte (da m-ésima sentença de texto) e, $m$, o tamanho do conjunto $\mathcal{D}$. 
Com o conjunto de árvores $\mathcal{D}$, implicitamente tem-se um conjunto de regras de gramática livre de contexto (Jurafsky e Martin, 2008). Formalmente, uma gramática livre de contexto é definida por quatro parâmetros: $N, \Sigma, R$ e $S 1$, onde $N$ é o conjunto de símbolos não terminais e $\Sigma$ é o conjunto de símbolos terminais. $R$ é o conjunto de regras gramaticais da forma $A \rightarrow \beta$, onde $A$ é um não terminal. $\beta$ é uma cadeia de símbolos a partir de $(\Sigma \cup N) *$, onde * é uma estrela de Kleene (Jurafsky e Martin, 2008). Finalmente, $S 1$ é um símbolo de início da gramática.

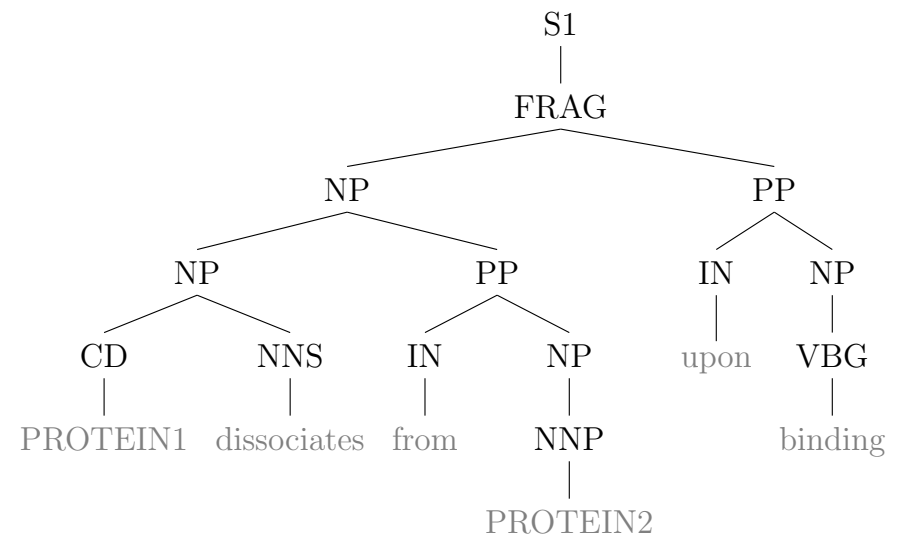

(a)

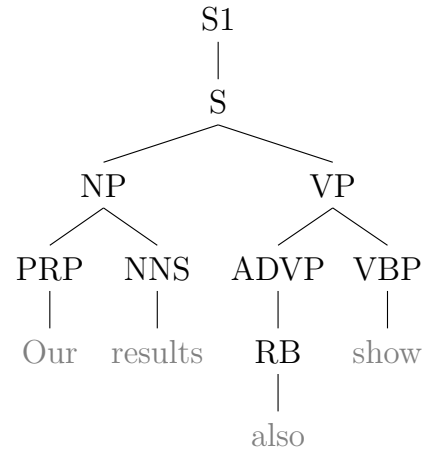

(b)

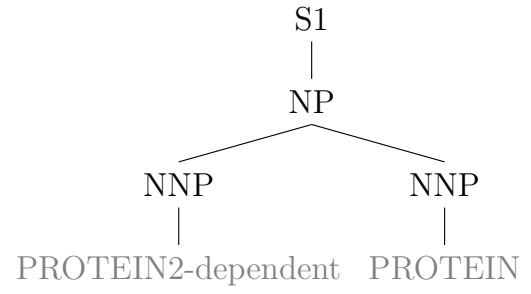

(c)

Figura 4.1: Exemplo de três árvores constituintes produzidas a partir de três extratos de sentenças com (a) ID="AIMed.d224.s1951", (b) ID="AIMed.d224.s1954" e (c) ID="AIMed.d224.s1945" respectivamente, pertencentes ao corpus AImed. Os nós de cor cinza são conhecidos como nós terminais, enquanto que o resto de nós são não terminais.

A gramática, a partir de $\mathcal{D}$, é expressa pelas árvores constituintes como exemplificado na Figura 4.1. Nessa figura, ilustram-se três árvores geradas a partir das sentenças: "PROTEIN1 dissociates from PROTEIN2 upon binding", "Our results also show" e "PROTEIN2-dependent PROTEIN". Também observa-se que o nó $S 1$, presente nas três árvores, é o símbolo de início da gramática. Considerando a forma da regra $A \rightarrow \beta$, onde $A=S 1$, obtêm-se três regras gramaticais: $S 1 \rightarrow F R A G, S 1 \rightarrow S$ e $S 1 \rightarrow N P$. Uma quantidade maior de regras pode ser inferida com $A=N P$ : 


$$
\begin{aligned}
& N P \rightarrow N P P P, \\
& N P \rightarrow N N P, \\
& N P \rightarrow V B G \\
& N P \rightarrow P R P N N S \\
& N P \rightarrow N N P N N P .
\end{aligned}
$$

Em geral, a quantidade de regras que podem ser inferidas alcança a milhares. Dado isso, na geração do grafo, $\mathcal{G}^{\circ}$, são consideradas separadamente as subpartes de uma regra. Cada subparte é composta por apenas dois nós não terminais, os quais são POS tags. Por exemplo, a partir da regra $S \rightarrow N P V P$, obtêm-se duas subpartes: $S \rightarrow N P$ e $S \rightarrow V P$. No caso das regras a partir do nó $N P$, obtêm-se as seguintes relações binárias: $N P \rightarrow N P, N P \rightarrow P P, N P \rightarrow N N P, N P \rightarrow V B G, N P \rightarrow P R P$ e $N P \rightarrow N N S$. Assim, estabelecem-se relações binárias entre cada par de $P O S$ tags, simplificando as regras correspondentes.

Do ponto de vista de redes bayesianas, essa relação binária é uma dependência causal entre dois POS tags. Em suma, cada POS tag é visto como uma variável aleatória (binária), cujos dois valores indicam "presença" ou "ausência" de tal variável em uma árvore dada. Esse compromisso entre a simplificação das regras e a modelagem de rede bayesiana permite construir a base da estrutura de uma rede, visando usar cada POS tag como uma variável aleatória relacionada diretamente com outras de acordo com as árvores em $\mathcal{D}$. Naturalmente, essa simplificação leva a uma perda de regras mais específicas, porém, permite interpretar as milhares de regras em uma rede mais compacta, isto é, uma rede com menor complexidade em termos de número de nós e arestas. Com isso, deseja-se estabelecer um grafo com suficiente conhecimento extraído, para iniciar a construção da rede bayesiana usando algoritmos de aprendizado em um tempo razoável.

Note-se que para formar o conjunto de nós, $V_{\mathcal{G}^{\circ}}$, são considerados apenas os POS tags de cada árvore $\mathcal{T} \in \mathcal{D}$. Desse modo, as palavras (nós marcados em cinza na Figura 4.1) são desconsideradas na composição do grafo $\mathcal{G}^{\circ}$. Uma razão para desconsiderar as palavras, é que elas têm um aporte pouco relevante na extração de IPPs como demonstrado anteriormente (Fayruzov et al., 2009). Assim, o objetivo é aproveitar o uso das regras com POS tags, tentando generalizar a aplicação dessas para novas sentenças de texto.

Um exemplo de um grafo, $\mathcal{G}^{\circ}$, obtido a partir das três árvores da Figura 4.1, é ilustrado na Figura 4.2. Note-se que o grafo contém as relações presentes nas três árvores. Em cada aresta, no grafo, é efetuada a contagem do número de vezes em que essa foi encontrada nas árvores. Por exemplo, a relação $N P \rightarrow N N P$ foi encontrada 3 vezes nas árvores ilustradas nas Figuras 4.1(a) e 4.1(c). Embora o grafo contenha as regras gramaticais das árvores analisadas, o mesmo não pode ser a estrutura de uma rede bayesiana. Isso porque o grafo apresenta dois ciclos: $N P \rightleftharpoons N P$ e $P P \rightleftharpoons N P$. Entretanto, o grafo de uma rede 


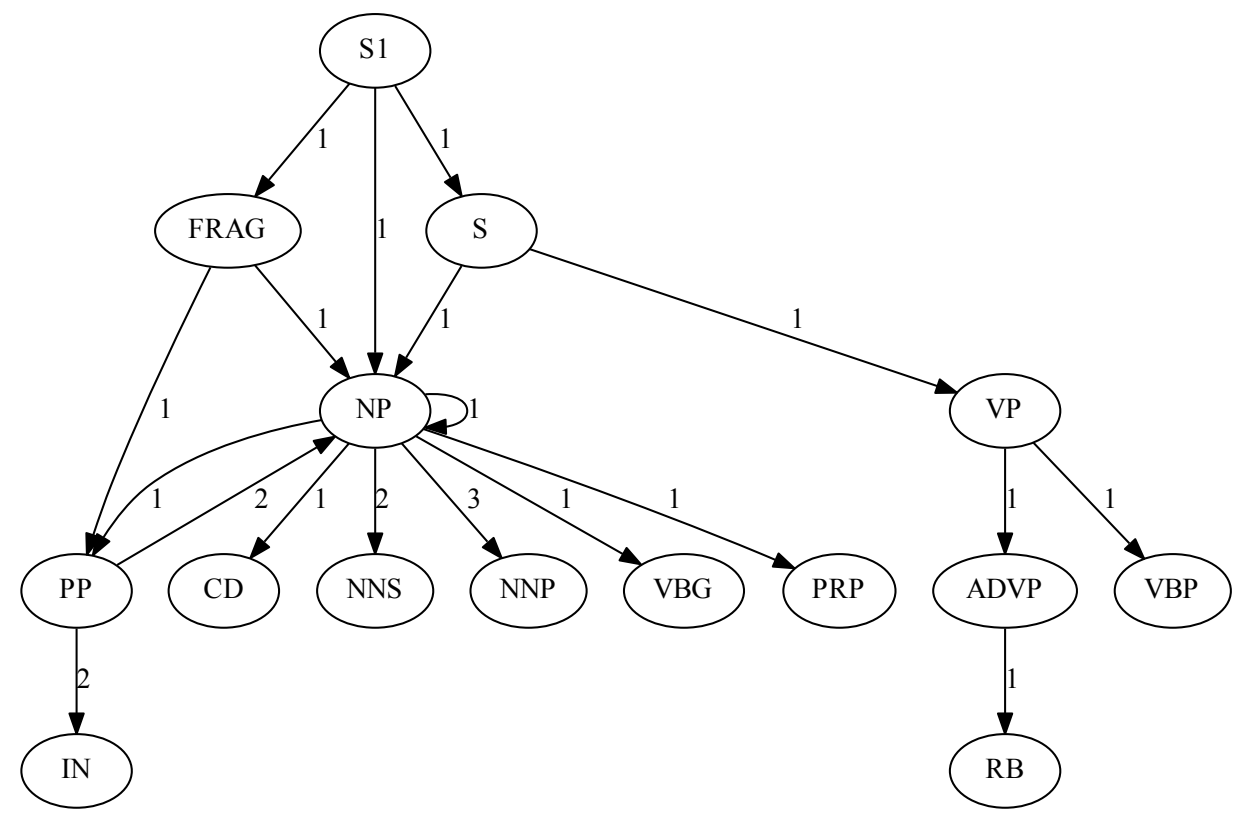

Figura 4.2: Grafo dirigido, gerado a partir das três árvores constituintes ilustradas na Figura 4.1.

bayesiana, por definição, é um grafo acíclico dirigido. Assim, é necessário remover tais ciclos a fim de continuar na construção da rede bayesiana.

O tempo de construção do grafo é de $O\left(\left|V_{\mathcal{T}}[1]\right|+\left|V_{\mathcal{T}}[2]\right|+\ldots+\left|V_{\mathcal{T}}[m]\right|\right)$, onde $\left|V_{\mathcal{T}}[i]\right|$, para $i \geq 1$ e $i \leq m$, é o número de nós da i-ésima árvore constituinte. Na seguinte seção, é detalhado o tratamento de remoção de ciclos a partir do grafo $\mathcal{G}^{\circ}$.

\subsection{Remoção de Ciclos a partir do Grafo Dirigido}

Uma vez construído o grafo $\mathcal{G}^{\circ}$, o passo seguinte é a remoção de arestas que produzem ciclos. Aqui, por conveniência, denotamos o grafo $\mathcal{G}$ como um grafo acíclico dirigido obtido a partir de $\mathcal{G}^{\circ}$. Em suma, qualquer aresta produzindo um ciclo é chamada de aresta conflitiva, $e_{c}$. Após essas definições, é possível descrever a remoção de ciclos em duas etapas: (1) a detecção de arestas conflitivas e, (2) a remoção de tais arestas.

Dado que, para construir um grafo acíclico dirigido, é necessário remover algumas subpartes das regras, um problema que surge é a remoção de subpartes importantes em comparação com outras. Isso pode afetar o desempenho da rede bayesiana após ser construída e aplicada sobre conjuntos de teste. Assim, para determinar o quanto afeta, foram usados dois algoritmos de detecção de arestas conflitivas. A partir desses algoritmos, 
propõem-se três métodos de remoção de arestas conflitivas, o que finalmente configura a estrutura base da rede bayesiana.

Nas seções 4.3.1 e 4.3.2 são descritas a etapa de detecção e de remoção de arestas respectivamente, avaliando, em ambos os casos, a remoção de subpartes importantes.

\subsubsection{Detecção de Arestas Conflitivas}

A detecção de arestas conflitivas tem como objetivo detectar um conjunto de arestas candidatas a serem removidas de $\mathcal{G}^{\circ}$, por formarem ciclos. Denotamos a esse conjunto de arestas como $\mathcal{L}$. Uma maneira típica de detectar arestas conflitivas é empregar o algoritmo de busca em profunidade (Algoritmo 4.2). Esse algoritmo usa uma estrutura fila, $\mathcal{Q}$, a qual permite armazenar os nós já visitados. Quando um nó é visitado mais de uma vez, a aresta formada por esse nó e seu nó pai é considerada como aresta conflitiva, $e_{c}$, e é armazenada na lista $\mathcal{L}$.

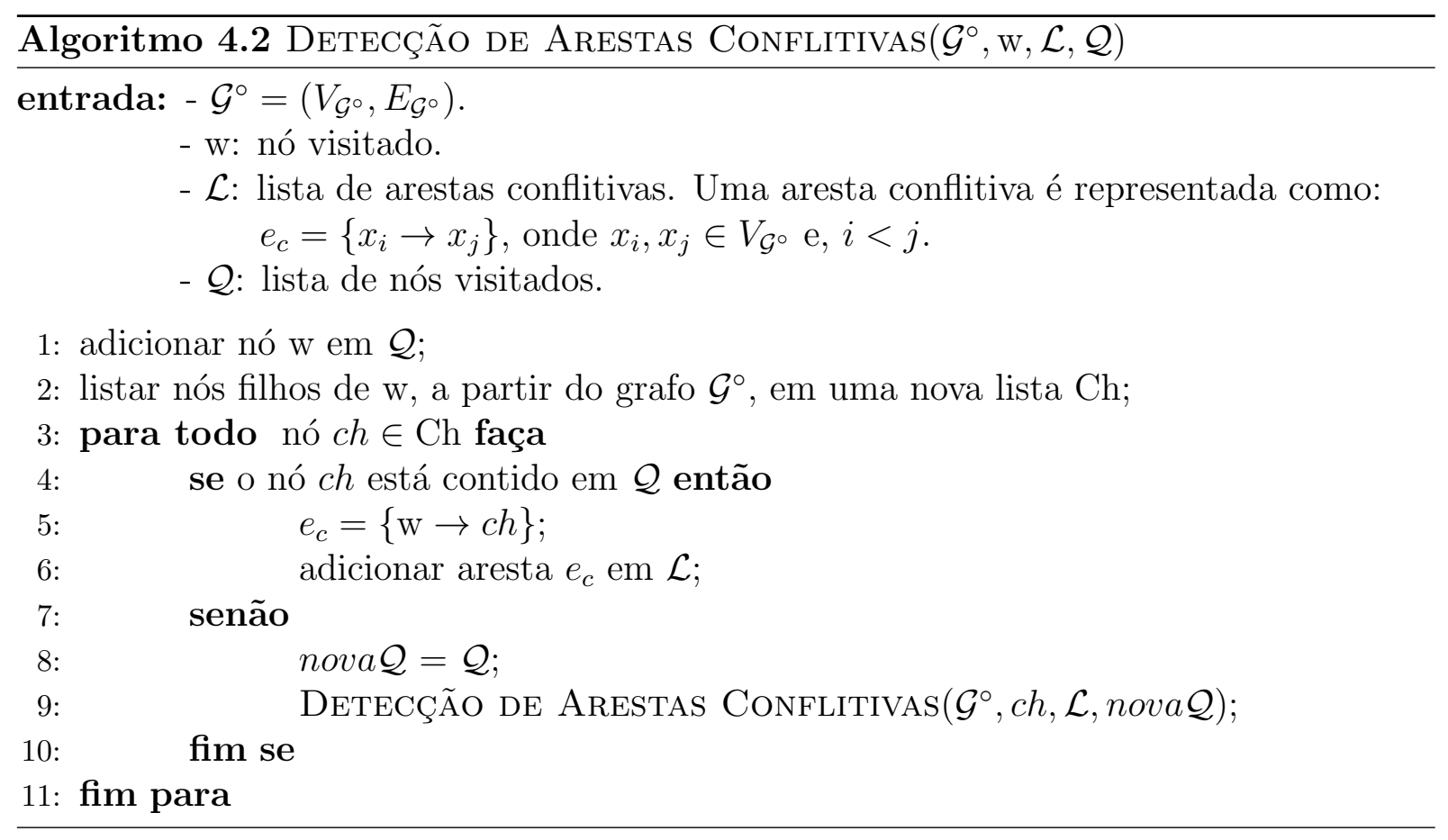

Como foi mencionado anteriormente, o símbolo de início da gramática é $S 1$. Esse símbolo é o nó raiz do grafo $\mathcal{G}^{\circ}$, já que é o acenstral de qualquer POS tag da gramática subjacente no conjunto $\mathcal{D}$. Assim, para aplicar o algoritmo de busca em profundidade, as entradas do algoritmo são inicializadas como: DetecÇão de $\operatorname{Arestas~} \operatorname{Conflitivas}\left(\mathcal{G}^{\circ}, S 1,\{\},\{\}\right)$, onde é indicado que o grafo $\mathcal{G}^{\circ}$ é percorrido a partir do nó $w=S 1$, com uma lista vazia de arestas conflitivas $\mathcal{L}=\{\}$ e, uma fila vazia de nós visitados $\mathcal{Q}=\{\}$.

Para observar o comportamento do Algoritmo 4.2, na Figura 4.3 é ilustrado o grafo $\mathcal{G}^{\circ}$ da Figura 4.2, com o número de ordem em que cada nó foi visitado. Nesse exemplo, a lista armazenou duas arestas conflitivas: $\mathcal{L}=\{2 \rightleftharpoons 2,8 \rightleftharpoons 2\}$, as quais estão marcadas 
em linhas pontilhadas na figura. Uma vantagem do Algoritmo 4.2 é que pode detectar várias arestas conflitivas no grafo $\mathcal{G}^{\circ}$, porém, a sua complexidade, em termos de tempo, aumenta quanto mais ciclos existam.

Uma abordagem alternativa é o uso do Algoritmo 4.3, descrito em Sedgewick e Wayne (2011). Diferentemente do anterior, este algoritmo detecta apenas um ciclo e retorna uma lista de nós que formam parte de tal ciclo. Este algoritmo requer como entrada a estrutura grafo, $\mathcal{G}^{\circ}$, e retorna uma lista, $\mathcal{L}$, contendo uma aresta conflitiva. Para fazer isso, o algoritmo faz uso de uma busca em profundidade no grafo $\mathcal{G}^{\circ}$ (Algoritmo 4.4). A complexidade do algoritmo Detecção de Uma Aresta Conflitiva é de $O\left(V_{\mathcal{G}^{\circ}}+\right.$ $\left.E_{\mathcal{G}^{\circ}}\right)$. No entanto, o número de vezes em que esse algoritmo é usado é proporcional ao número de ciclos existentes no grafo $E_{\mathcal{G}^{\circ}}$.

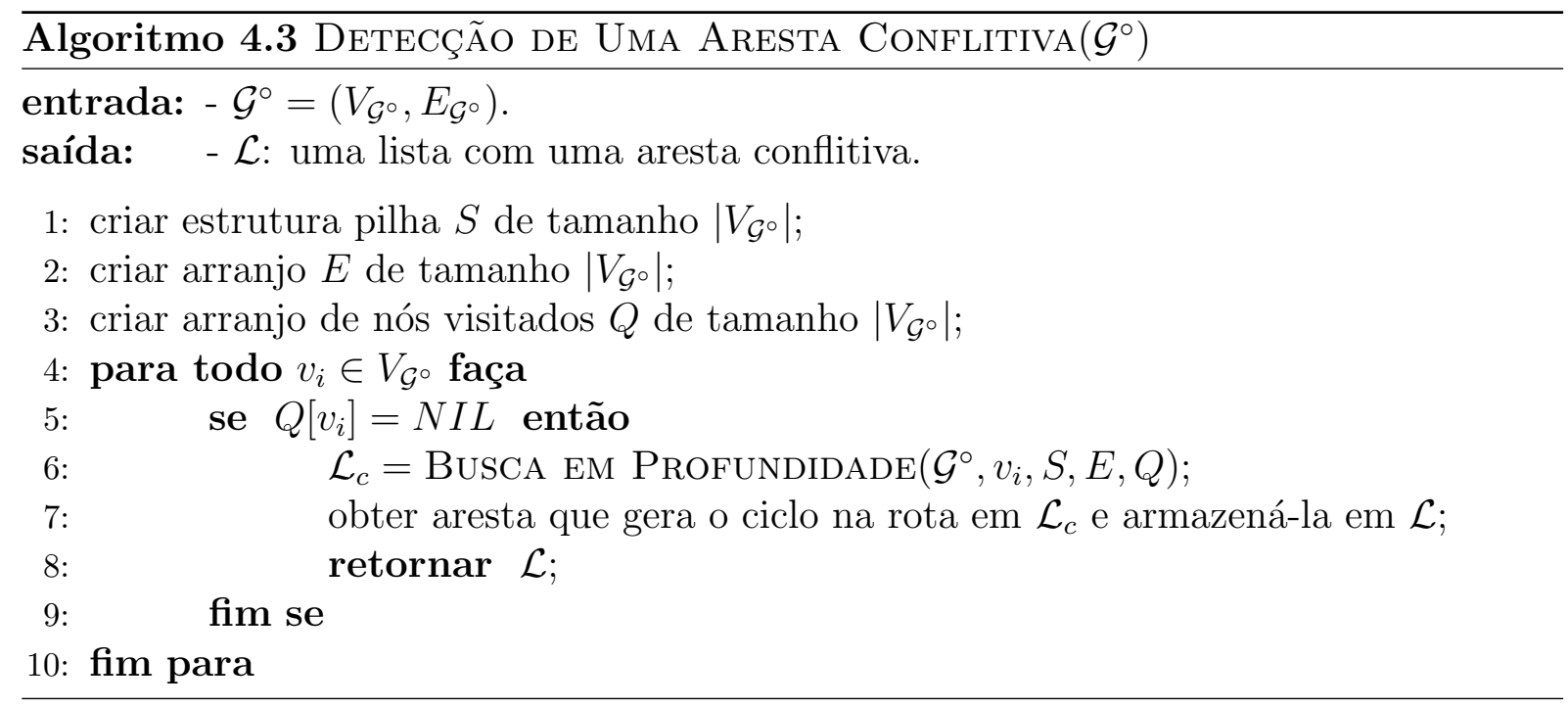

Com esses dois algoritmos, na seguinte seção são descritos três algoritmos de remoção de arestas conlifitivas.

\subsubsection{Remoção de Arestas Conflitivas}

Uma vez que as arestas conflitivas foram detectadas e armazenadas na lista $\mathcal{L}$, é usado o Algoritmo 4.5 para remover arestas conflitivas. Esse algoritmo analisa o grafo $\mathcal{G}^{\circ}$, fazendo uso iterativo de um dos algoritmos de detecção de arestas conflitivas descrito na subseção anterior, sendo que a condição de parada do algoritmo acontece quando já não existem ciclos no grafo.

Em cada iteração, o algoritmo ordena as arestas conflitivas em $\mathcal{L}$. No ordenamento, para cada aresta conflitiva, $\left\{w_{i} \rightleftharpoons w_{j}\right\} \in \mathcal{L}$, é calculado o valor $\left|n v\left(w_{i}\right)-n v\left(w_{j}\right)\right|$, onde $n v$ indica o número de nó visitado correspondente a $w_{i}$ e $w_{j}$. Por exemplo, no grafo da Figura 4.3, o valor da aresta conflitiva $\{P P \rightleftharpoons N P\}($ i.e $\{8 \rightleftharpoons 2\})$ é $|n v(P P)-n v(N P)|=$ $|2-8|=6$. O ordenamento é realizado em ordem decrescente desses valores. Desse modo, os nós mais distantes entre si têm maior preferência para serem removidos. 


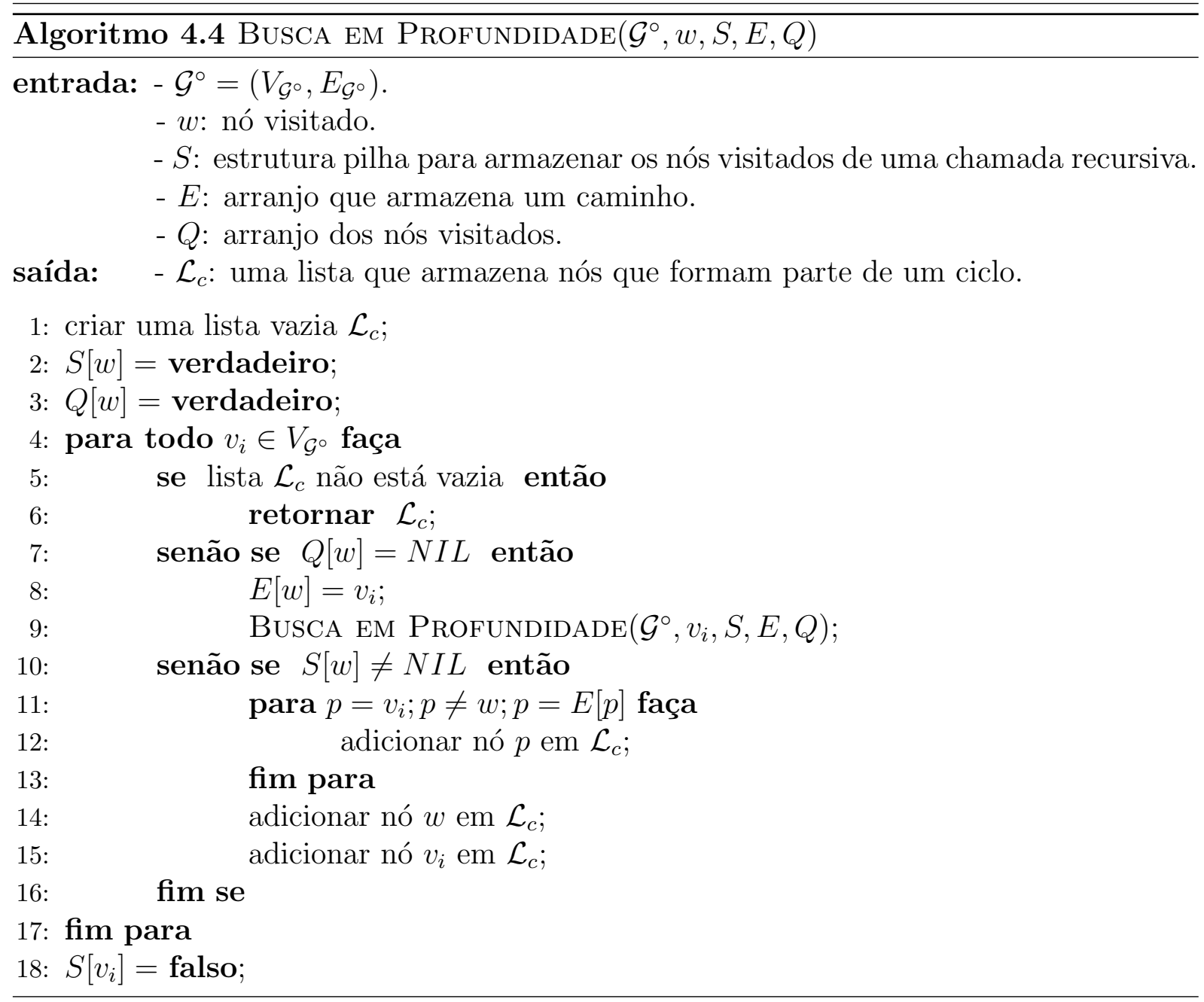

Uma vez que as arestas estão ordenadas em $\mathcal{L}$, a remoção das arestas é realizada considerando um dos seguintes critérios de remoção:

Critério de remoção 1 (C1): Remover do grafo $\mathcal{G}^{\circ}$ apenas a primeira aresta da lista ordenada $\mathcal{L}$.

Critério de remoção 2 (C2): Remover do grafo $\mathcal{G}^{\circ}$ todas as arestas contidas na lista $\mathcal{L}$.

Usando o critério C1, é possível remover apenas as arestas conflitivas que geram ciclos sem o risco de remover uma falsa aresta conflitiva, implicando um falso ciclo. No entanto, o número de iterações necessárias para remover todos os ciclos é proporcional ao número de ciclos do grafo $\mathcal{G}^{\circ}$. Por outro lado, usando critério C2 é possível remover várias arestas conflitivas em uma iteração, diminuindo o custo de tempo para remover todos os ciclos em $\mathcal{G}^{\circ}$. Porém, usando esse critério, existe o risco de remover falsas arestas conflitivas e perder relações importantes.

Considerando os dois algoritmos de detecção de arestas conflitivas e os critérios de remoção anteriormente mencionados, o algoritmo de remoção de arestas (Algoritmo 4.5) pode ser configurado de várias maneiras. Essas configurações são descritas na Tabela 4.1: 


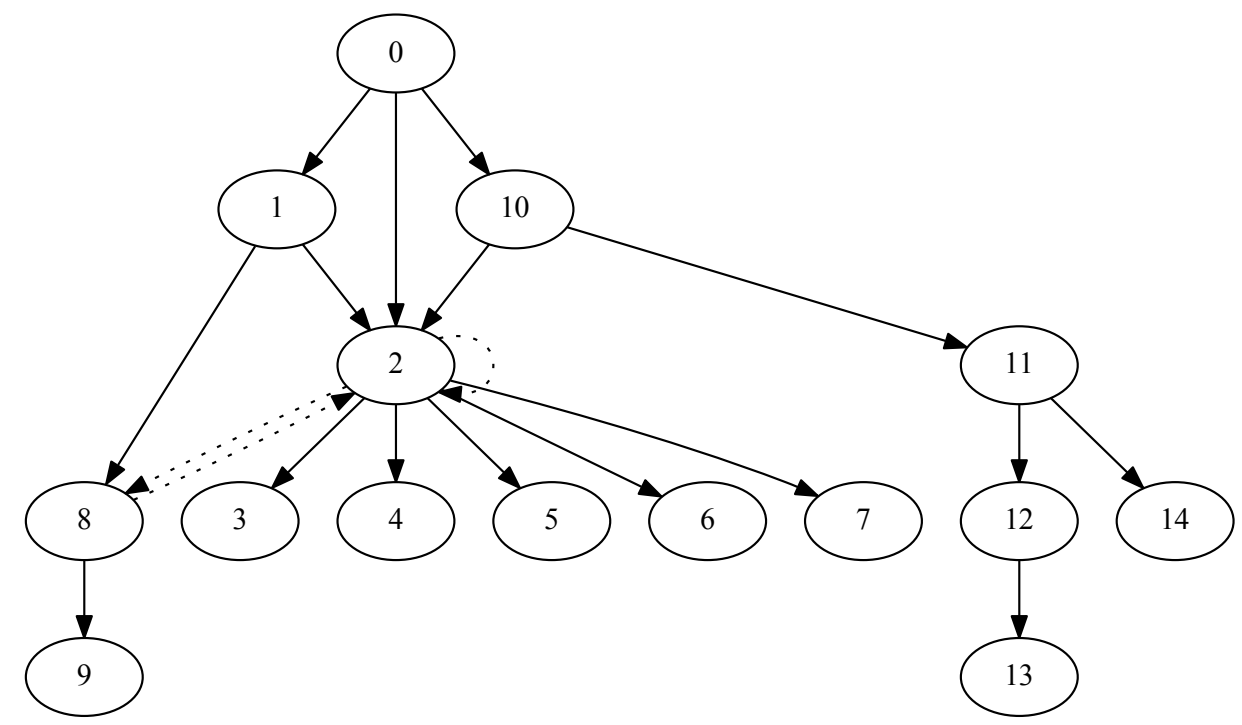

Figura 4.3: Grafo dirigido com dois ciclos detectados, os quais são marcados em linhas pontilhadas. O número em cada nó é a ordem em que esse nó foi visitado ao percorrer o grafo.

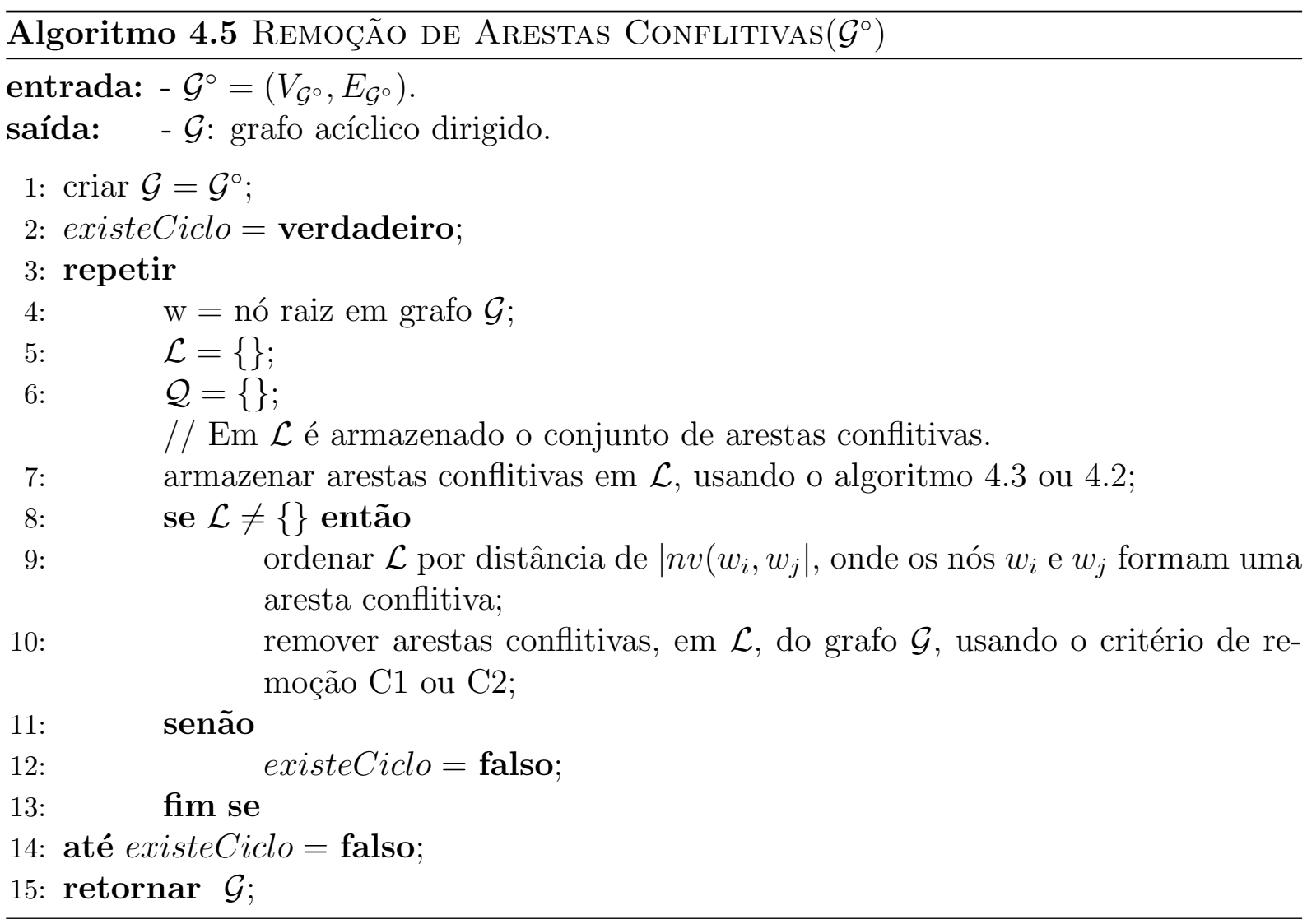

Na Tabela 4.1 são mostradas três tipos de configurações: Rem1, Rem2 e Rem3. Em Rem1 e Rem2 é usado o Algoritmo 4.2 de detecção de arestas conflitivas, empregando os 
Tabela 4.1: Configurações do Algoritmo 4.5 para a remoção de ciclos a partir de um grafo dirigido.

\begin{tabular}{ccc}
\hline Configuração & Detecção de $e_{c}$ & Critério de Remoção \\
\hline Rem1 & Algoritmo de dectação 4.2 & C1 \\
Rem2 & Algoritmo de dectação 4.2 & C2 \\
Rem3 & Algoritmo de dectação 4.3 & C1 \\
\hline
\end{tabular}

critérios C1 e C2, respetivamente. Por outro lado, em Rem3, é usado o Algoritmo 4.3, o qual é usado só com o critério $\mathrm{C} 1$ já que retorna apenas uma aresta conflitiva em cada chamada.

Uma vez que os ciclos são removidos, usando uma das configurações anteriormente descritas, o último passo para construir a estrutura de rede bayesiana é adicionar, ao grafo acíclico, um nó class, $\mathcal{C}$. Esse nó é uma variável aleatória binária que modela a distribuição de probabilidade, a partir do conjunto $\mathcal{D}$, de sentenças contendo IPPs. Assim, esse passo é descrito a seguir.

\subsection{Adição do Nó Classe $\mathcal{C}$}

Considerando o grafo acíclico dirigido $\mathcal{G}$, o último passo para construir a estrutura de uma rede bayesiana $\mathcal{B}=\{\mathcal{G}, \Theta\}$ é a adição do nó classe $\mathcal{C}$ ou também chamado de $C L A S S$. Esse nó será usado posteriormente na inferência probabilística (ver Equação (3.4)) para classificar uma IPP candidata como verdadeira ou falsa.

A avaliação de ligações, entre o nó $\mathcal{C}$ e cada POS tag, tem como objetivo determinar quais dessas ligações favorecem o desempenho da rede bayesiana final. A Figura 4.4 ilustra a adição do nó $\mathcal{C}$ no grafo acíclico dirigido, $\mathcal{G}$, onde as linhas pontilhadas indicam as ligações a serem avaliadas usando uma medida de qualidade, $Q$.

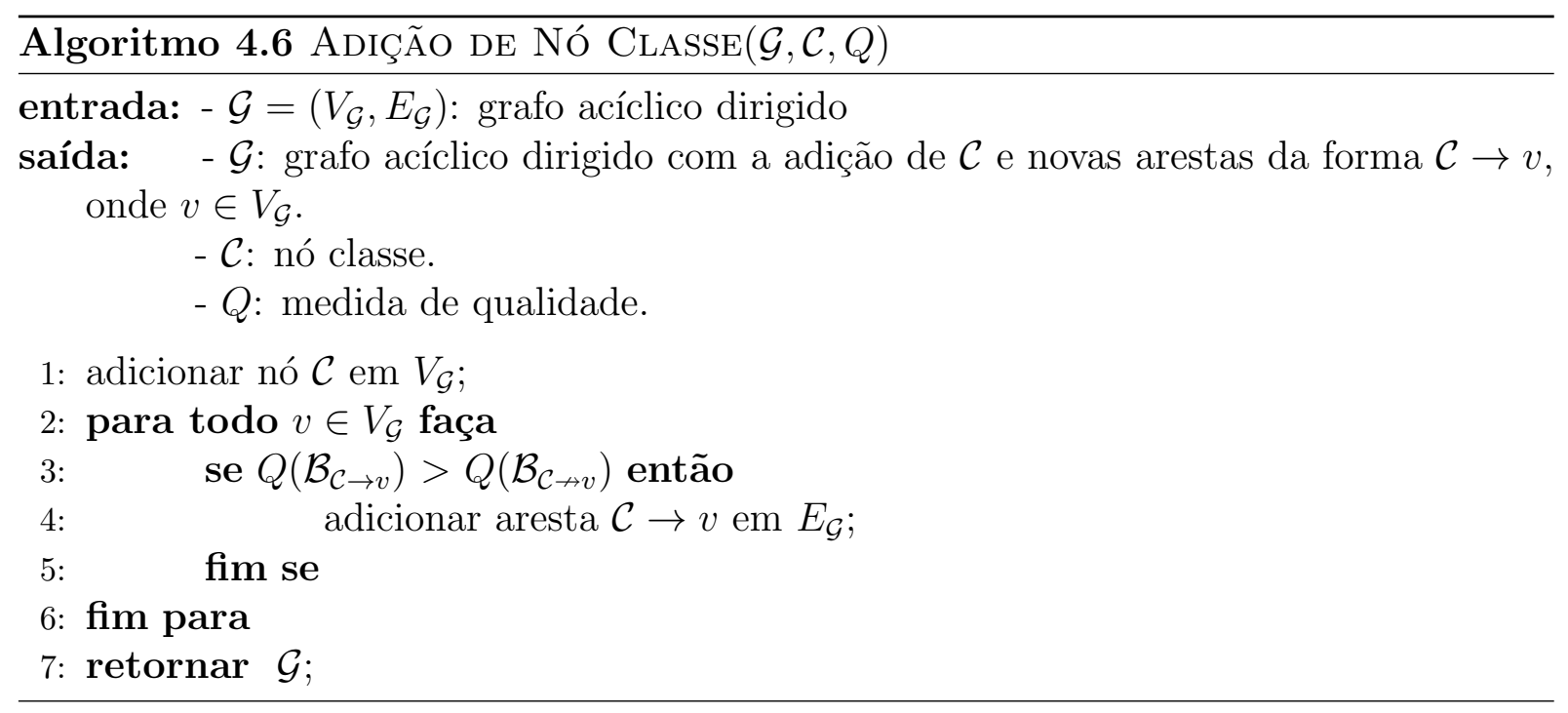




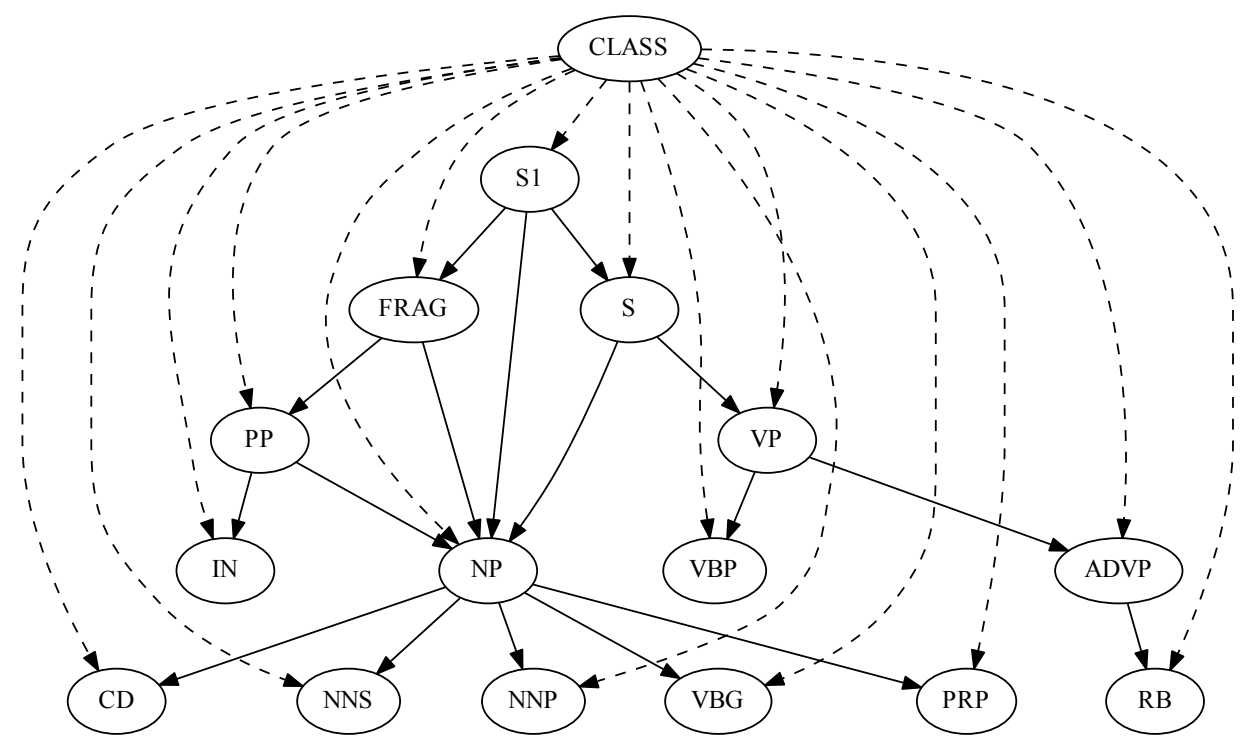

Figura 4.4: Adição do nó chamado de $C L A S S(\mathcal{C})$ no grafo acíclico dirigido, $\mathcal{G}$. As linhas pontilhadas indicam as ligações que serão avaliadas usando uma medida de qualidade, $Q$.

Para avaliar as ligações entre o nó $\mathcal{C}$ e os POS tags, é proposto o Algoritmo 4.6. Esse algoritmo tem como entradas a um grafo acíclico dirigido $\mathcal{G}$, um nó classe $\mathcal{C}$ e uma medida de qualidade $Q$ (ver Seção 3.5). Uma vez que $\mathcal{C}$ é adicionado como nó, a ligação desse com cada nó $v \in\left\{V_{\mathcal{G}}-\mathcal{C}\right\}$ é avaliada iterativamente. Em total, são realizadas $2 \times\left|V_{\mathcal{G}}-\mathcal{C}\right|$ cálculos com uma medida de qualidade $Q$. Assim, a avaliação consiste em usar uma medida de qualidade $Q$ sobre uma estrutura de rede bayesiana com aresta $C \rightarrow v\left(\mathcal{B}_{\mathcal{C} \rightarrow v}\right)$ e sem a mesma aresta $\left(\mathcal{B}_{\mathcal{C} \rightarrow v}\right)$. Se a pontuação $Q\left(\mathcal{B}_{\mathcal{C} \rightarrow v}\right)$ é maior do que a $Q\left(\mathcal{B}_{\mathcal{C} \rightarrow v}\right)$, então é adicionada a aresta $\mathcal{C} \rightarrow v$. Uma vez que essa avaliação é realizada com cada nó $v \in\left\{V_{\mathcal{G}}-\mathcal{C}\right\}$, é retornada a estrutura da nova rede bayesiana $\mathcal{G}$. A Figura 4.5 ilustra a estrutura final da rede bayesiana de exemplo usando uma medida $Q$. Observa-se que tal estrutura apresenta três novas ligações: $\mathcal{C} \rightarrow F R A G, \mathcal{C} \rightarrow V B G$ e $\mathcal{C} \rightarrow C D$. Isso indica que foram encontradas as seguintes relações:

- $Q\left(\mathcal{B}_{\mathcal{C} \rightarrow F R A G}\right)>Q\left(\mathcal{B}_{\mathcal{C} \rightarrow F R A G}\right)$

- $Q\left(\mathcal{B}_{\mathcal{C} \rightarrow V B G}\right)>Q\left(\mathcal{B}_{\mathcal{C} \nrightarrow V B G}\right)$,

- $Q\left(\mathcal{B}_{\mathcal{C} \rightarrow C D}\right)>Q\left(\mathcal{B}_{\mathcal{C} \rightarrow C D}\right)$.

Em suma, nas ligações da variável $\mathcal{C}$ com o resto de nós, os valores foram menores em comparação com as ausências das mesmas ligações. Uma vez construída a estrutura de rede bayesiana, são calculados os parâmetros $\theta_{i} \in \Theta$, de cada variável aleatoria $v_{i} \in V_{\mathcal{G}}$. O cálculo de parâmetros é realizado empregando a MLE ou a estimação bayesiana baseada 


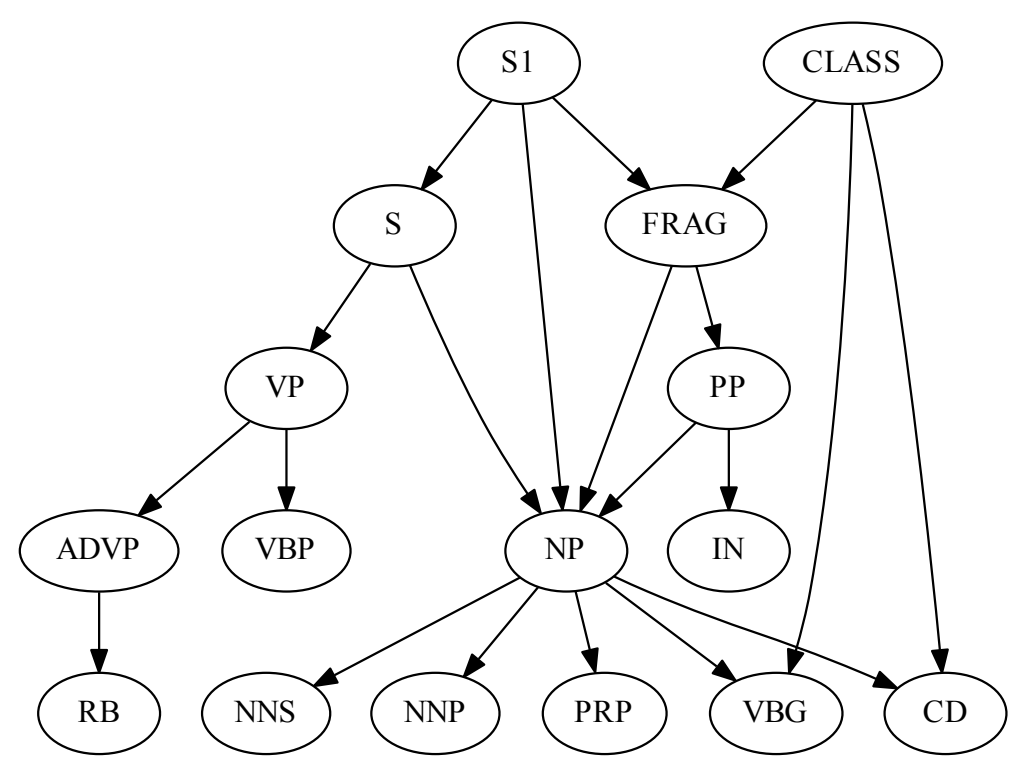

Figura 4.5: Estrutura final de rede bayesiana, contendo $P O S$ tags e uma variável $C L A S S$. A variável CLASS deve ser ligada com os POS tags, usando uma medida de qualidade $Q$ para avaliar tais ligações.

em hiperparâmetros de Dirichlet. Essas estimações são especificadas na Subseção 3.5.3. Desse modo, tanto a estrutura quanto os parâmetros definem a rede bayesiana $\mathcal{B}=\{\mathcal{G}, \Theta\}$, construída a partir das árvores constituintes contidas no conjunto de treinamento, $\mathcal{D}=$ $\{\mathcal{T}[1], \ldots, \mathcal{T}[m]\}$.

\subsection{Restrição do Número de Nós Pais}

Para qualquer nó $\mathcal{Z} \in \mathcal{G}$, ter um número alto de nós pais representa um problema para a modelagem de uma rede bayesiana (Heckerman e Chickering, 1995), já que esse número determina o número de parâmetros que $\mathcal{Z}$ terá. Então, se esse número for muito alto, existe o risco do modelo de rede bayesiana ter overfitting. Por outro lado, se o número de pais for pequeno, existe o risco do modelo não generalizar a partir do conjunto de treinamento $\mathcal{D}$. Assim, é necessário levar em conta o uso de restrição do número de nós pais para cada nó $\mathcal{Z}$.

A fim de usar a restrição do número de nós pais, é usada a medida de informação mútua (ver Seção 3.5.2). Uma vantagem da informação mútua é que identifica o grau de independência entre duas variáveis $X$ e $Y$ a partir dos dados, $\mathcal{D}$. Caso ambas as variáveis forem independentes, o valor retornado seria 0 , por outro lado, caso essas variáveis tenham uma relação de dependência, o valor máximo que podem atingir é 1. Esta medida é aplicada para cada par de variáveis contidas no grafo $\mathcal{G}$, antes de adicionar o nó classe. 
Nesse momento, são selecionados como nós pais de um nó $\mathcal{Z}$, aqueles que tem um alto valor de informação mútua.

\subsection{Classificação de uma IPP}

Uma vez que a rede bayesiana, $\mathcal{B}$, já foi construída, a mesma será usada para extrair uma IPP a partir de uma nova sentença (sentença de teste). Para fazer isso, é necessário obter a árvore constituinte correspondente a essa nova sentença. Na Figura 4.6, é ilustrada uma árvore constituinte que corresponde a uma sentença de teste.

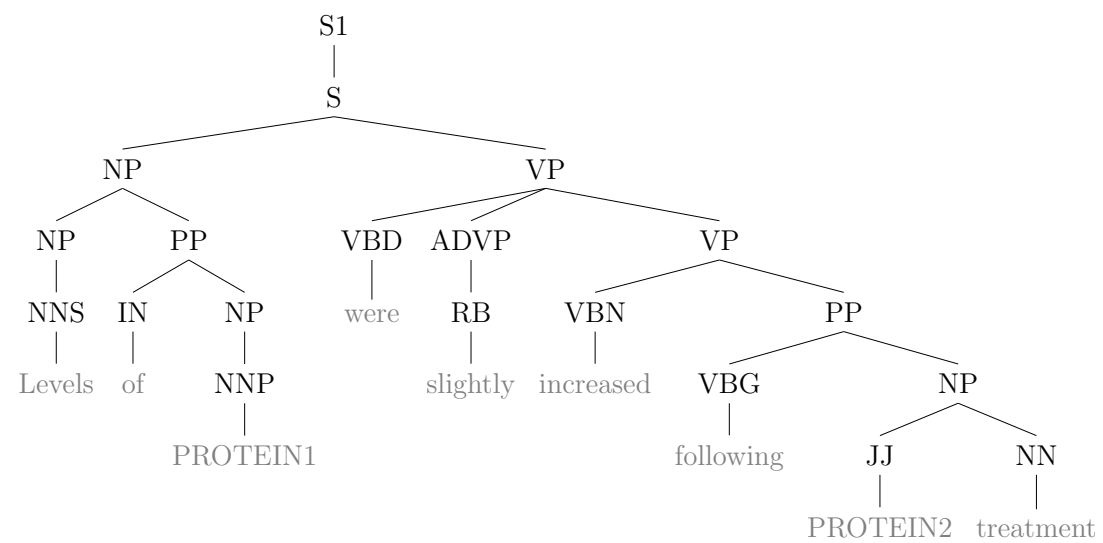

Figura 4.6: Árvore constituinte que corresponde a uma sentença de teste.

Com as informações dessa árvore constituinte, os atributos da rede bayesiana, $\mathcal{B}$, são instanciados com os valores correspondentes. Por exemplo, como a variável aleatória $V P$ está presente na árvore constituinte da sentença de teste, essa variável é instanciada com $V P=1$. Em geral, "1" indica a presença de um POS tag e "0" indica a ausência do mesmo. A Figura 4.7 ilustra a instanciação das variáveis aleatórias da rede bayesiana $\mathcal{B}$. Todas as variáveis são instanciadas, com exceção do nó $C L A S S$. As variáveis instanciadas são chamadas de variáveis observadas.

O valor do nó $C L A S S$ é estimado usando a probabilidade conjunta descrita na Equação (3.4). Essa estimação é redefinida na Equação (4.1):

$$
\hat{y}=\arg _{\mathcal{C}} \max \{P(\mathcal{C}=0 \mid \mathcal{B}, \mathcal{D}, \mathcal{T}), P(\mathcal{C}=1 \mid \mathcal{B}, \mathcal{D}, \mathcal{T})\}
$$

onde $\mathcal{C}$ é o nó $C L A S S, \hat{y}$ é o valor do nó $C L A S S, \mathcal{B}$ é a rede bayesiana construída pelo método PT-BN, $\mathcal{D}$ é o conjunto de árvores constituintes de treinamento e $\mathcal{T}$ é a árvore constituinte de uma sentença de teste. 


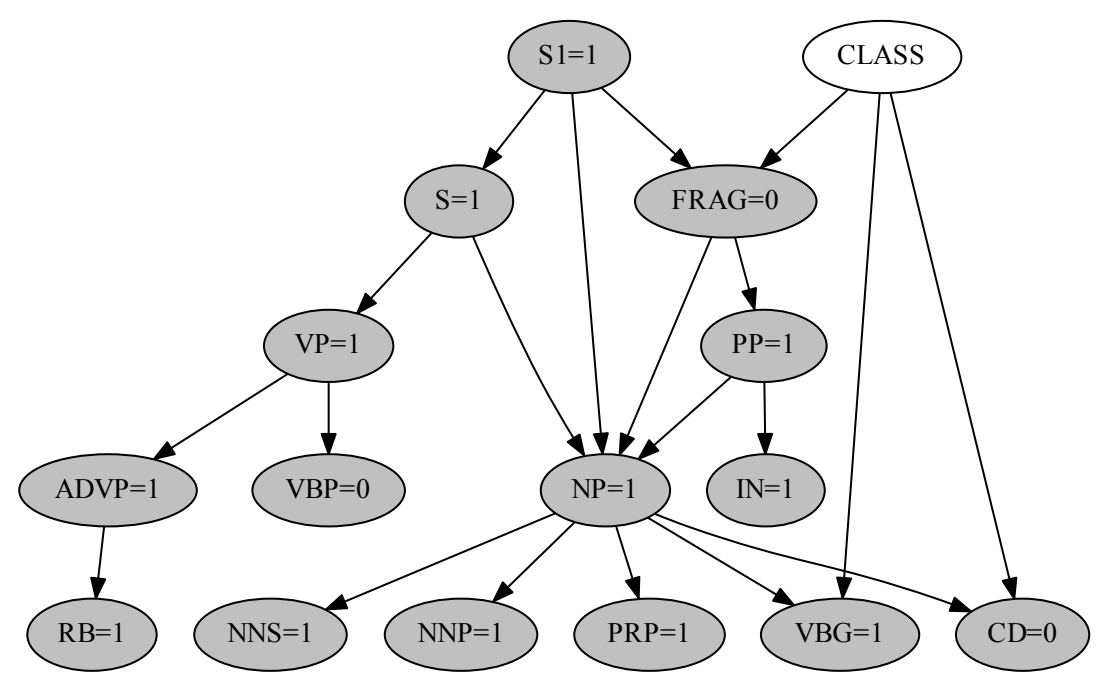

Figura 4.7: Classificação de uma sentença de teste usando a rede bayesiana construída pelo método PT-BN. Os nós em cor cinza representam variáveis aleatórias observadas. Quando o valor de uma variável é "1", indica a presença desse POS tag na sentença de teste. Caso contrário, indica a ausência de tal POS tag. O nó CLASS é a única variável oculta, cujo valor deve ser estimado usando a probabilidade conjunta da rede bayesiana.

\subsection{Considerações Finais}

Neste capítulo foi descrito o método PT-BN, detalhando as fases para criar um modelo de rede bayesiana a partir de árvores constituintes. Dado que essas árvores constituintes contêm implicitamente uma gramática, os POS tags dessas são modelados como variáveis aleatórias. As variáveis aleatórias são ligadas entre elas, formando um grafo, de acordo com informação das árvores constituintes.

Porém, na maioria dos casos, o grafo é acíclico. Desse modo, é proposto um algoritmo de remoção de arestas com várias configurações para obter um grafo acíclico dirigido. Nesse sentido, o método inicia detectando arestas conflitivas. Uma vez que os ciclos são removidos da estrutura grafo, é adicionado um nó classe $\mathcal{C}$. Para realizar tal adição, é proposto um algoritmo com complexidade linear em termos do número de nós. Após isso, é empregado o cálculo de parâmetros de um modelo de rede bayesiana, para o qual foram usadas duas estimações da teoria de aprendizado de parâmetros: MLE e Bayes. Além disso, o método apresenta um passo adicional para reduzir o número máximo de nós pais para cada nó da rede bayesiana. O objetivo de tal redução é evitar o overfitting da rede.

Posteriormente, uma vez a rede bayesiana é construída, essa é usada para classificar novas sentenças de texto. Para fazer isso, é usada a estimação de probabilidade conjunta tanto para o caso que exista quanto para o caso que não exista interação. Finalmente, o rótulo de uma nova sentença é a classe que corresponde à maior probabilidade conjunta. 


\subsection{Considerações Iniciais}

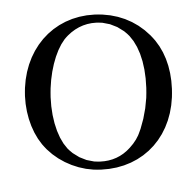
método proposto nesta dissertação foi avaliado em cinco conjuntos ou corpora padrões de IPPs: AImed, BioInfer, IEPA, HPRD50 e LLL (ver Subseção 2.5.1). A partir das sentenças de tais corpora, foram obtidas árvores constituintes por meio de um parser do estado da arte, descrito a seguir. Essas árvores foram usadas diretamente na construção dos modelos de redes bayesianas. Também, usando o critério de pré-processamento de árvores constituintes proposto em (Choi e Myaeng, 2010), essas árvores foram podadas, a fim de obter uma versão menor da árvore que permita melhores resultados.

Considerando isso, a avaliação do método proposto nesta dissertação, relacionado com a construção automática de redes bayesianas usando árvores constituintes na extração de IPPs é apresentada. Em tal avaliação, são levados em conta dois pontos. No primeiro ponto, comparam-se os diversos modelos de redes bayesianas construídos por meio do método PT-BN, i.e compara-se o uso das métricas de pontuação para a seleção de estrutura de cada modelo de rede e o uso dos métodos MLE e Bayes para o cálculo de parâmetros do mesmo modelo. No segundo ponto, os modelos construídos pelo método PT-BN são comparados com outros classificadores do estado da arte na extração de IPPs.

Na próxima seção é detalhado o pré-processamento para obter as árvores constituintes a partir de sentenças e a poda de tais árvores. Em seguida, descreve-se a configuração dos experimentos e, posteriormente, são apresentados os experimentos usando o método 
PT-BN na extração de IPPs a partir dos cinco corpora, também como uma comparação com os métodos do estado da arte.

\subsection{Pré-processamento de Sentenças}

As sentenças de texto devem ser pré-processadas para obter as árvores constituintes necessária para a extração de IPPs. Para tal fim, é usado o Charniak-Johnson parser (Charniak e Johnson, 2005). O mesmo que está disponível em http://bllip.cs.brown. edu/resources.shtml. Assim, a entrada do parser é uma sentença de texto, enquanto que a saída é uma árvore constituinte em notação de tree bank (Jurafsky e Martin, 2008). Por exemplo, considerando a sentença,

Levels of PROTEIN1 were slightly increased following PROTEIN2 treatment $(P=0.09)$.

a saída correspondente é uma árvore constituinte representada por

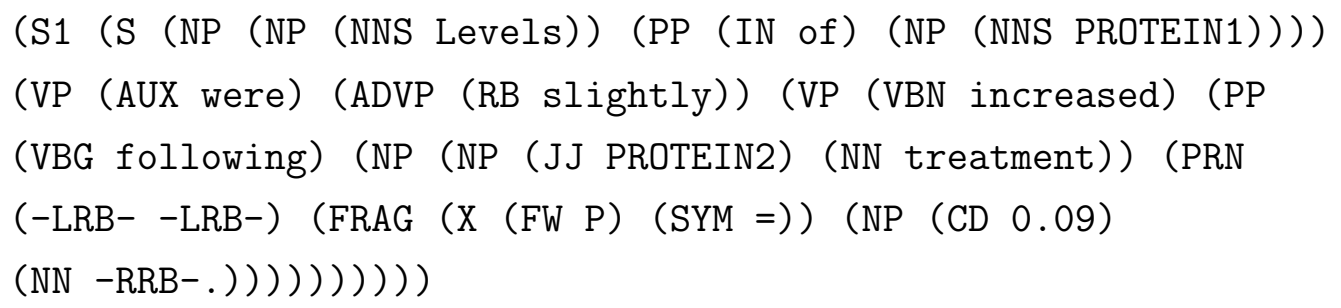

A árvore constituinte é transformada em uma árvore menor por meio de um préprocessamento de poda. Essa poda já foi usada em um trabalho prévio de extração de IPPs, usando kernels (Choi e Myaeng, 2010). Isso permitiu melhorar o desempenho de tais kernels na extração de IPPs.

O objetivo desse tipo de poda é considerar apenas a subestrutura árvore que contenha como nó terminal de início e final aos tokens: PROTEIN1, PROTEIN2 ou PROTEIN.

Na Figura 5.1, é mostrado um exemplo de poda, realizado sobre a árvore constituinte da sentença do exemplo anterior. Note-se que a poda considera os nomes das proteínas e os nós ancestrais dos mesmos.

No exemplo, a poda desconsidera as frases: "Levels of" e "treatment ( $P=0.09)$ ".

\subsection{Configuração dos Experimentos}

Os corpora foram usados de duas maneiras na avaliação dos métodos. A primeira consiste em usar individualmente cada corpus, para o qual é usada validação cruzada com 10 folds. $\mathrm{Na}$ validação, as sentenças de um mesmo documento foram incluídas em um mesmo fold, 


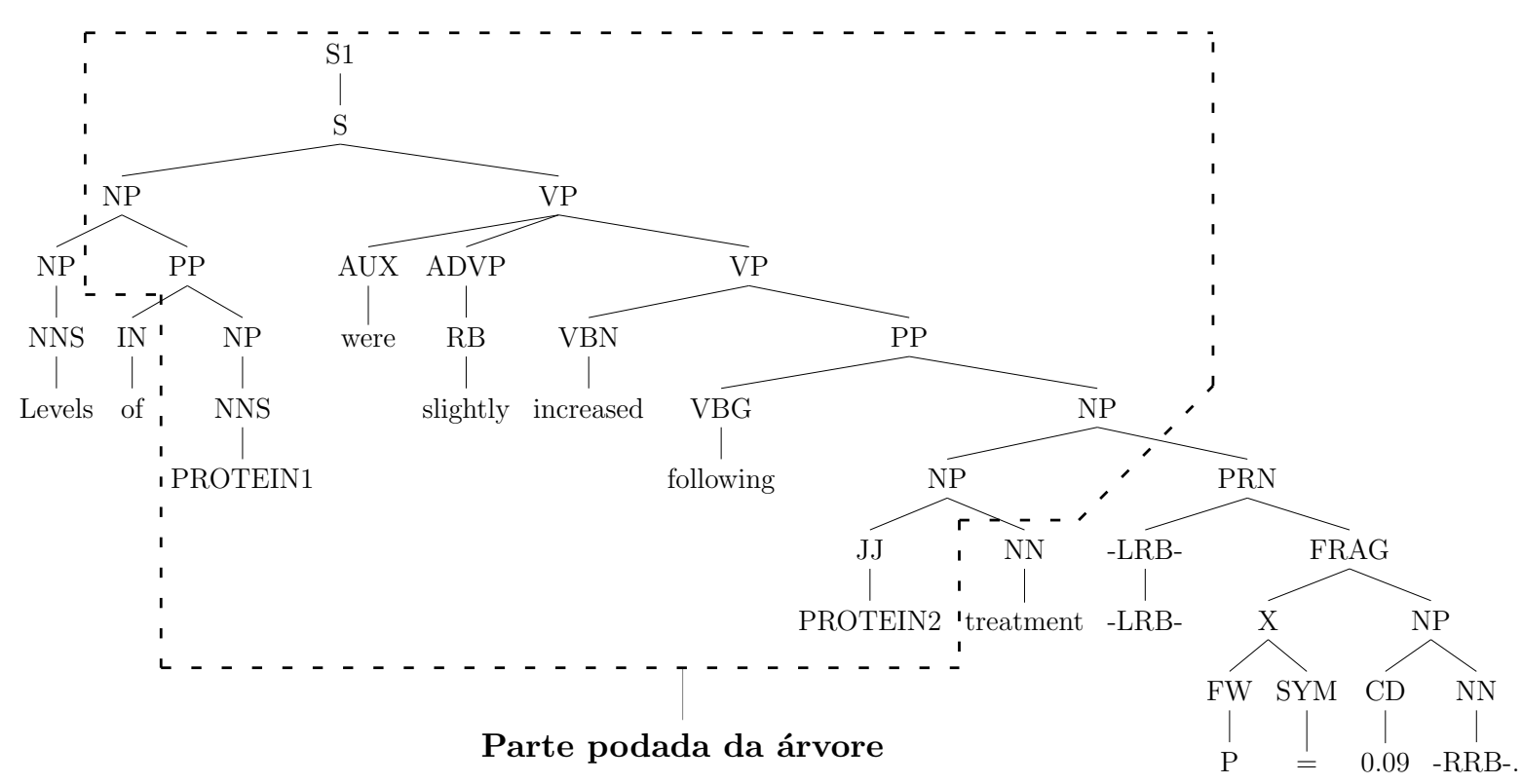

Figura 5.1: Método de poda aplicado sobre uma árvore constituinte. A árvore constituinte foi obtida a partir da sentença com ID="AIMed.d0.s6", pertencente ao corpus AImed.

para evitar um sobreajuste (overfitting) quando o classificador é treinado (Airola et al., 2008; Miwa et al., 2009b; Choi e Myaeng, 2010). Isso porque as sentenças de um mesmo documento podem conter informação similar. A segunda, é o uso de corpora cruzados (cross-corpora), a qual consiste em usar um corpus para treinamento e outro para teste. Em ambas as maneiras, as instâncias são obtidas por meio do procedimento one-answerper-ocurrence.

\subsection{Avaliação do Método Proposto}

A avaliação está focada no desempenho do algoritmo proposto nesta dissertação (ver Algoritmo 4.6), ajustando diferentes configurações para ele (ver Seção 4.3.2). Cada uma dessas configurações constitui um modelo de rede bayesiana, $\mathcal{B}=\{\mathcal{G}, \Theta\}$, com apoio de uma medida de qualidade e um método de estimação de parâmetros. Para identificar quais medidas e quais métodos de estimação de parâmetros são mais adequados, todos são avaliados usando o algoritmo proposto.

Com relação às medidas de qualidade, as configurações são avaliadas com 6 dessas medidas, detalhadas na Seção 3.5.1.1. A medida de qualidade selecionada é usada para atribuir uma pontuação a cada estrutura de modelo de rede bayesiana, pertencente a um espaço de modelos gerado pelo algoritmo proposto. O objetivo é escolher o modelo com maior pontuação. Em suma, tais configurações também são avaliadas com dois métodos de estimação de parâmetros, descritos na Seção 3.5.3. O método de estimação de parâmetros selecionado é usado, após construir a estrutura do modelo, para calcular as distribuições 
de probabilidades associadas com cada variável aleatória da rede bayesiana, i.e., com cada nó da estrutura.

Os resultados experimentais são mostrados a seguir, usando as várias configurações do algoritmo proposto junto com as medidas de qualidade e os métodos de estimação de parâmetros. Primeiro, é apresentada a avaliação das medidas de qualidade, usando todas as configurações propostas. Depois, os métodos de estimação de parâmetros também são avaliados com cada uma das configurações. Finalmente, é apresentada uma discussão dos resultados dessas avaliações.

\subsubsection{Experimentos com as Medidas de Qualidade}

Os resultados da avaliação das medidas de qualidade, apresentados nesta seção, são mostrados em boxplots. Cada valor, em um boxplot, representa o valor da medida F correspondente a um modelo de rede bayesiana construída usando validação cruzada com 10-folds.

Para avaliar cada medida de qualidade, foram usados 153 modelos de redes bayesianas construídos a partir de árvores constituintes. Esse número de modelos é produzido ao usar as 3 configurações do Algoritmo 4.6 junto com uma estimação de parâmetro de máxima verossimilhança e também com 50 hiperparâmetros $(\alpha=\{1,2,3 \ldots, 50\})$ para a estimação de parâmetros baseada na abordagem bayesiana. Esse número de modelos foi empregado tanto em árvores podadas quanto em árvores sem poda. Cada boxplot contém os mesmos modelos de redes bayesianas, sendo a diferença entre cada boxplot, o uso particular da medida de qualidade. Desse modo, é possível estimar o desempenho de cada medida de qualidade, na extração de IPPs, usando os modelos de redes bayesianas construídos a partir de árvores constituintes.

Dois tipos de medidas de qualidade foram avaliadas: (1) as baseadas na abordagem bayesiana e, (2) as baseadas em entropia (ver Seção 3.5.1.1). As medidas de qualidade bayesianas preferem estruturas de pouca complexidade quando o número de instâncias é pequeno, mudando as estruturas de maior complexidade de acordo com o aumento das instâncias. A complexidade de uma estrutura está associada com o número de arestas na estrutura da rede bayesiana. Quanto maior número de arestas apresenta um modelo de rede bayesiana, maior sua complexidade. Por outro lado, as medidas baseadas em entropia preferem estruturas simples e penalizam as complexas. Considerando essa classificação de medidas, as medidas bayesianas avaliadas são: "Bayes", "BDeu" e "K2" e, as baseadas em entropia são: "H", "AIC" e "BIC".

No corpus BioInfer, o maior corpus com relação ao número de instâncias (ver mais informações dos corpora na Seção 2.5.1), os melhores resultados das medidas de qualidade foram atingidos usando árvores podadas. Nesse caso, as medidas "Bayes" e "K2" atingiram os melhores resultados com 0.723 e 0.724 de medida F, respectivamente. Em contraste, 


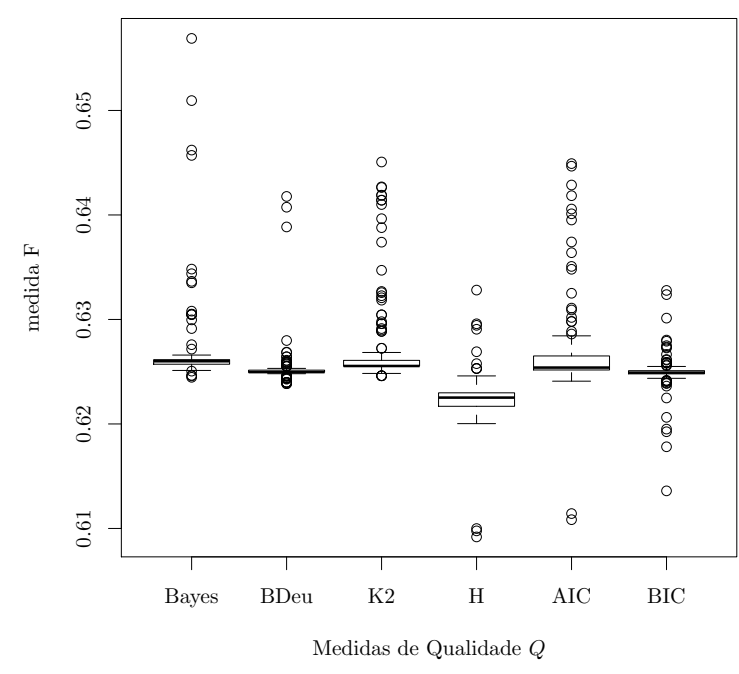

(a) Árvores consituintes de BioInfer sem poda

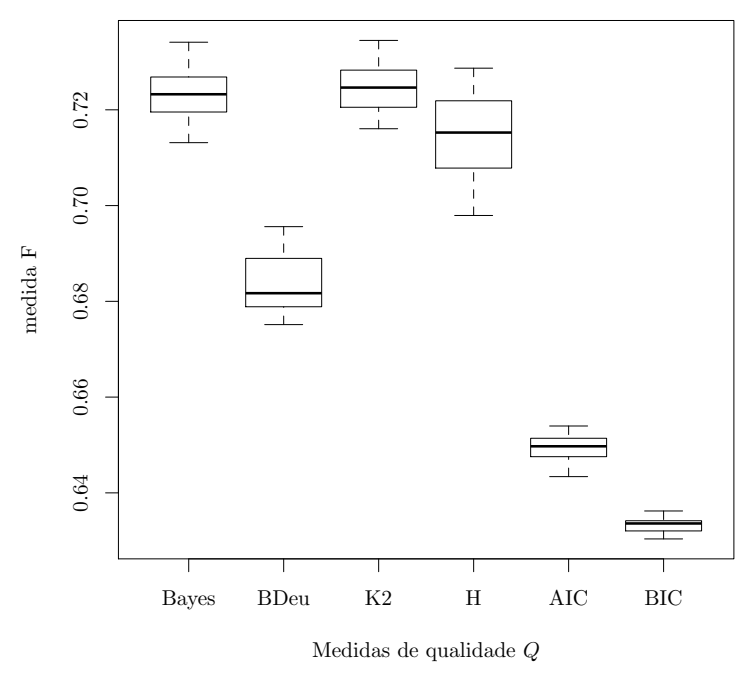

(b) Árvores consituintes de BioInfer podadas

Figura 5.2: Boxplot do desempenho, em termos de medida F, de todas as configurações com relação a seis medidas de qualidade no corpus BioInfer.

os piores resultados são das medidas baseadas em entropia: "AIC" e "BIC", com 0.65 e 0.633 de medida F respectivamente. Nas árvores sem poda, todas as medidas tiveram um desempenho semelhante, sendo a média de todas elas de 0.62 (ver Figura 5.2).

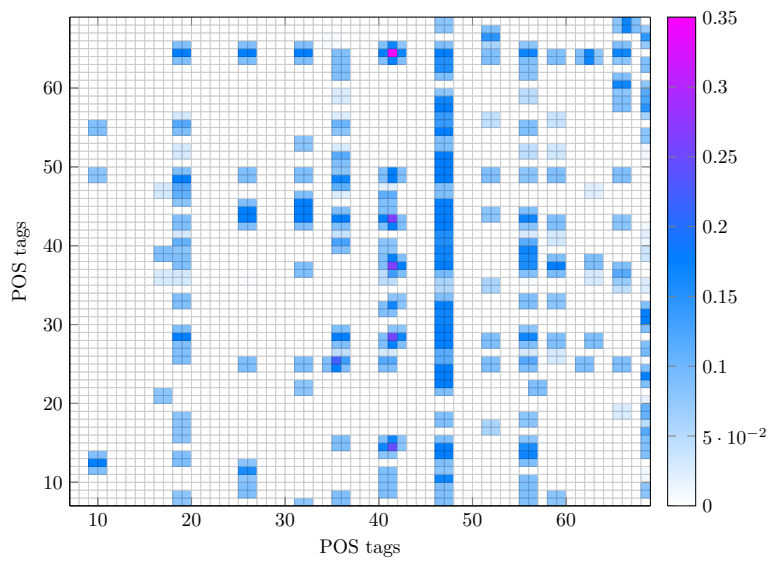

(a)

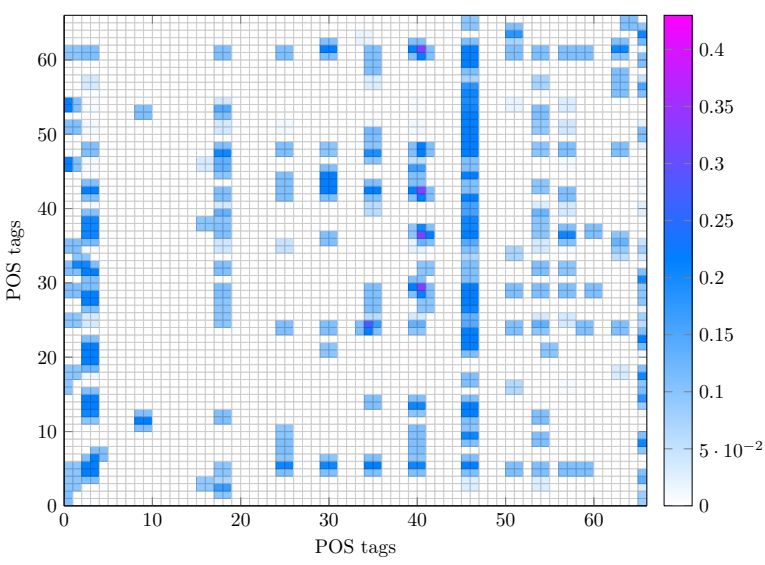

(b)

Figura 5.3: Frequência de uso de regras entre POS tags no corpus BioInfer. Tais regras pertencem a diferentes modelos de redes bayesianas construídos a partir de árvores constituintes. Em (a) são mostradas tais frequências usando árvores sem poda. Em (b) são mostradas tais frequências usando árvores podadas.

Na Figura 5.3 ilustra-se a frequência com que relações entre POS tags são usadas, pelo menos uma vez em um modelo de rede bayesiana. Essas frequências são mostradas tanto para árvores constituintes sem poda quanto para as podadas. Nas árvores sem poda, o 
número de POS tags usados é de 70 e, o número de arestas únicas, usadas pelos menos uma vez, foi de 382. No caso das árvores podadas, o número de POS tags é de 67 e o número de arestas é de 317. Isso quer dizer que o número de relações (e, portanto, parâmetros) em uma rede, é considerávelmente menor (65 arestas a menos).

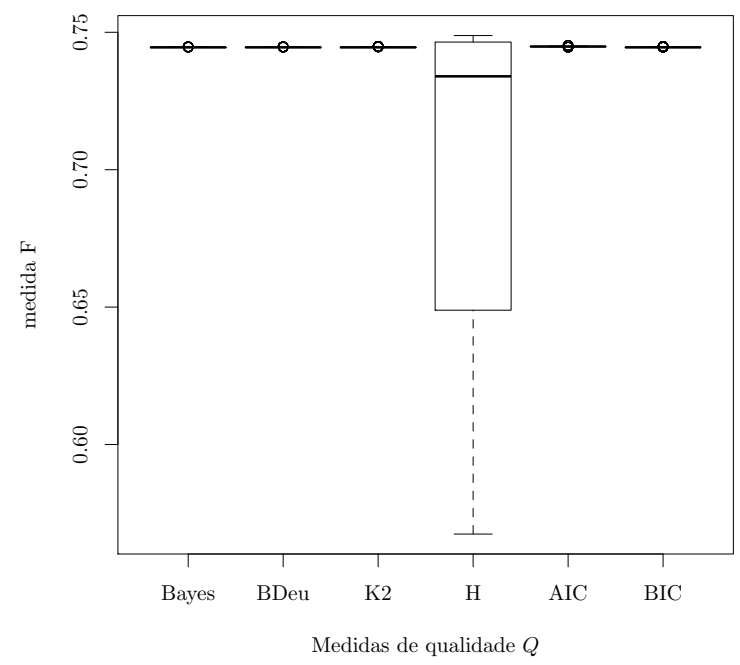

(a) Árvores consituintes de AImed sem poda

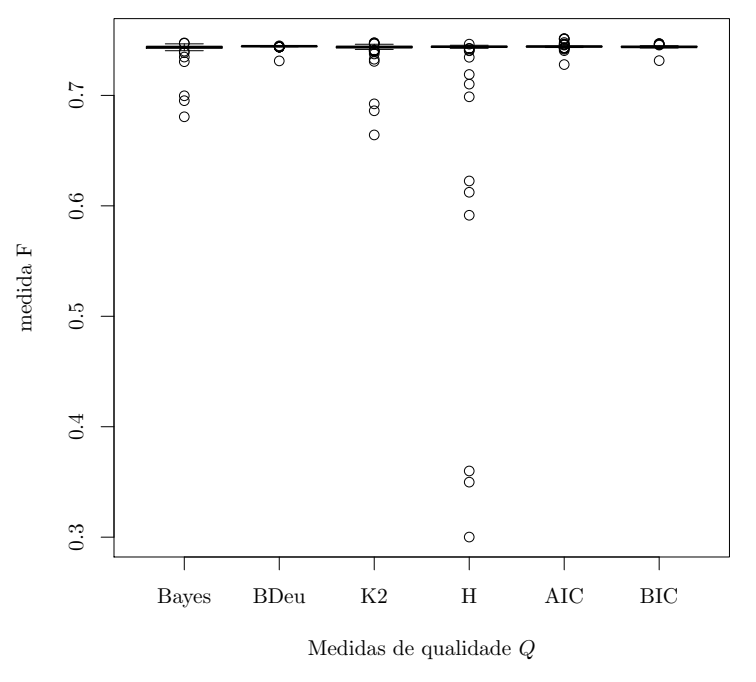

(b) Árvores consituintes de AImed podadas

Figura 5.4: Boxplot do desempenho, em termos de medida F, de todas as configurações com relação a seis medidas de qualidade no corpus AImed.

No corpus AImed, os resultados de todas as medidas de qualidade são semelhantes tanto nas árvores sem poda como nas podadas (ver Figura 5.4). A medida F de todas é de 0.74, com exceção da medida "H", a qual apresenta uma média de 0.69 quando as ávores não estão podadas.

$\mathrm{Na}$ avaliação desse empate, foi encontrado que, usando árvores podadas ou sem poda, as arestas foram semelhantes em ambos os casos (ver Figura 5.5). De fato, os números de nós e de regras únicas, usadas pelo menos uma vez com modelos construídos a partir de árvores sem poda, são de 69 e 337, respectivamente. Por outro lado, os números de nós e regras únicas usando árvores podadas são de 300 e 68, respectivamente.

No corpus IEPA, com árvores sem podar, as medidas "Bayes", "K2", "BDeu", "AIC" e "BIC" obtiveram melhores resultados com uma média entre 0.59 e 0.60 de medida $\mathrm{F}$ (ver Figura 5.6). Por outro lado, usando árvores podadas, as medidas "Bayes", "K2" e "H" obtiveram melhores resultados com $0.663,0.647$ e 0.66 respectivamente.

Na Figura 5.7 são ilustradas as frequências de uso de algumas arestas entre POS tags. Quando as árvores são podadas, o número de arestas é reduzido de 294 a 256. Também, o número de nós é reduzido de 0.67 a 0.62. 


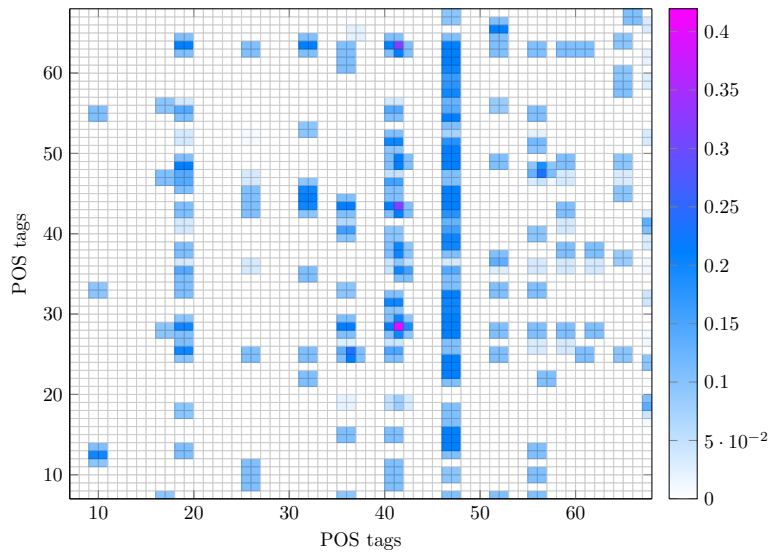

(a)

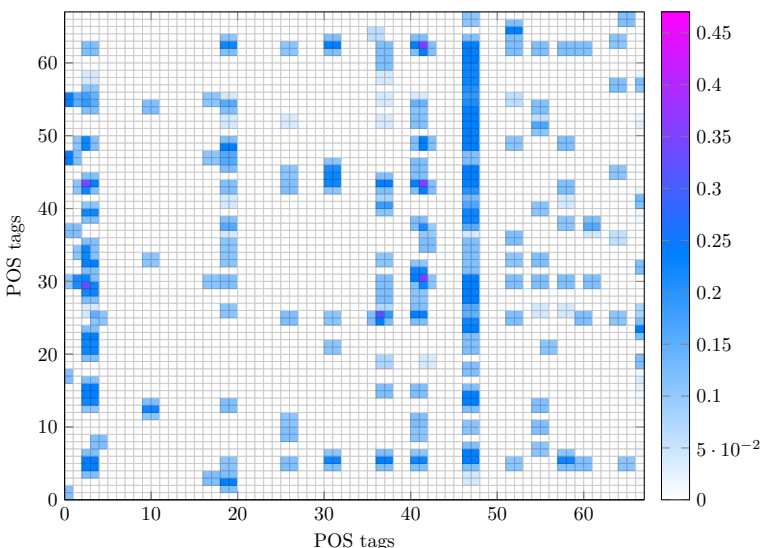

(b)

Figura 5.5: Frequência de uso de regras entre POS tags no corpus AImed. Tais regras pertencem a diferentes modelos de redes bayesianas construídos a partir de árvores constituintes. Em (a) são mostradas tais frequências usando árvores sem poda. Em (b) são mostradas tais frequências usando árvores podadas.

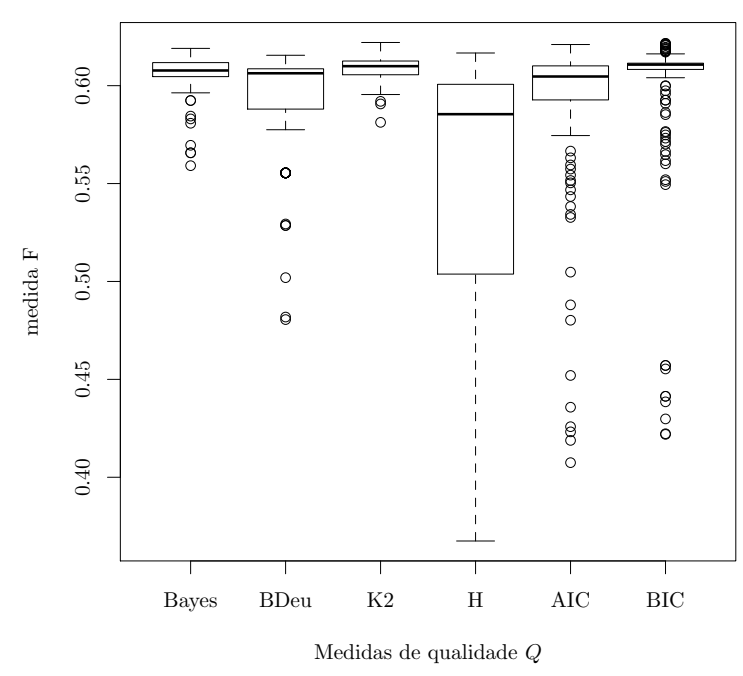

(a) Árvores consituintes de IEPA sem poda

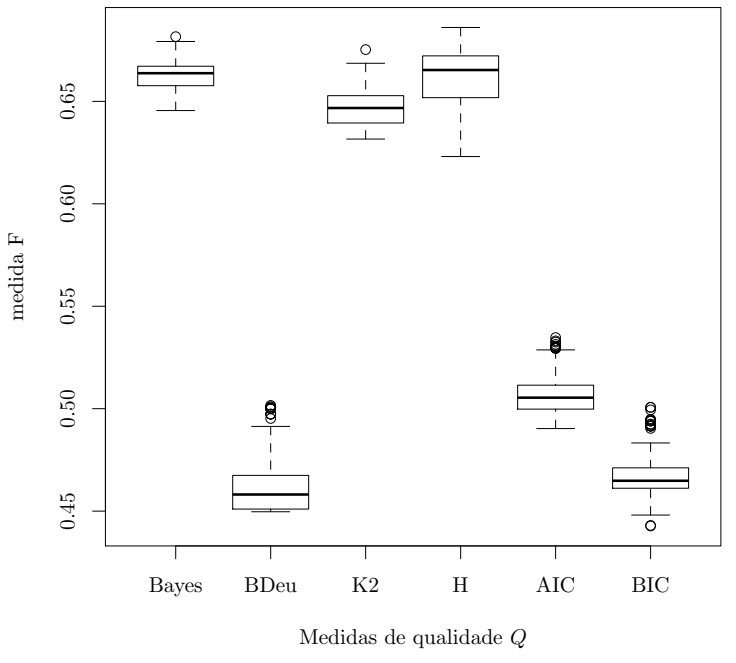

(b) Árvores consituintes de IEPA podadas

Figura 5.6: Boxplot do desempenho, em termos de medida F, de todas as configurações com relação a seis medidas de qualidade no corpus IEPA. 


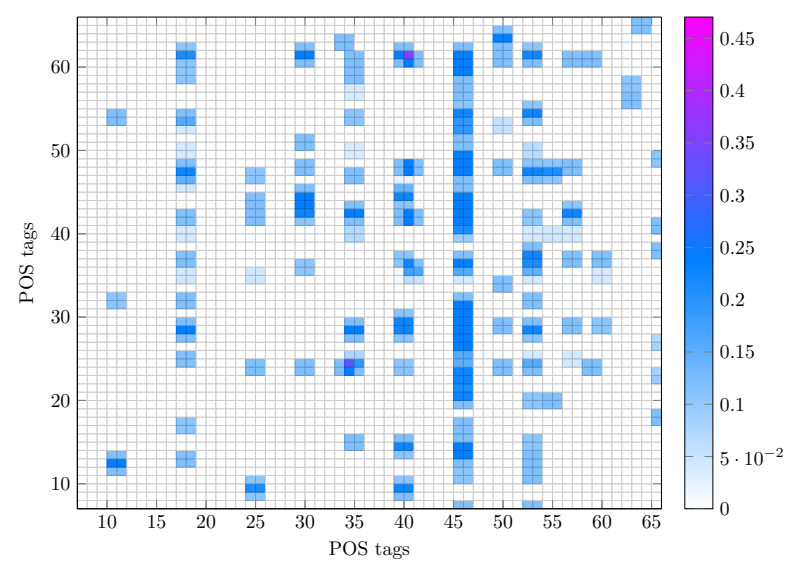

(a)

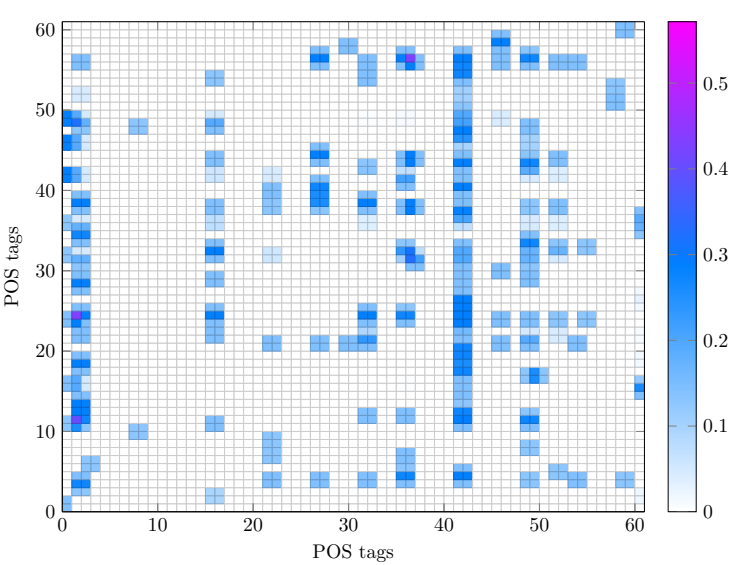

(b)

Figura 5.7: Frequência de uso de regras entre POS tags no corpus IEPA. Tais regras pertencem a diferentes modelos de redes bayesianas construídos a partir de árvores constituintes. Em (a) são mostradas tais frequências usando árvores sem poda. Em (b) são mostradas tais frequências usando árvores podadas.

No corpus HPRD50, o uso de árvores sem poda permitiu atingir melhores resultados. As medidas de qualidade baseadas em entropia obtiveram melhores resultados: "AIC" (0.62), "BIC" (0.61) e "H" (0.60) (ver Figura 5.8). Quando as ávores são podadas, "AIC" decrementa sua medida F para 0.59, "BIC" para 0.55 e "H" para 0.50.

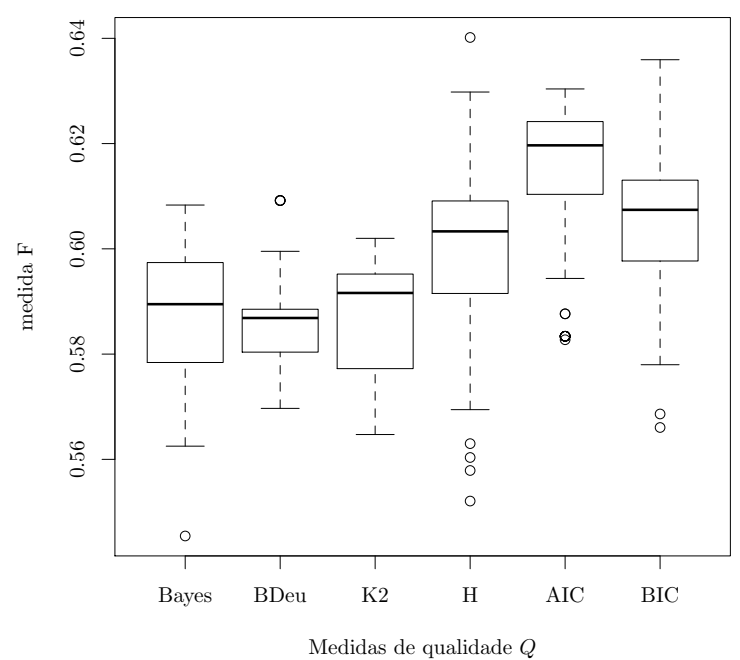

(a) Árvores consituintes de HPRD50 sem poda

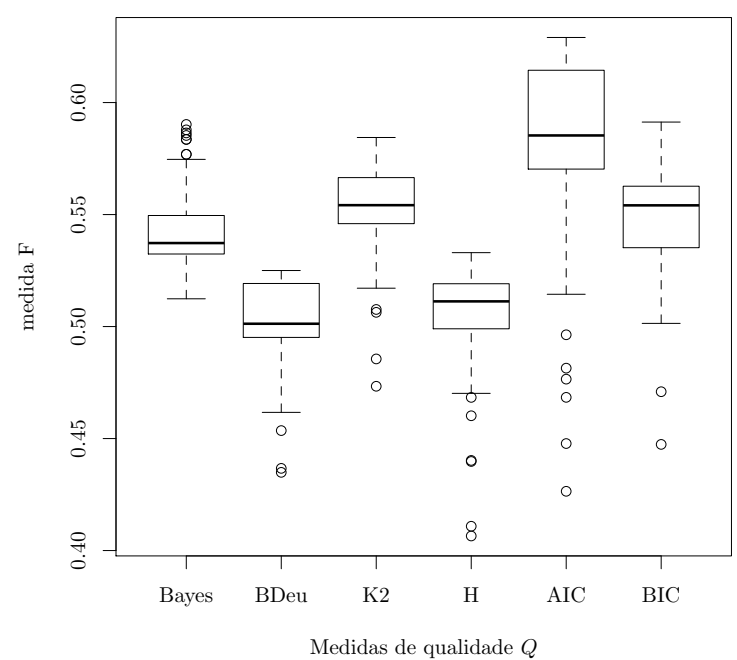

(b) Árvores consituintes de HPRD50 podadas

Figura 5.8: Boxplot do desempenho, em termos de medida F, de todas as configurações com relação a seis medidas de qualidade no corpus HPRD50.

Na Figura 5.9 são ilustradas as frequências de arestas entre POS tags. O número de POS tags usando árvores sem podar é de 0.55, com o uso de árvores podadas, é de 50. 
Também, o número de arestas é diminuido de 205 a 187, quando a poda das árvores é realizada.

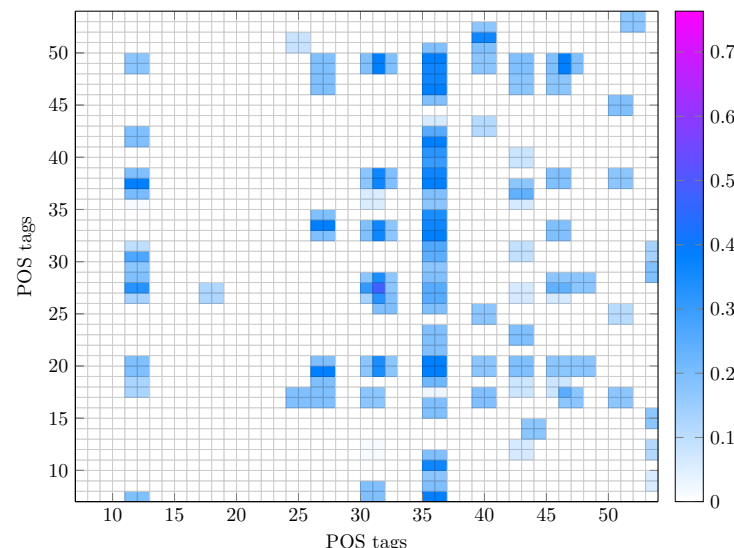

(a)

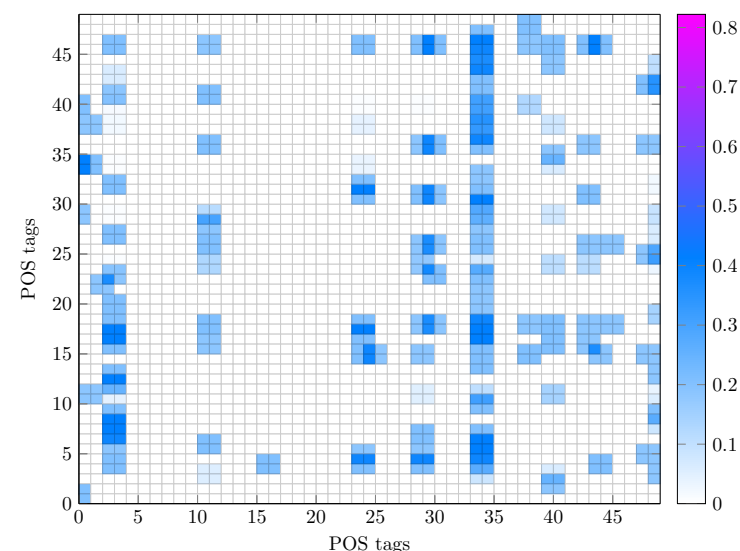

(b)

Figura 5.9: Frequência de uso de regras entre POS tags no corpus HPRD50. Tais regras pertencem a diferentes modelos de redes bayesianas construídos a partir de árvores constituintes. Em (a) são mostradas tais frequências usando árvores sem poda. Em (b) são mostradas tais frequências usando árvores podadas.

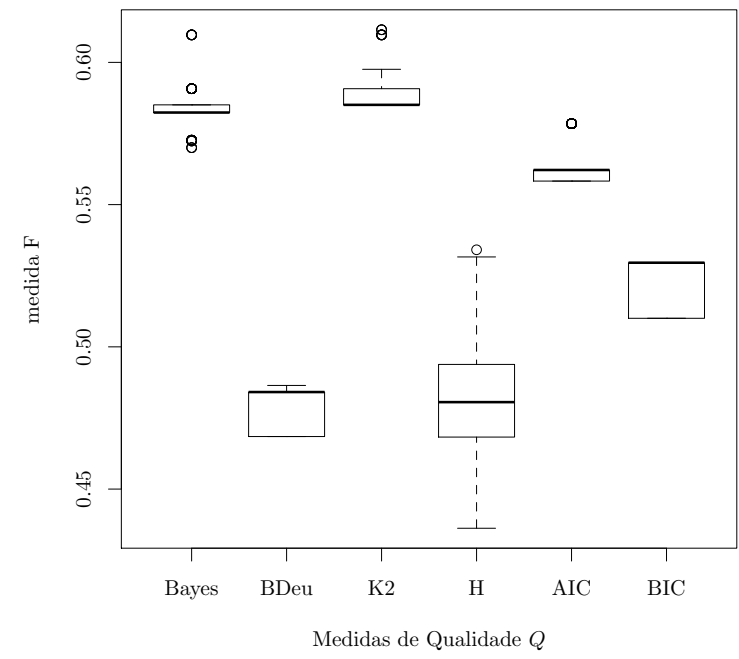

(a) Árvores consituintes de LLL sem poda

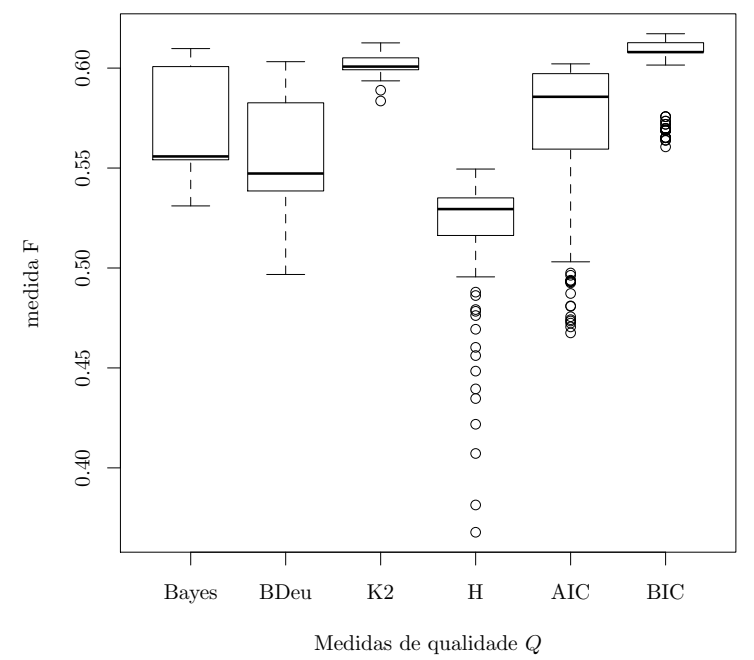

(b) Árvores consituintes de LLL podadas

Figura 5.10: Boxplot do desempenho, em termos de medida F, de todas as configurações com relação a seis medidas de qualidade no corpus LLL.

No corpus LLL, os melhores resultados foram atingidos usando árvores podadas. A Figura 5.10 ilustra o desempenho das 6 medidas de qualidade. Com árvores podadas, "BIC" e "K2" apresentaram os melhores resultados na média, com 0.601 e 0.603 de medida F respectivamente. A medida "H" teve o pior resultado com uma média de 0.52 de medida 
F. Entretanto, no uso de árvores sem poda, "Bayes" e "K2" atingiram os melhores resultados com médias de 0.584 e 0.588 , respectivamente. De maneira similar ao desempenho com árvores podadas, "H" teve o pior resultado com 0.48 de medida F, o que implica uma diminuição da média em $4 \%$.

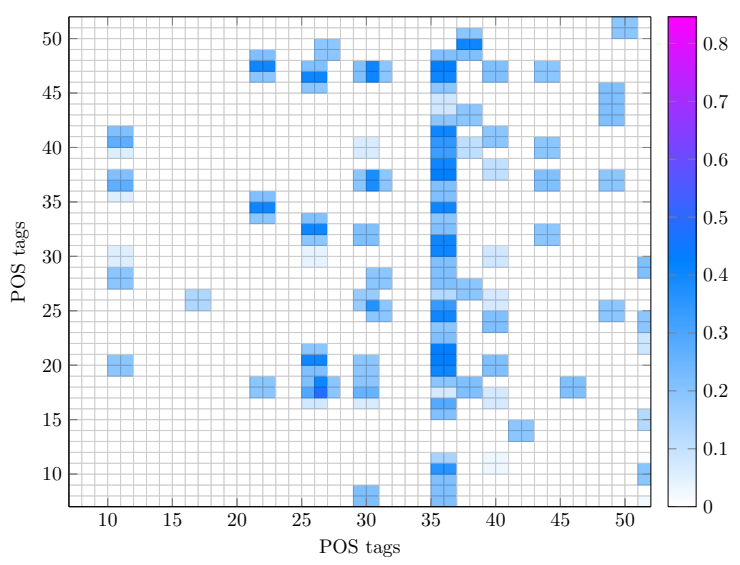

(a)

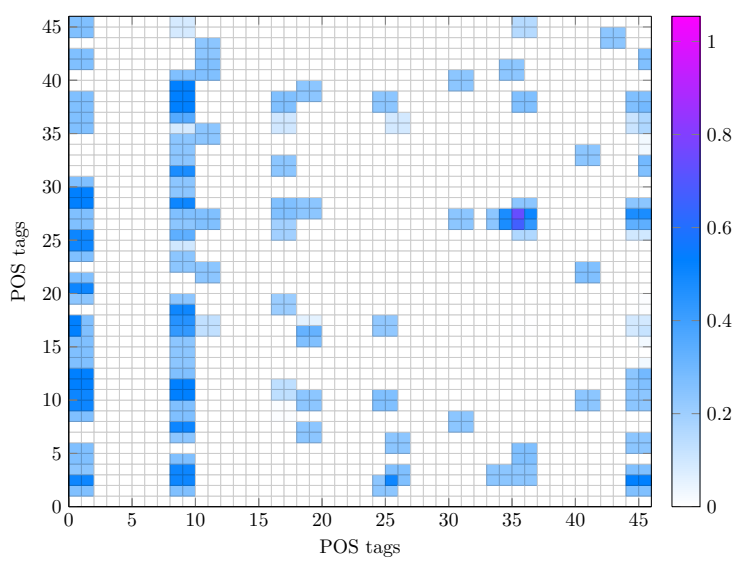

(b)

Figura 5.11: Frequência de uso de regras entre POS tags no corpus LLL. Tais regras pertencem a diferentes modelos de redes bayesianas construídos a partir de árvores constituintes. Em (a) são mostradas tais frequências usando árvores sem poda. Em (b) são mostradas tais frequências usando árvores podadas.

Na Figura 5.11, observa-se a dimiuição do número de POS tags de 52 a 46, quando a poda é usada. Além disso, as ligações são visívelmente menores quando são usadas as árvores podadas.

\subsubsection{Experimentos com as Estimações de Parâmetros: MLE e Bayes}

As configurações Rem1, Rem2 e Rem3 (ver Seção 4.3.2) foram usadas com diferentes estimações de parâmetros para seus modelos de redes bayesianas. Inicialmente foi usada a estimação MLE nas três configurações. Depois, foi usada a estimação de parâmetros Bayesiana. Nesta estimação, são usados hiperparâmetros chamados de Dirichlet, o qual é denotado por $\alpha$. Os valores para esses hiperparâmetros foram de $\alpha=\{1,2,3, \ldots, 50\}$.

Na Figura 5.12 são ilustrados os desempenhos de vários modelos de redes bayesianas no corpus BioInfer com árvores constituintes podadas e sem poda. A estimação de Bayes permite melhores resultados em comparação a MLE, usando árvores com poda. Por outro lado, quando as árvores sem poda são usados, ambas as estimações atingem altos resultados. Um caso parecido acontece com o corpus AImed (ver Figura 5.13).

Na Figura 5.14 é possível observar que, no desempenho dos modelos de redes bayesianas, os melhores resultados são obtidos usando árvores podadas tanto para a estimação MLE quanto para a bayesiana. Na Figura 5.15 mostra-se um exemplo inverso com o conjunto HPRD50. 


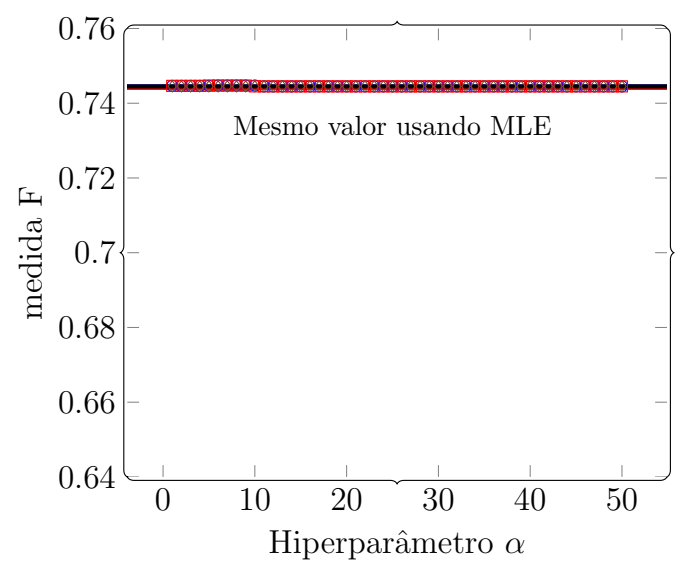

(a)

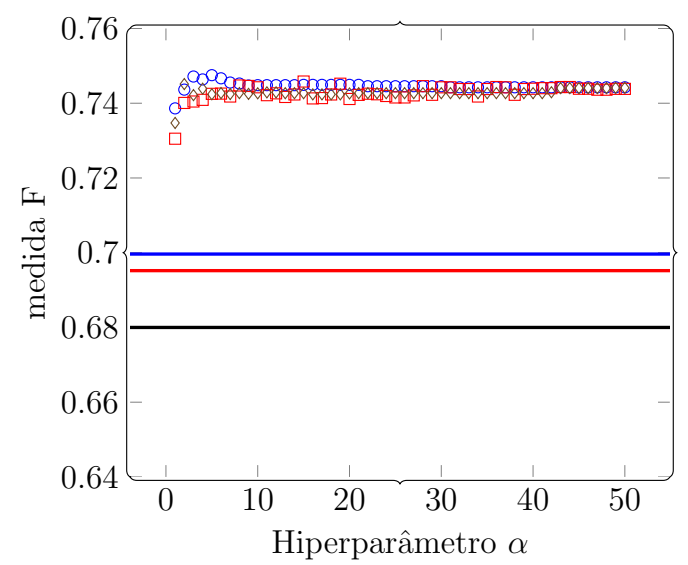

(b)

\section{$\circ$ Rem $1 \sqsubset \operatorname{Rem} 2 \diamond \operatorname{Rem} 3-\operatorname{Rem} 1$-MLE — Rem 2-MLE — Rem 3-MLE}

Figura 5.12: Comparação, no corpus BioInfer, de três algoritmos de remoção de ciclos: Rem1, Rem2 e Rem3. Os algoritmos foram testados com a medida de pontuação Bayes. O cálculo de parâmetros foi feito usando a estimação de Bayes com hiperparâmetros $\alpha=\{1, \ldots, 50\}$. Em (a) é ilustrado o desempenho dos três algoritmos, usando árvores constituintes de treinamento sem poda. Em contraste, em (b) é mostrado o desempenho com as árvores podadas.

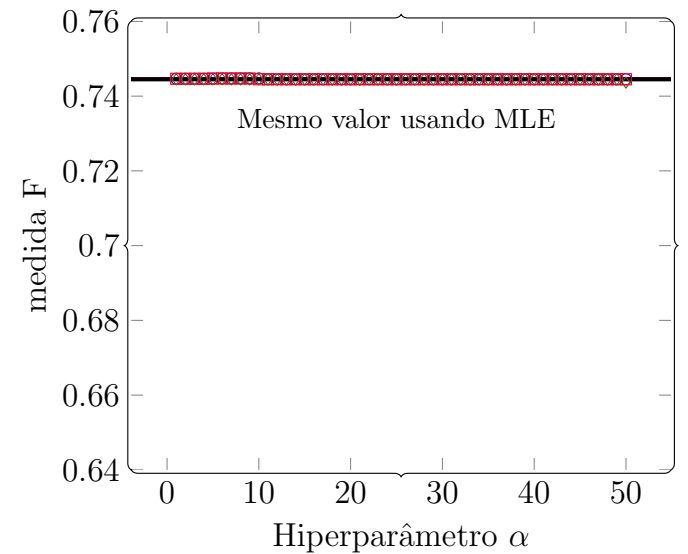

(a)

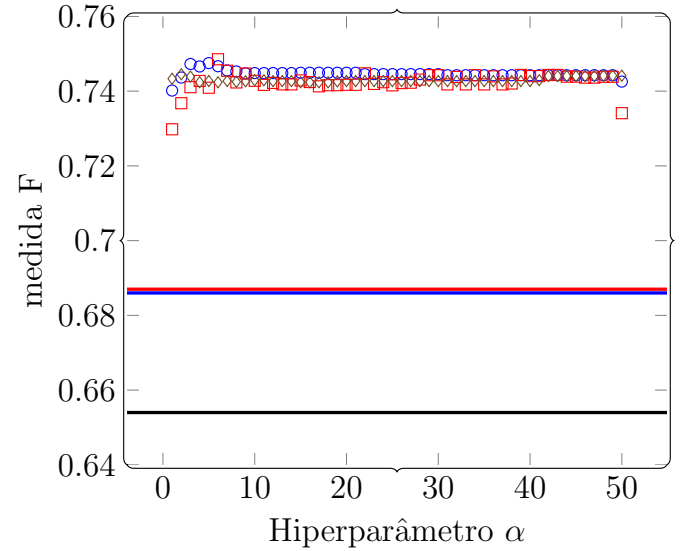

(b)

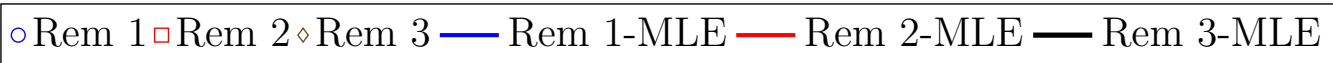

Figura 5.13: Comparação, no corpus AImed, de três algoritmos de remoção de ciclos: Rem1, Rem2 e Rem3. Os algoritmos foram testados com a medida de pontuação Bayes. O cálculo de parâmetros foi feito usando a estimação de Bayes com hiperparâmetros $\alpha=\{1, \ldots, 50\}$. Em (a) é ilustrado o desempenho dos três algoritmos, usando árvores constituintes de treinamento sem poda. Em contraste, em (b) é mostrado o desempenho com as árvores podadas.

Na Figura 5.16, nota-se que a estimação bayesiana obtem melhores resultados quando o hiperparâmetro é $\alpha \geq 30$. 


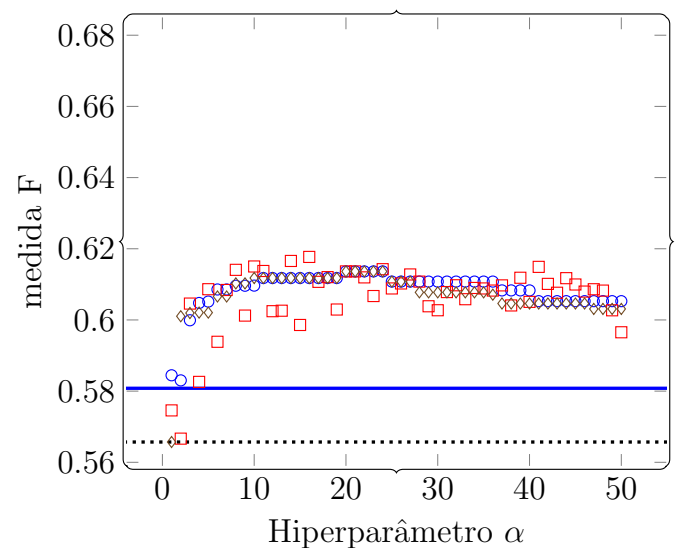

(a)

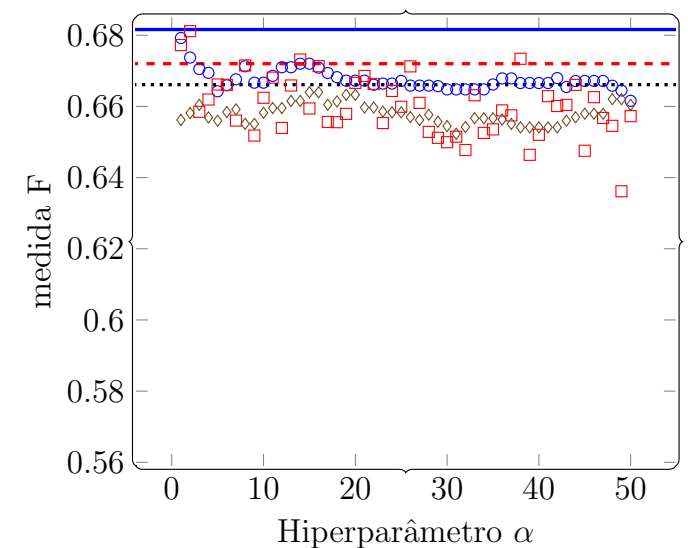

(b)

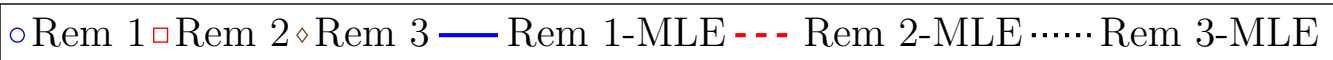

Figura 5.14: Comparação, no corpus IEPA, de três algoritmos de remoção de ciclos: Rem1, Rem2 e Rem3. Os algoritmos foram testados com a medida de pontuação Bayes. O cálculo de parâmetros foi feito usando a estimação de Bayes com hiperparâmetros $\alpha=\{1, \ldots, 50\}$. Em (a) é ilustrado o desempenho dos três algoritmos, usando árvores constituintes de treinamento sem poda. Em contraste, em (b) é mostrado o desempenho com as árvores podadas.

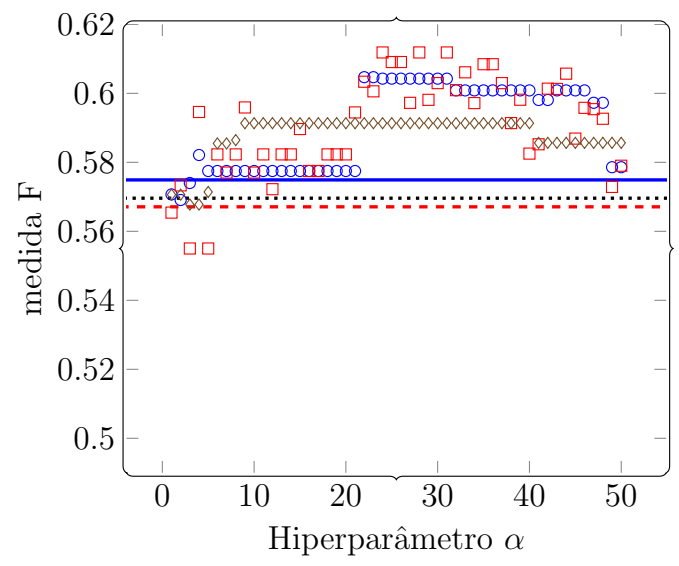

(a)

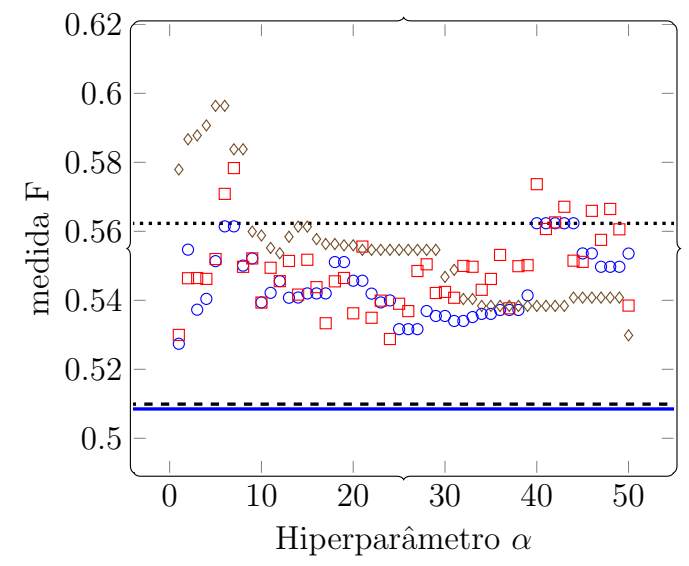

(b)

\section{○Rem 1ロRem $2 \diamond$ Rem 3 - Rem 1-MLE - - Rem 2-MLE …... Rem 3-MLE}

Figura 5.15: Comparação, no corpus HPRD50, de três algoritmos de remoção de ciclos: Rem1, Rem2 e Rem3. Os algoritmos foram testados com a medida de pontuação Bayes. O cálculo de parâmetros foi feito usando a estimação de Bayes com hiperparâmetros $\alpha=\{1, \ldots, 50\}$. Em (a) é ilustrado o desempenho dos três algoritmos, usando árvores constituintes de treinamento sem poda. Em contraste, em (b) é mostrado o desempenho com as árvores podadas.

Em geral, observa-se que quando $\alpha \geq 20$, o desempenho dos modelos de redes bayesianas aumenta. No caso de AImed e BioInfer, os resultados para qualquer $\alpha$ são parecidos. 


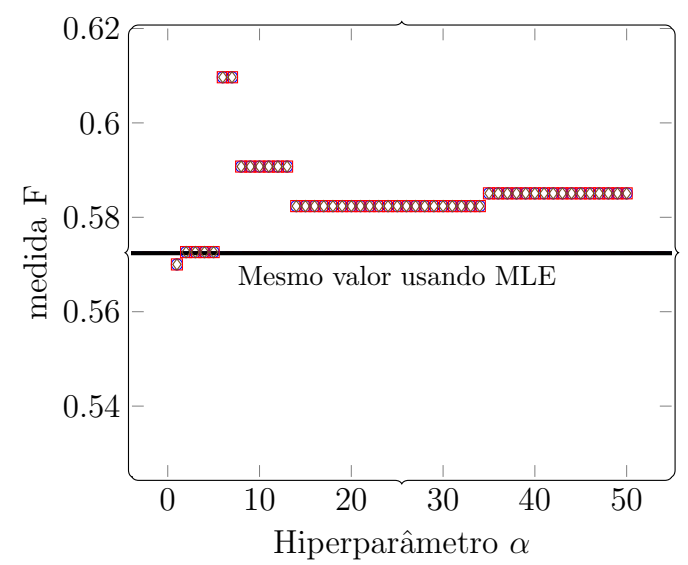

(a)

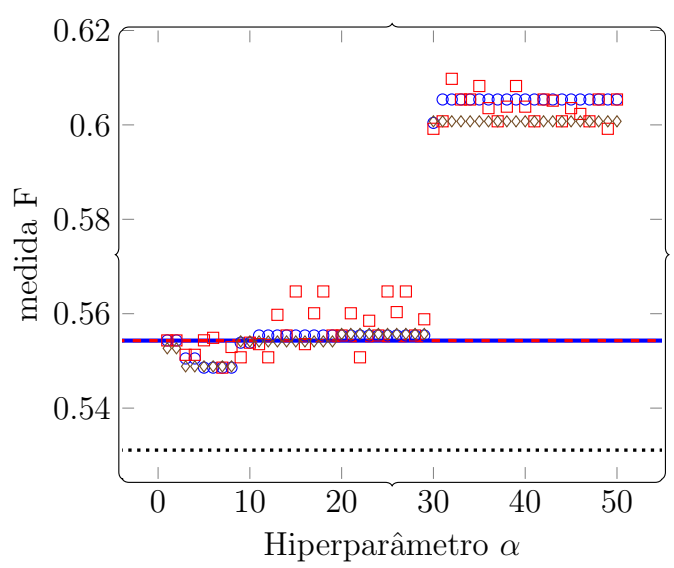

(b)

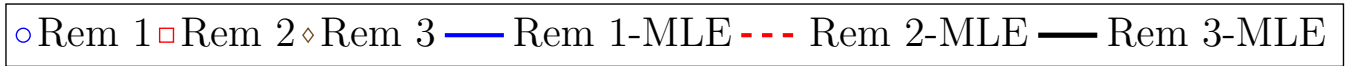

Figura 5.16: Comparação, no corpus LLL, de três algoritmos de remoção de ciclos: Rem1, Rem2 e Rem3. Os algoritmos foram testados com a medida de pontuação Bayes. O cálculo de parâmetros foi feito usando a estimação de Bayes com hiperparâmetros $\alpha=\{1, \ldots, 50\}$. Em (a) é ilustrado o desempenho dos três algoritmos, usando árvores constituintes de treinamento sem poda. Em contraste, em (b) é mostrado o desempenho com as árvores podadas.

No entanto, para corpora menores, o hiperparâmetro $\alpha$ torna-se importante. Por outro lado, na maioria dos casos, as três configurações (Rem1, Rem2 e Rem3) obtêm resultados parecidos.

\subsection{Comparação de Resultados com o Estado da Arte}

Na Tabela 5.1 é mostrado o desempenho dos modelos produzidos usando a técnica proposta neste trabalho de mestrado, PT-BN. Os modelos são chamados de PT-BN $d=\infty$ e PT-BN $d=3$. O primeiro modelo $d=\infty$, usa as dependências originais produzidas depois da remoção de ciclos explicada no capítulo anterior. Já o segundo modelo utiliza um número máximo $d=3$ de nós pais para cada nó da rede bayesiana.

É observado que o modelo com número de pais restringidos (PT-BN $d=3$ ) teve um melhor desempenho em comparação ao modelo que conserva as relações originais entre nós. Isso pode ser explicado já que, quanto maior for a quantidade de arestas, essas exigem o cálculo de um maior número de parâmetros na rede. Assim, a restrição do número de pais baseado em informação mútua permite incrementar o desempenho do modelo.

Comparando com trabalhos da literatura como Choi e Myaeng (2010) e Miwa et al. (2009b), o desempenho dos modelos PT-BN têm sido competitivos em relação aos conjuntos AImed e BioInfer. De fato, o modelo PT-BN $(d=\infty)$ foi melhor que o método 
Tabela 5.1: Comparação de métodos do estado da arte, em termos da medida F, usando cinco corpora de IPPs. Para cada corpus, foi usada a validação cruzada com 10-fold. PT-BN $d=\infty$ : Proposta sem restrição de número máximo de nós pais. PT-BN $d=3$ : Proposta com restrição de número máximo de nós pais igual a 3. CM (2010): Choi e Myaeng (2010). Miwa (2009): Miwa et al. (2009b). ma-F: Média da medida F. $\sigma_{m a-F}$ : desvio padrão da medida $\mathrm{F}$.

\begin{tabular}{lcc|cc|cc|cc}
\hline & PT-BN $d=\infty$ & \multicolumn{2}{|c|}{ PT-BN $d=3$} & \multicolumn{2}{c|}{ CM $(2010)$} & \multicolumn{2}{c}{ Miwa (2009a) } \\
\hline & ma-F & $\sigma_{m a-F}$ & ma-F & $\sigma_{m a-F}$ & ma-F & $\sigma_{m a-F}$ & ma-F & $\sigma_{m a-F}$ \\
\hline AImed & 0.69 & 0.06 & $\mathbf{0 . 7 6}$ & 0.03 & 0.67 & 0.05 & 0.61 & 0.07 \\
BioInfer & 0.72 & 0.05 & $\mathbf{0 . 7 3}$ & 0.05 & $\mathbf{0 . 7 3}$ & 0.03 & 0.68 & 0.03 \\
HPRD50 & 0.51 & 0.13 & 0.53 & 0.11 & $\mathbf{0 . 7 3}$ & 0.1 & 0.71 & 0.1 \\
IEPA & 0.68 & 0.05 & 0.67 & 0.005 & $\mathbf{0 . 7 3}$ & 0.06 & 0.72 & 0.08 \\
LLL & 0.55 & 0.02 & 0.59 & 0.19 & $\mathbf{0 . 8 2}$ & 0.1 & 0.8 & 0.14 \\
\hline
\end{tabular}

proposto em Miwa et al. (2009b) nos corpora AImed e BioInfer. No entanto, nos conjuntos pequenos, os resultados de ambos os modelos PT-BN foram os piores.

Tabela 5.2: Comparação de métodos do estado da arte, em termos da medida F, usando cross-corpora. PT-BN $d=\infty$ : Proposta sem restrição de número máximo de nós pais. PT-BN $d=3$ : Proposta com restrição de número máximo de nós pais igual a 3. CM: Choi e Myaeng (2010). Miwa (2009): Miwa et al. (2009b). Airola (2008): Airola et al. (2008). Os corpora de cada fila foram usados para treinamento, enquanto que os corpora das colunas foram usados para teste. Quando é usado o mesmo corpus tanto para treinamento quanto para teste, é reportado o resultado da validação cruzada com 10-fold.

\begin{tabular}{|c|c|c|c|c|c|c|}
\hline & Methods & BioInfer & AIMed & IEPA & HPRD50 & LLL \\
\hline \multirow[t]{4}{*}{ BioInfer } & PT-BN $d=3$ & $\underline{0.73}$ & 0.69 & 0.67 & 0.66 & 0.66 \\
\hline & CM (2010) & 0.73 & 0.65 & 0.73 & 0.72 & 0.78 \\
\hline & Miwa (2009) & $\overline{0.68}$ & 0.5 & $\overline{0.71}$ & $\overline{0.68}$ & $\overline{0.77}$ \\
\hline & Airola (2008) & 0.61 & 0.47 & 0.68 & 0.64 & 0.78 \\
\hline \multirow[t]{4}{*}{ AIMed } & PT-BN $d=3$ & $\underline{0.64}$ & $\underline{0.76}$ & 0.47 & 0.54 & 0.4 \\
\hline & CM (2010) & $\underline{0.64}$ & 0.67 & 0.59 & $\underline{0.73}$ & 0.63 \\
\hline & Miwa (2009) & 0.53 & 0.61 & $\underline{0.68}$ & 0.68 & 0.74 \\
\hline & Airola (2008) & 0.47 & 0.56 & $\overline{0.67}$ & 0.69 & $\underline{0.75}$ \\
\hline \multirow[t]{4}{*}{ IEPA } & PT-BN $d=3$ & $\underline{0.67}$ & $\underline{0.64}$ & 0.67 & 0.62 & 0.63 \\
\hline & CM (2010) & $\overline{0.66}$ & $\overline{0.58}$ & 0.73 & 0.66 & 0.78 \\
\hline & Miwa (2009) & 0.56 & 0.4 & 0.72 & 0.67 & $\underline{0.83}$ \\
\hline & Airola (2008) & 0.52 & 0.39 & $\underline{0.75}$ & $\underline{0.68}$ & $\overline{0.78}$ \\
\hline \multirow[t]{4}{*}{ HPRD50 } & PT-BN $d=3$ & 0.65 & 0.67 & $\overline{0.54}$ & $\overline{0.53}$ & 0.57 \\
\hline & CM (2010) & $\underline{0.66}$ & $\overline{0.63}$ & $\underline{0.69}$ & $\underline{0.73}$ & $\underline{0.74}$ \\
\hline & Miwa (2009) & 0.49 & 0.44 & 0.68 & 0.71 & 0.72 \\
\hline & Airola (2008) & 0.43 & 0.42 & 0.65 & 0.63 & 0.68 \\
\hline \multirow[t]{4}{*}{ LLL } & $\mathrm{PT}-\mathrm{BN} d=3$ & 0.59 & 0.44 & 0.52 & 0.55 & 0.59 \\
\hline & CM (2010) & $\underline{0.64}$ & $\underline{0.56}$ & $\underline{0.71}$ & $\underline{0.69}$ & 0.82 \\
\hline & Miwa (2009) & $\overline{0.49}$ & $\overline{0.39}$ & $\overline{0.66}$ & $\overline{0.64}$ & $\underline{0.83}$ \\
\hline & Airola (2008) & 0.43 & 0.33 & 0.65 & 0.6 & 0.77 \\
\hline
\end{tabular}


Na Tabela 5.2 são mostrados os desempenhos de vários métodos do estado da arte, os quais são baseados em kernels. Neste caso, é usado o critério de cross-corpora para avaliar os métodos, onde um corpus é usado para treinamento e outro para teste. Nessa tabela, os resultados do uso de um mesmo corpus para treinamento e teste é obtido por validação cruzada de 10-fold.

Observa-se que a tendência dos resultados é parecida com os resultados mostrados na Tabela 5.1. O PT-BN apresenta melhores resultados quando é usado em conjuntos grandes. Por outro lado, em conjuntos pequenos, o resultado é menor em comparação com os outros. Isso pode ter relação com os números de nós e o número de instâncias usadas. Isto é, apesar dos conjuntos pequenos apresentar um número substancialmente menor de instâncias para construir uma rede bayesiana, esses conjuntos têm uma quantidade similar de número de nós em comparação com os conjuntos grandes. Assim, os resultados sugerem que a complexidade de uma rede bayesiana pode afetar negativamente na classificação, já que para conjuntos pequenos, o número de parâmetros, nós e arestas da rede bayesiana continua sendo alto. 


\section{Conclusões}

este trabalho de mestrado tem sido abordado o estudo de redes bayesianas para a extração de IPPs a partir de sentenças de texto. Dado que o processo de construção de uma rede bayesiana influência no desempenho final, este trabalho aborda as duas fases da construção de uma rede bayesiana: (1) construção da estrutura - $\mathcal{G}$ e (2) estimação de parâmetros $-\Theta$. Essas fases são desenvolvidas pela técnica chamada PT-BN. Um aspecto importante de usar redes bayesianas na extração de IPPs, é estabelecer um compromisso entre a construção da rede e as informações linguísticas subjacentes aos textos. Assim, a principal contribuição deste trabalho é o desenvolvimento de uma técnica, PT-BN, para a extração de IPPs, usando redes bayesianas com árvores constituintes.

Na revisão bibliográfica deste trabalho, foram encontrados dois trabalhos prévios que tratam a extração de IPPs usando redes bayesianas. Porém, ambos os trabalhos usam informações lexicais, os quais não são suficientes para extrair adequadamente as IPPs. Em contraste, o método PT-BN construi redes bayesianas usando árvores constiuintes, onde uma árvore constituinte é a representação da gramática subjacente de uma sentença de texto.

A técnica foi testada usando corpora padrões na extração de IPPs, facilitando uma comparação com métodos de trabalhos prévios. Em particular, os experimentos demonstraram o bom desempenho da técnica PT-BN em corpora maiores, isto é, corpora com mais de 5000 instâncias. Assim, é atingido o objetivo de dar importância ao compromisso entre as informações linguísticas e a construção de uma rede bayesiana. Na Seção 6.1 são 
descritas em detalhe as contribuições deste trabalho de mestrado. Finalmente, na Seção 6.2 são descritos trabalhos futuros.

\subsection{Contribuições}

,O método PT-BN obteve 0.764 e 0.728 , em termos da medida F, nos conjuntos AImed e BioInfer respectivamente, tendo um alto desempenho em comparação a métodos de extração de IPPs do estado da arte.

Na construção da estrutura, foi proposto o uso de árvores constituintes para criar um grafo, usando POS tags como nós. As ligações entre POS tags foram atribuídas de acordo com as ligações dos mesmos POS tags nas árvores constituintes das sentenças de treinamento. Em suma, foi proposto um algoritmo de remoção de ciclos para obter um grafo acíclico dirigido que seja a base da rede bayesiana. Esse algoritmo usa várias configurações pelo que é possível remover ciclos de três maneiras diferentes. Nos experimentos, foi determinado que a diferença entre cada configuração não tem uma grande influência no desempenho final da rede bayesiana.

$\mathrm{Na}$ fase final da construção da rede, foi proposto um algoritmo de complexidade linear para adicionar um nó classe na rede bayesiana. Para isso foram usados medidas de qualidade que permitem avaliar as ligações desse nó classe com os POS tags. Foram usadas 6 medidas de qualidade. Em geral, em conjuntos grandes como AImed ou BioInfer, as medidas baseadas em entropia tais como AIC e BIC, atingiram apenas 0.65 e 0.63 respectivamente, em termos da medida F. Em contraste, as medidas baseadas em Bayes tais como "Bayes" e K2, atingiram aproximadamente 0.73 de medida F. Um caso parecido acontece usando o conjunto IEPA, que tem quase 900 instâncias. Por outro lado, nos conjuntos pequenos (menos de 500 instâncias), os melhores resultados são obtidos pelas medidas baseadas em entropia. Isso pode ser explicado devido ao fato que essas medidas penalizam as redes bayesianas complexas. Isto é, redes bayesianas com um grande número de atributos e aresta em comparação com o número de instâncias de treinamento. Assim, as medidas baseadas em entropia preferem a eleição de estruturas de redes bayesianas menos complexas, o que favorece a construção de uma rede bayesiana a partir de conjuntos pequenos.

Na estimação de parâmetros, em geral, o uso da estimação Bayesiana baseada em hiperparâmetros dirichlet $(\alpha)$ permitiu aos modelos de redes bayesianas atingir melhores resultados em comparação com a estimação MLE. Em particular, o uso de hiperparâmetros $\alpha \geq 40$ permitiu melhorar os desempenhos dos modelos nos conjuntos pequenos. Porém, nos conjuntos grandes, o desempenho dos modelos usando as estimações MLE e Bayes são semelhantes. 
Apesar do método obter bons resultados em conjuntos como AImed e BioInfer, o mesmo não consegue o mesmo desempenho em conjuntos pequenos tais como IEPA, LLL e HPRD50. Em suma, o método tem uma dependência com relação ao parser usado para obter a árvore constituinte a partir de uma sentença de texto. A precisão de um parser tem uma influência direta sobre o desempenho da extração final de IPPs. Porém, a informação fornecida pelos parsers tem demonstrado ser importantes no tratamento do problema de extração de IPPs.

Como resultado deste trabalho de mestrado, foi publicado um artigo (ShiguiharaJuárez e de Andrade Lopes, 2013) intitulado: Learning Bayesian Network using Parse Trees for Extraction of Protein-Protein Interaction. O trabalho foi publicado no congresso denominado: Conference on Intelligent Text Processing and Computational Linguistics (CICLing).

\subsection{Trabalhos Futuros}

Algoritmos de aprendizado de redes bayesianas baseados em restrições ainda não foram explorados concretamente na extração de IPPs. A vantagem desses algoritmos é que poderiam permitir a seleção de dependências entre POS tags. Com isso, a remoção de ciclos poderia ser guiada por essa seleção de dependências com base em medidas como: informação mútua ou desvio padrão. Isso poderia melhorar os desempenhos na construção das redes bayesianas usando árvores constituintes.

O algoritmo proposto usa apenas um operador para gerar diferentes modelos de redes bayesianas. Esse operador é a adição. Porém, outros operadores poderiam ser usados tais como "a mudança de direção de uma aresta" e a "remoção de uma aresta". 


\section{Referências Bibliográficas}

Airola, A.; Pyysalo, S.; Buörne, J.; Pahikkala, T.; Ginter, F.; Salakoski, T. A graph kernel for protein-protein interaction extraction. In: Proceedings of the Workshop on Current Trends in Biomedical Natural Language Processing, BioNLP '08, Stroudsburg, PA, USA: Association for Computational Linguistics, 2008, p. 1-9 (BioNLP'08, ).

Akaike, H. A new look at the statistical model identification. Automatic Control, IEEE Transactions on, v. 19, n. 6, p. 716-723, 1974.

AlPAYDIN, E. Introduction to machine learning (adaptive computation and machine learning). The MIT Press, 2004.

BARBER, D. Bayesian reasoning and machine learning. New York, NY, USA: Cambridge University Press, 2012.

Bernardi, L.; Ratsch, E.; Kania, R.; Saric, J.; Rojas, I.; Park, J.; Schatz, B.; Blaschke, C.; Valencia, A.; Nedellec, C. Mining information for functional genomics. Intelligent Systems, IEEE, v. 17, n. 3, p. $66-80,2002$.

Blaschke, C.; Hoffmann, R.; Carlos Oliveros, J.; Valencia, A. Extracting information automatically from biological literature. Comparative and Functional Genomics, v. 2, n. 5, p. 310-313, 2001.

http://dx.doi.org/10.1002/cfg.102

BOUCKAERT Bayesian belief networks: From construction to inference remco ronaldus bouckaert. Tese de Doutoramento, 1995.

Browne, F.; Zheng, H.; Wang, H.; Azuaje, F. From experimental approaches to computational techniques: a review on the prediction of protein-protein interactions. Adv. in Artif. Intell., v. 2010, p. 7:5-7:5, 2010. 
Bui, Q.-C.; Sloot, P. M. A. Extracting biological events from text using simple syntactic patterns. In: Proceedings of the BioNLP Shared Task 2011 Workshop, BioNLP Shared Task '11, Stroudsburg, PA, USA: Association for Computational Linguistics, 2011, p. 143-146 (BioNLP Shared Task '11, ).

http: //dl . acm.org/citation. cfm?id=2107691 . 2107711

Bui, Q.-C. C.; Katrenko, S.; Sloot, P. M. A hybrid approach to extract proteinprotein interactions. Bioinformatics (Oxford, England), v. 27, n. 2, p. 259-265, 2011.

Bunescu; Mooney, R. Subsequence kernels for relation extraction. In: Y. WeIss, B. S.; Platt, J., eds. Advances in Neural Information Processing Systems 18, Cambridge, MA: MIT Press, 2005, p. 171-178.

Bunescu, R.; Ge, R.; Kate, R. J.; Marcotte, E. M.; Mooney, R. J.; Ramani, A. K.; Wong, Y. W. Comparative experiments on learning information extractors for proteins and their interactions. Artif. Intell. Med., v. 33, n. 2, p. 139-155, 2005.

Buntine, W. Theory refinement on bayesian networks. Morgan Kaufmann, 1991, p. $52-60$.

Cannataro, M.; Guzzi, P. H.; Veltri, P. Protein-to-protein interactions: Technologies, databases, and algorithms. ACM Comput. Surv., v. 43, p. 1:1-1:36, 2010.

Charniak, E.; Johnson, M. Coarse-to-fine n-best parsing and maxent discriminative reranking. In: Proceedings of the 43rd Annual Meeting on Association for Computational Linguistics, ACL '05, Stroudsburg, PA, USA: Association for Computational Linguistics, 2005, p. 173-180 (ACL '05, ).

http://dx.doi.org/10.3115/1219840.1219862

Choi, S.-P.; Myaeng, S.-H. Simplicity is better: revisiting single kernel ppi extraction. In: Proceedings of the 23rd International Conference on Computational Linguistics, COLING '10, Stroudsburg, PA, USA: Association for Computational Linguistics, 2010, p. 206-214 (COLING' 10, ).

Chowdhary, R.; Zhang, J.; Liu, J. S. Bayesian inference of protein-protein interactions from biological literature. Bioinformatics (Oxford, England), v. 25, n. 12, p. $1536-1542,2009$.

Chowdhury, F. M.; Lavelli, A.; Moschitti, A. A study on dependency tree kernels for automatic extraction of protein-protein interaction. In: Proceedings of BioNLP 2011 Workshop, BioNLP '11, Stroudsburg, PA, USA: Association for Computational Linguistics, 2011, p. 124-133 (BioNLP' '11, ). 
Cooper, G. F.; Herskovits, E. A bayesian method for the induction of probabilistic networks from data. Mach. Learn., v. 9, p. 309-347, 1992.

Cristianini, N.; Hahn, M. W. Introduction to computational genomics: A case studies approach. New York, NY, USA: Cambridge University Press, 2007.

Culotta, A.; Sorensen, J. Dependency tree kernels for relation extraction. In: Proceedings of the 42nd Annual Meeting on Association for Computational Linguistics, ACL '04, Stroudsburg, PA, USA: Association for Computational Linguistics, 2004 (ACL '04, ).

http://dx.doi.org/10.3115/1218955.1219009

Daraselia, N.; Yuryev, A.; Egorov, S.; Novichkova, S.; Nikitin, E.; Mazo, I. Extracting human protein interactions from medline using a full-sentence parser. Bioinformatics, v. 20, p. 604-611, 2004.

Ding, J.; Berleant, D.; Nettleton, D.; Wurtele, E. S. Mining medline: Abstracts, sentences, or phrases? In: Pacific Symposium on Biocomputing'02, 2002, p. $326-337$.

Donaldson, I.; Martin, J.; Bruijn, B.; Wolting, C.; Lay, V.; Tuekam, B.; Zhang, S.; Baskin, B.; Bader, G.; Michalickova, K.; Pawson, T.; Hogue, C. Prebind and textomy - mining the biomedical literature for protein-protein interactions using a support vector machine. BMC Bioinformatics, v. 4, n. 1, p. 11, 2003.

ERKAN, G. Semi-supervised classification for extracting protein interaction sentences using dependency parsing. In: Proceedings of the Joint Conference on Empirical Methods in Natural Language Processing and Computational Natural Language Learning (EMNLP-CoNLL), 2007, p. 228-237.

Fayruzov, T.; De Cock, M.; Cornelis, C.; Hoste, V. Linguistic feature analysis for protein interaction extraction. BMC Bioinformatics, v. 10, n. 1, p. 374, 2009.

Feldman, R.; SAnger, J. The text mining handbook: Advanced approaches in analyzing unstructured data. Cambridge University Press, 2006.

Fundel, K.; KÜFfneR, R.; Zimmer, R. Relex-relation extraction using dependency parse trees. Bioinformatics, v. 23, n. 3, p. 365-371, 2007.

Hakenberg, J.; Leaman, R.; Ha Vo, N.; Jonnalagadda, S.; Sullivan, R.; MilLer, C.; TARI, L.; Baral, C.; Gonzalez, G. Efficient extraction of protein-protein interactions from full-text articles. IEEE/ACM Trans. Comput. Biol. Bioinformatics, v. 7, p. 481-494, 2010. 
Heckerman, D.; Chickering, D. M. Learning bayesian networks: The combination of knowledge and statistical data. In: Machine Learning, 1995, p. 20-197.

Higgs, P. G.; Attwood, T. K. Bioinformatics and molecular evolution. WileyBlackwell, 2005.

Huang, M.; Zhu, X.; Hao, Y.; Payan, D. G.; Qu, K.; Li, M. Discovering patterns to extract protein-protein interactions from full texts. Bioinformatics, v. 20, n. 18, p. 3604-3612, 2004.

http://dx.doi.org/10.1093/bioinformatics/bth451

JurAfsky, D.; Martin, J. H. Speech and language processing (2nd edition) (prentice hall series in artificial intelligence). 2 ed. Prentice Hall, 2008.

Kim, S.; Yoon, J.; YAng, J.; PARK, S. Walk-weighted subsequence kernels for protein-protein interaction extraction. BMC Bioinformatics, v. 11, n. 1, p. 107, 2010. http://www . biomedcentral.com/1471-2105/11/107

Kolchinsky, A.; Abi-Haidar, A.; Kaur, J.; Hamed, A. A.; Rocha, L. M. Classification of protein-protein interaction full-text documents using text and citation network features. IEEE/ACM Trans. Comput. Biol. Bioinformatics, v. 7, p. 400-411, 2010 .

Koller, D.; Friedman, N. Probabilistic graphical models: Principles and techniques. Adaptive Computation and Machine Learning Series. MIT Press, 2009.

Konchady, M. Text mining application programming. Boston, Mass: Charles River Media, 2006.

KorB, K.; Nicholson, A. E. Bayesian artificial intelligence. Boca Raton, FL, USA: CRC Press, Inc., 2003.

LAM, W.; BACChus, F. Learning bayesian belief networks: An approach based on the mdl principle. Computational Intelligence, v. 10, p. 269-293, 1994.

Li, L.; HuAng, D.; WAng, M. Protein-protein interaction extraction based on ensemble kernel model and active learning strategy. In: Natural Language Processing andKnowledge Engineering (NLP-KE), 2011 7th International Conference on, 2011a, p. $9-14$.

LI, Y.; Hu, X.; Lin, H.; YANG, Z. A framework for semisupervised feature generation and its applications in biomedical literature mining. IEEE/ACM Trans. Comput. Biol. Bioinformatics, v. 8, n. 2, p. 294-307, 2011b.

http://dx.doi.org/10.1109/TCBB.2010.99 
Liu, B.; Qian, L.; Wang, H.; Zhou, G. Dependency-driven feature-based learning for extracting protein-protein interactions from biomedical text. In: Proceedings of the 23rd International Conference on Computational Linguistics: Posters, COLING '10, Stroudsburg, PA, USA: Association for Computational Linguistics, 2010, p. 757-765 (COLING'10, ).

Manning, C. D.; Schuetze, H. Foundations of statistical natural language processing. 1 ed. The MIT Press, 1999.

Margaritis, D.; Thrun, S.; Faloutsos, C.; Moore, A. W.; Cooper, G. F. Learning bayesian network model structure from data. Tese de Doutoramento, 2003.

Miwa, M.; Sætre, R.; Miyao, Y.; Ohta, T.; Tsujin, J. Combining Multiple Layers of Syntactic Information for Protein-Protein Interaction Extraction. In: SALAKOsKI, T.; Schuhmann, D. R.; Pyysalo, S., eds. Proceedings of the Third International Symposium on Semantic Mining in Biomedicine (SMBM 2008), Turku, Finland, Turku Centre for Computer Science (TUCS), 2008, p. 101-108.

Miwa, M.; Saetre, R.; Miyao, Y.; Tsujiı, J. Protein-protein interaction extraction by leveraging multiple kernels and parsers. International Journal of Medical Informatics, v. 78, n. 12, p. e39-e46, 2009a.

Miwa, M.; Saetre, R.; Miyao, Y.; TsujiI, J. A rich feature vector for proteinprotein interaction extraction from multiple corpora. In: Proceedings of the 2009 Conference on Empirical Methods in Natural Language Processing: Volume 1, EMNLP '09, Stroudsburg, PA, USA: Association for Computational Linguistics, 2009b, p. 121130 (EMNLP'O9, ).

Miwa, M.; Sætre, R.; Mryao, Y.; Tsujil, J. Entity-focused sentence simplification for relation extraction. In: Proceedings of the 23rd International Conference on Computational Linguistics, COLING '10, Stroudsburg, PA, USA: Association for Computational Linguistics, 2010, p. 788-796 (COLING '10, ).

Miyao, Y.; Sagae, K.; Saetre, R.; Matsuzaki, T.; Tsujiı, J. Evaluating contributions of natural language parsers to protein-protein interaction extraction. Bioinformatics, v. 25, p. 394-400, 2009.

Moens, M. F. Information extraction: Algorithms and prospects in a retrieval context. The Information Retrieval Series. New York: Springer, 2006.

Murphy, K. Machine learning: A probabilistic perspective. Adaptive Computation and Machine Learning Series. MIT Press, 2012. 
NG, S.-K.; Wong, M. Toward routine automatic pathway discovery from on-line scientific text abstracts. Genome Informatics, v. 10, p. 104-112, 1999.

NÉDELLEC, C. Learning language in logic - genic interaction extraction challenge. In: Proceedings of the Learning Language in Logic 2005 Workshop at the International Conference on Machine Learning, 2005.

PARK, J. C.; Kim, H. S.; Kim, J. J. Bidirectional incremental parsing for automatic pathway identification with combinatory categorial grammar. In: Pacific Symposium On Biocomputing, 2001, p. 396-407.

PEARL, J. Probabilistic reasoning in intelligent systems: networks of plausible inference. San Francisco, CA, USA: Morgan Kaufmann Publishers Inc., 1988.

Pernkopf, F.; Bilmes, J. A. Efficient heuristics for discriminative structure learning of bayesian network classifiers. J. Mach. Learn. Res., v. 99, p. 2323-2360, 2010.

Pyysalo, S.; Airola, A.; Heimonen, J.; Buorne, J.; Ginter, F.; Salakoski, T. Comparative analysis of five protein-protein interaction corpora. BMC Bioinformatics, v. 9, p. S6, 2008a.

Pyysalo, S.; Ginter, F.; Heimonen, J.; Buorne, J.; Boberg, J.; Jarvinen, J.; Salakoski, T. Bioinfer: a corpus for information extraction in the biomedical domain. BMC Bioinformatics, v. 8, n. 1, p. 50, 2007.

Pyysalo, S.; Sætre, R.; TsujiI, J.; SAlakoski, T. Why biomedical relation extraction results are incomparable and what to do about it. In: Proceedings of the Third International Symposium on Semantic Mining in Biomedicine (SMBM 2008), 2008b, p. 149-152.

Qian, L.; Zhou, G. Tree kernel-based protein-protein interaction extraction from biomedical literature. J. of Biomedical Informatics, v. 45, n. 3, p. 535-543, 2012. http://dx.doi.org/10.1016/j.jbi.2012.02.004

Qian, W.; Fu, C.; Cheng, H. Semi-supervised method for extraction of proteinprotein interactions using hybrid model. In: Intelligent System Design and Engineering Applications (ISDEA), 2013 Third International Conference on, 2013, p. 1268 -1271.

Rosario, B.; Hearst, M. A. Multi-way relation classification: application to proteinprotein interactions. In: Proceedings of the conference on Human Language Technology and Empirical Methods in Natural Language Processing, HLT '05, Stroudsburg, PA, USA: Association for Computational Linguistics, 2005, p. 732-739 (HLT '05, ). http://dx.doi.org/10.3115/1220575.1220667 
Russell, S. J.; Norvig, P. Artificial intelligence - a modern approach (3. internat. ed.). Pearson Education, I-XVIII, 1-1132 p., 2010.

Sætre, R.; Sagae, K.; Tsujil, J. Syntactic features for protein-protein interaction extraction. In: BAKer, C. J. O.; Su, J., eds. Short Paper Proceedings of the 2nd International Symposium on Languages in Biology and Medicine (LBM 2007), Singapore: CEUR Workshop Proceedings (CEUR-WS.org), 2007, p. 6.1-6.14.

Saetre, R.; Yoshida, K.; Miwa, M.; Matsuzaki, T.; Kano, Y.; Tsujil, J. Extracting protein interactions from text with the unified akanere event extraction system. IEEE/ACM Trans. Comput. Biol. Bioinformatics, v. 7, p. 442-453, 2010.

Schneider, G.; Clematide, S.; Rinaldi, F. Detection of interaction articles and experimental methods in biomedical literature. BMC Bioinformatics, v. 12, n. Suppl 8, p. S13, 2011.

Schwarz, G. Estimating the dimension of a model. Annals of Statistics, v. 6, p. 461464, 1978.

Sedgewick, R.; Wayne, K. Algorithms, 4th edition. Addison-Wesley, I-XII, 1-955 p., 2011.

Shiguihara-Juárez, P.; Andrade Lopes, A. Learning bayesian network using parse trees for extraction of protein-protein interaction. In: Proceedings of the 14th international conference on Computational Linguistics and Intelligent Text Processing, CICLing'14, Berlin, Heidelberg: Springer-Verlag, 2013 (CICLing'14, ).

Simpson, M. S.; Demner-Fushman, D. Biomedical text mining: A survey of recent progress. In: Aggarwal, C. C.; Zhai, C., eds. Mining Text Data, Springer US, p. 465-517, 2012.

Stapley, B. J.; Benoit, G. Biobibliometrics: information retrieval and visualization from co-occurrences of gene names in medline abstracts. Pacific Symposium On Biocomputing, v. 537, p. 526-537, 2000.

TARDY, C. The role of english in scientific communication: lingua franca or tyrannosaurus rex? Journal of English for Academic Purposes, v. 3, n. 3, p. 247 - 269, 2004.

Tsamardinos, I.; Aliferis, C. F.; Statnikov, E. Algorithms for Large Scale Markov Blanket Discovery. In: The 16th International FLAIRS Conference, St, 2003, p. $376-380$.

Wong, L. Pies: A protein interaction extraction system. In: In the Proceedings of the Pacific Symposium on Biocomputing, 2001, p. 520-531. 
Yakushisi, A.; Miyao, Y.; Ohta, T.; Tateisi, Y.; Tsuji, J. Automatic construction of predicate-argument structure patterns for biomedical information extraction. In: Proceedings of the 2006 Conference on Empirical Methods in Natural Language Processing, EMNLP '06, Stroudsburg, PA, USA: Association for Computational Linguistics, 2006, p. 284-292 (EMNLP '06, ).

http://dl.acm.org/citation.cfm?id=1610075.1610116

YAnG, Z.; ZhaO, Z.; Li, Y.; Hu, Y.; Lin, H. Ppiextractor: A protein-protein interaction extractor for biom x00e9; dical literature. In: Bioinformatics and Biomedicine (BIBM), 2012 IEEE International Conference on, 2012, p. 1-6.

Zhang, H.; HuAng, M.; Zhu, X. Protein-protein interaction extraction from bioliterature with compact features and data sampling strategy. In: Biomedical Engineering and Informatics (BMEI), 2011 4th International Conference on, 2011, p. $1767-1771$.

Zhang, Y.; Lin, H.; YAng, Z.; WAng, J.; Li, Y. Hash subgraph pairwise kernel for protein-protein interaction extraction. IEEE/ACM Trans. Comput. Biol. Bioinformatics, v. 9, n. 4, p. 1190-1202, 2012. 


\section{Tabelas de crescimento da quantidade de textos biomédicos}

ste apêndice contém tabelas correspondentes a um estudo de crescimento da quantidade de textos biomédicos presentados como artigos científicos no período entre 1984 a 2012. Esses dados coletados são aproveitados como dados referenciais na presente monografia. Cabe ressaltar que tal estimação é uma extensão da revisão (até o ano 2002) feita por Higgs e Attwood (2005) e são considerados os textos biomédicos relacionados a cinco tópicos de pesquisa: Proteômica, Genômica, Microarranjos, Bioinformática e Filogenética. Cada tópico foi associado com palavraschave: "proteomics", "genomics", "microarray", "bioinformatics" e "phylogenetic" respectivamente. Posteriormente, as palavras-chave foram usadas para encontrar a quantidade de artigos relacionados empregando o buscador ISI Science Citation Index, disponível em http: //apps. webofknowledge.com/.

Na Tabela A.1 são apresentadas as quantidades de artigos publicados por ano e segundo cada tópico. Após isso, na Tabela A.2 são apresentadas as distribuições anuais dos tópicos a partir das suas frequências (mostradas na Tabela A.1). Em seguida, a Tabela A.3 apresenta o período médio estimado para dobrar o número de publicações segundo o tópico. Por fim, na Figura 1.1 é ilustrada a sumarização de informações das tabelas anteriores. 
Tabela A.1: Frequência de artigos publicados no período entre 1984 a 2012.

\begin{tabular}{|c|c|c|c|c|c|}
\hline Ano & Proteômica & Genômica & Microarranjos & Bioinformática & Filogenética \\
\hline 1984 & 0 & 0 & 2 & 0 & 710 \\
\hline 1985 & 0 & 0 & 3 & 0 & 848 \\
\hline 1986 & 0 & 0 & 0 & 0 & 992 \\
\hline 1987 & 0 & 0 & 0 & 0 & 943 \\
\hline 1988 & 0 & 1 & 0 & 0 & 994 \\
\hline 1989 & 0 & 1 & 1 & 1 & 1,006 \\
\hline 1990 & 0 & 2 & 2 & 1 & 1,113 \\
\hline 1991 & 0 & 7 & 6 & 1 & 1,548 \\
\hline 1992 & 0 & 7 & 5 & 0 & 1,726 \\
\hline 1993 & 0 & 18 & 4 & 4 & 2,050 \\
\hline 1994 & 0 & 14 & 12 & 8 & 2,273 \\
\hline 1995 & 0 & 32 & 10 & 15 & 2,661 \\
\hline 1996 & 0 & 69 & 18 & 32 & 2,966 \\
\hline 1997 & 2 & 156 & 47 & 55 & 4,551 \\
\hline 1998 & 33 & 307 & 101 & 108 & 7,289 \\
\hline 1999 & 97 & 484 & 331 & 142 & 8,266 \\
\hline 2000 & 333 & 931 & 809 & 310 & 8,937 \\
\hline 2001 & 643 & 1,292 & 2,526 & 423 & 9,964 \\
\hline 2002 & 1,086 & 1,743 & 6,243 & 642 & 10,571 \\
\hline 2003 & 1,418 & 2,010 & 8,212 & 871 & 11,698 \\
\hline 2004 & 2,134 & 4,274 & 10,644 & 1,210 & 13,835 \\
\hline 2005 & 4,149 & 4,675 & 12,793 & 1,390 & 14,113 \\
\hline 2006 & 4,801 & 4,697 & 13,959 & 1,542 & 15,654 \\
\hline 2007 & 5,076 & 5,006 & 14,708 & 1,721 & 17,395 \\
\hline 2008 & 5,490 & 5,289 & 15,114 & 1,787 & 18,063 \\
\hline 2009 & 5,966 & 5,337 & 15,299 & 2,009 & 18,849 \\
\hline 2010 & 6,744 & 5,611 & 15,179 & 2,001 & 20,008 \\
\hline 2011 & 6,956 & 5,837 & 14,640 & 2,175 & 20,962 \\
\hline 2012 & 7,256 & 5,772 & 14,192 & 2,251 & 20,215 \\
\hline
\end{tabular}


Tabela A.2: Distribuição de artigos publicados no período entre 1984 a 2012.

\begin{tabular}{|c|c|c|c|c|c|}
\hline Ano & Proteômica & Genômica & Microarranjos & Bioinformática & Filogenética \\
\hline 1984 & 0 & 0 & 2 & 0 & 710 \\
\hline 1985 & 0 & 0 & 5 & 0 & 1,558 \\
\hline 1986 & 0 & 0 & 5 & 0 & 2,550 \\
\hline 1987 & 0 & 0 & 5 & 0 & 3,493 \\
\hline 1988 & 0 & 1 & 5 & 0 & 4,487 \\
\hline 1989 & 0 & 2 & 6 & 1 & 5,493 \\
\hline 1990 & 0 & 4 & 8 & 2 & 6,606 \\
\hline 1991 & 0 & 11 & 14 & 3 & 8,154 \\
\hline 1992 & 0 & 18 & 19 & 3 & 9,880 \\
\hline 1993 & 0 & 36 & 23 & 7 & 11,930 \\
\hline 1994 & 0 & 50 & 35 & 15 & 14,203 \\
\hline 1995 & 0 & 82 & 45 & 30 & 16,864 \\
\hline 1996 & 0 & 151 & 63 & 62 & 19,830 \\
\hline 1997 & 2 & 307 & 110 & 117 & 24,381 \\
\hline 1998 & 35 & 614 & 211 & 225 & 31,670 \\
\hline 1999 & 132 & 1,098 & 542 & 367 & 39,936 \\
\hline 2000 & 465 & 2,029 & 1,351 & 677 & 48,873 \\
\hline 2001 & 1,108 & 3,321 & 3,877 & 1,100 & 58,837 \\
\hline 2002 & 2,194 & 5,064 & 10,120 & 1,742 & 69,408 \\
\hline 2003 & 3,612 & 7,074 & 18,332 & 2,613 & 81,106 \\
\hline 2004 & 5,746 & 11,348 & 28,976 & 3,823 & 94,941 \\
\hline 2005 & 9,895 & 16,023 & 41,769 & 5,213 & 109,054 \\
\hline 2006 & 14,696 & 20,720 & 55,728 & 6,755 & 124,708 \\
\hline 2007 & 19,772 & 25,726 & 70,436 & 8,476 & 142,103 \\
\hline 2008 & 25,262 & 31,015 & 85,550 & 10,263 & 160,166 \\
\hline 2009 & 31,228 & 36,352 & 100,849 & 12,272 & 179,015 \\
\hline 2010 & 37,972 & 41,963 & 116,028 & 14,273 & 199,023 \\
\hline 2011 & 44,928 & 47,800 & 130,668 & 16,448 & 219,985 \\
\hline 2012 & 52,184 & 53,572 & 144,860 & 18,699 & 240,200 \\
\hline
\end{tabular}

Tabela A.3: Taxa média em anos para dobrar o número de artigos publicados.

\begin{tabular}{crrrrr}
\hline Até o ano & Proteômica & Genômica & Microarranjos & Bioinformática & Filogenética \\
\hline 2012 & 1.18 & 1.3 & 1.4 & 1.34 & 1.64 \\
\hline
\end{tabular}




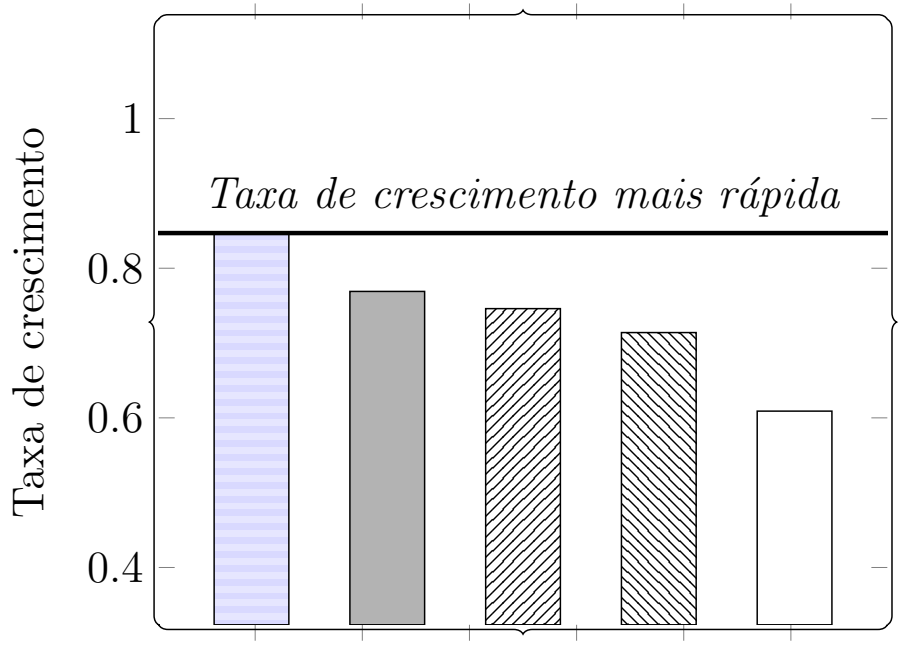

Tópicos biomédicos

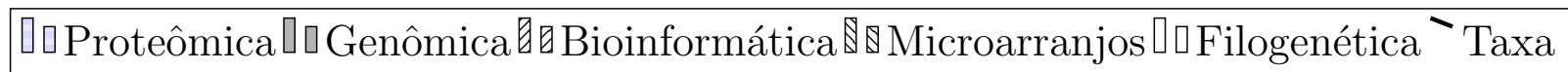


Símbolos e Autores

40

$$
P^{*}
$$
.40

$\mathcal{D}$

Airola et al.

$4,19,20$

Barber.

Bernardi et al.

Browne et al.

Bunescu et al. 19, 20

Cannataro et al.

Charniak e Johnson.

Choi e Myaeng . . . 4, 19, 20, 59, 60, 71

Chowdhary et al. $2,4,21$

Culotta e Sorensen 27

Daraselia et al.

Erkan 19,20

Fayruzov et al. $6,12,22,48$

Feldman e Sanger

Hakenberg et al.

Heckerman e Chickering

Huang et al.

Jurafsky e Martin $2,13,47,60$

Koller e Friedman . 5, 28, 32, 40, 42

Li et al.

Li et al. . 20

Miwa et al. 19, 20
Miwa et al.............. 6, 71, 72

Miyao et al............12, 14, 15, 19, 20

Murphy ..................... 4,16

Pyysalo et al................. 4, 16, 20

Qian et al.......................20

Rosario e Hearst . . . . . . . . . . . . . . 2, 22

Sedgewick e Wayne...................51

Shiguihara-Juárez e de Andrade Lopes . 75

Simpson e Demner-Fushman.......... 2-4

Stapley e Benoit...................... 3

Tardy............................

Yakushiji et al................. 19, 20

Yang et al...................... 19, 20

Zhang et al................ 13, 19, 20

Airola et al. ................. 4, 5, 10

Alpaydin ......................... 31

Blaschke et al. ................ 3, 18

Bouckaert ........................ 35

Bui e Sloot ....................... 4

Bui et al.................. 5, 18, 20

Buntine ......................... 37

Choi e Myaeng ............... 4, 5, 10

Chowdhary et al............14, 21, 22

Chowdhary et al.Bunescu e MooneyRosario e Hearst .................... 12

Chowdhury et al................. 5, 6

Cooper e Herskovits..........31, 37, 38 
Cristianini e Hahn

Daraselia et al.

Donaldson et al.

Erkan.

Heckerman e Chickering

Kolchinsky et al.

Koller e Friedman

Korb e Nicholson

Lam e Bacchus . .

Li et al.

Liu et al.

Margaritis et al.

Miwa et al.

Ng e Wong

Russell e Norvig.

Park et al.

$5,30,35$

Pearl

Pernkopf e Bilmes

Pyysalo et al.

Pyysalo et al. .

Qian e Zhou

Qian et al.

Rosario e Hearst

Saetre et al.

Schneider et al.

Stapley e Benoit

Tsamardinos et al.

Wong 3,18

Zhang et al. .. 14

Akaike. .37

Konchady 13

Manning e Schuetze ... 25

Miwa et al. 10

Moens .18

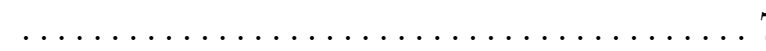

kernels ........................ 4

naive Bayes.......................5

templates
$31 \mathbf{A}$

aprendizado de estrutura de rede bayesiana 35

aprendizado de estrutura de rede bayesiana baseado em pontuação .35

aprendizado de estrutura de rede bayesiana baseado em restrições ...... 35, 38 Aprendizado de Máquina..........25, 35 aprendizado de máquina. $.4,10$ aprendizado de máquina supervisionado 4

aprendizado de rede bayesiana ........ 30

atributo ........................ 32

B

busca subida de encosta ............. 21

C

classificação......................... 3

cobertor de Markov .............38, 40

conjunto de dados de treinamento ...21, 35

conjunto de teste .................. 16

conjunto de treinamento .............. 16

coocorrência .................... 3, 25

corpora.........................16

\section{D}

distribuição de probabilidade condicional local.

E

estrutura de rede bayesiana ....... 31, 37

extração de informação ............... 2

extração de IPPs................... 1, 2

extração de relação ................... 3

F

f-measure.......................25

\section{I}

independência condicional .......... 40

instâncias ......................11, 16 
interação proteína-proteína

$1,5 \mathrm{~V}$

bancos de ...

. 1 variáveis aleatórias .31

IPP

$10,21,25$

variáveis aleatórias binárias . .

K

variável aleatória ..................... 27

kernel

M

medida de qualidade................ 37

medida F .......................... 4

MLE ............................ 41

modelo de rede bayesiana ......... 31, 32

modelo gráfico ..................... 31

$\mathrm{O}$

ocultamento de nomes de proteínas .... 10

$\mathbf{P}$

palavras ...................... 6

parâmetro.................... 32, 35, 36

parâmetros independentes ........... 32

PP candidato .................... 11

PPs candidatas ...................... 11

precisão........................ 3, 24

probabilidade a priori .............. 30

probabilidade a posteriori ..... i, 30, 34, 42

probabilidade a priori......i, 30, 32, 36, 42

probabilidade condicional........30, 32, 36

probabilidade condicional local..........32

problema de classificação binário . . . . . . 10

proteômica ....................... 1

taxa de crescimento de............2

$\mathbf{R}$

reconhecimento de entidades mencionadas 3 redes bayesianas.........5, 21, 29-31, 35

redes bayesianas dinâmicas (RBD) . . . . 22

regras gramaticais ................. 25

revocação ...................... 3, 25

$\mathbf{T}$

teorema de Bayes ............... 29, 35 